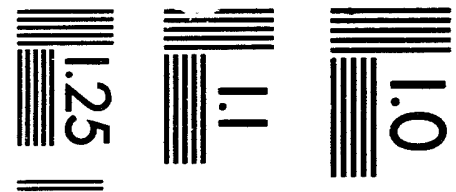

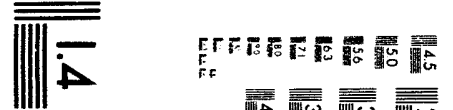

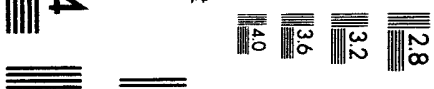

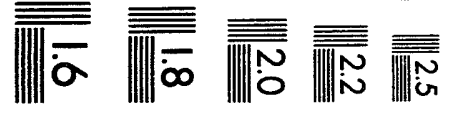



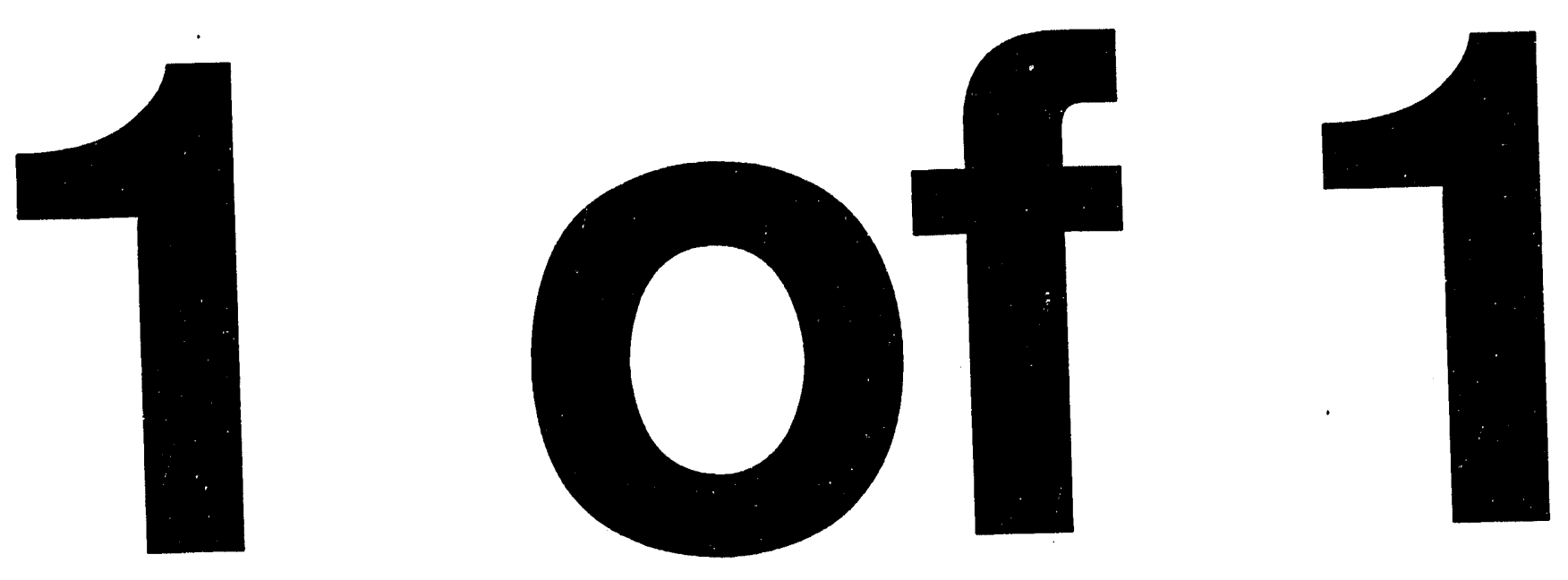


\title{
Final Project Report Staff Exchange with Chemical Waste Management
}

\author{
B. J. Harrer \\ D. W. Barak ${ }^{(a)}$
}

Prepared for

U.S. Department of Energy

under Contract DE-ACO6-76RLO 18306

Pacific Northwest Laboratory

Richland, Washington 99352

(a) Chemical Waste Management, Geneva, Illinois. 


\section{Abbreviations}

BDAT

CRADA

CWM

DOE

EPA

PNL

PST

RAAS

$\operatorname{ReOpt}^{\mathrm{Tw}}$

TEES ${ }^{\text {nt }}$
Best Demonstrated Available Technology

Cooperative Research and Development Agreement

Chemical Waste Management, Inc.

U.S. Department of Energy

U.S. Environmental Protection Agency

Pacific Northwest Laboratory

Petroleum Sludge Treatment

Remedial Action Assessment System

Remedial Options

Thermochemical Environmental Energy System 


\section{Final Project Report Staff Exchange with Chemical Waste Management}

Staff exchanges, such as the one described in this report, are intended to facilitate communication and collaboration among scientists and engineers at Department of Energy (DOE) laboratories, in U.S. industry, and academia. Funding support for these exchanges is provided by the DOE, Office of Energy Research, Laboratory Technology Transfer Program. Funding levels for each exchange typically range from $\$ 20,000$ to $\$ 40,000$. The exchanges offer the opportunity for the laboratories to transfer technology and expertise to industry, gain a perspective on industry's problems, and develop the basis for further cooperative efforts through Cooperative Research and Development Agreements (CRADAs) or other mechanisms.

\section{Purpose/Objective}

The original objective of the exchange between Pacific Northwest Laboratory (PNL) and Chemical Waste Management, Inc. (CWM) was the transfer of PNL technology and expertise in computational chemistry and waste flow/treatment modeling to CWM. However, as the exchange progressed, this objective was broadened and modified somewhat to better address the needs of CWM. Identification and characterization of a broader portfolio of PNL's environmental remediation technologies with a high potential for rapid application to CWM's businesses became the focus of the exchange. This expansion in objectives resulted in a wider involvement of both CWM and PNL staff in the exchange.

\section{Summary of Activities}

Mr. Dan Barak, the primary CWM exchange participant and other representatives of CWM made several visits to PNL. The first visit was in August 1992. This visit focused on logistics of the staff exchange and included some general discussions about technical areas of interest to CWM. Mr. Barak was also linked into PNL's E-MAIL system to facilitate communication with PNL staff.

The second visit occurred over a 2-week period in September and October 1992. During this visit, Mr. Barak held technical discussions regarding 14 PNL technologies (listed in Appendix A) that were of potential interest to CWM. In addition, Mr. Barak provided technical input to PNL personnel on a chemical process modeling program that PNL is developing under the sponsorship of the DOE Office of Energy Efficiency and Renewable Energy, Office of Industrial Technologies.

Of the 14 technologies discussed, Mr. Barak identified the following as being of the highest interest to CWM:

- Six Phase Soil Heating (In-Situ Heating) - a low-temperature approach $\left(\sim 212^{\circ} \mathrm{F}\right)$ used in conjunction with soil vapor extraction for removal of volatile and semi-volatile organics from soils 
- High Energy Corona (Electrical Corona Destruction) - use of a high voltage corona to oxidize organics in gas streams

- RAAS/ReOpt ${ }^{\mathrm{Tw}}$ - remedial investigation technology and expert system software designed to help remedial investigation/feasibility studies

- TEES' - a catalytic technique that produces methane from biological wastes (cellulose, food processing, etc.)

- PST - a process for treating petroleum sludge that uses heat and pressure to break emulsions resulting in distinct oil/water/solid phases.

Mr. Barak visited PNL in November 1992, to obtain more detailed information with a focus on TEES and PST. A meeting was also held at the offices of PNL's current licensee for the TEES process (Onsite*Ofsite).

After the November meeting, Mr. Barak proposed to CWM management that serious discussions be undertaken with PNL with regard to the transfer and commercialization of either the TEES or PST processes. Unfortunately, in December 1992, CWM was substantially reorganized. As a result, nearly all of the principal CWM staff involved with the staff exchange (including Mr. Barak) either left CWM or were transferred to other divisions. Mr. Barak was assigned to a specific project in the Dallas, Texas, area that did not give him the opportunity to visit PNL again for several months. However, he continued to work within the Waste Management, Inc. (new name for CWM) operating companies to identify suitable contacts to continue the exchange activities. Candldates were identified in both RUST Engineering and Wheelabrator Engineered Systems. A memo from Mr. Barak to Wheelabrator regarding TEES and PST is provided in Appendix B.

Finally, in July 1993, Mr. Barak made his final visit to PNL, along with Dr. John North of RUST Engineering and Mr. Steve Uban of Wheelabrator Engineered Systems. Dr. North presented a 2-hour seminar on technologies built and used by RUST for waste management and remediation services. A copy of the material provided by Dr. North is included as Appendix C. Discussions were held with PNL staff regarding several technologies, including TEES, PST, Six Phase Soil Heating, and High Energy Corona.

After this meeting, additional interactions on the exchange were planned. However, a substantial reduction in force occurred at CWM and Mr. Barak was forced to leave the company in September 1993. Subsequent interactions were conducted with Mr. Uban leading to a proposal to utilize the remaining funds from the exchange for a joint project to do a "proof-of-concept" test of the efficacy of the PST process in treating sludge waste streams of interest to Wheelabrator.

Copies of E-MAIL correspondence between Mr. Barak and various PNL staff are included in Appendix D. 


\section{Significant Accomplishments}

Through the exchange, a major company providing environmental remediation and waste management services became much more familiar with a wide variety of PNL technologies and experise relevant to its business. PNL staff also had an opportunity to gain "real-world" knowledge and understanding of practical issues in waste management and environmental remediation. Owing to financial pressures within CWM (described below), the objectives of the exchange were narrowed to focus on technologies with near-term applicability to CWM's business. Substantial communication and interactions with regard to these technologies occurred, leading to a proposal for a follow-on project with Wheelabrator Engineered Systems to explore the applicability of the PST process to specific waste streams.

\section{Significant Problems}

During the exchange, CWM was under significant financial pressure as a result of operating losses in its waste incineration business. The initial goal of the exchange was to initiate joint research and development between PNL and CWM. However, CWM's financial pressures resulted in a change of focus to identify near-term opportunities to apply PNL technologies to CWM business needs.

In December 1992, CWM underwent a substantial reorganization that resulted in the disbanding of its centralized research and development organization. This reorganization made the transfer of PNL technologies into application by CWM more difficult, because many of the principal individuals associated with the exchange were either transferred to other Waste Management, Inc., divisions or left the company.

The principal exchange participant (Mr. Barak) was assigned to a project in Dallas, Texas, that did not allow him to visit PNL for several months. During this time, Mr. Barak continued to contact individuals within various divisions of Waste Management, Inc., to identify interest in cooperating with PNL in applying specific technologies. Finally, in July 1993, Mr. Barak visited PNL with representatives from two other Waste Management, Inc., divisions (Wheelabrator and RUST Engineering). Approximately 2 months after the visit, CWM underwent a major downsizing and Mr. Barak was forced to leave the organization.

\section{Industry Benefits Realized}

The reorganizations and downsizing of CWM during the exchange almost certainly reduced the potential benefits to industry. However, it is believed that CWM became more familiar with the technologies and capabilities of PNL as a result of the exchange. As a result of these interactions, a proposal for a specific cooperative project related to the PST technology was developed. 


\section{Recommended Follow-on Work}

A cooperative effort is proposed between Wheelabrator Engineered Systems and PNL to explore the potential transfer and application of the PST technology to Wheelabrator's business. The initial project in the effort will focus on the ability of the PST technology to meet U.S. Environmental Protection Agency (EPA) Best Demonstrated Available Technology (BDAT) standards. Assuming this initial effort is successful, further efforts would focus on developing a continuous flow system for PST that could be commercially applied.

\section{Potential Benefits from Pursuing Follow-on Work}

Most oil refineries need a new method for disposing of oil sludge. Land farming was the standard disposal method for oil sludge until it was banned by the EPA in 1990. The only EPAaccepted alternative has been incineration, which is costly, heavily reguiated, and produces a substantial ash stream that also requires disposal as a hazardous waste. The PST process separates highly stable emulsified petroleum wastes into oil, water, and solids. The oil is recovered and returned to the refinery for processing, and the water is believed to be suitable for discharge to the refinery wastewater treating plant or to a publicly-owned treatment plant, leaving a greatly reduced volume of solids for disposal.

If the PST process can be successfully developed and transferred into commercial application, Wheelabrator Engineered Systems would benefit from the ability to add a new product line to their business. More importantly, an environmentally benign alternative to existing methods of oil sludge disposal will be available. 
Appendix A

Summary List of Technologies 


\section{MEMORANDUM}

DATE: October 27,1992

TO: $\quad$ George Vander Velde

FROM: Dan Barak

SUBJECT: PNL Summary of Technology Presentations

I spent two weeks at PNL in late September and early October for the staff exchange project. During that time 1 received presentations on 15-20 technologies and research areas at the lab. I have prepared a summary listing of the areas of greatest potential interest on our part, with a very brief description of the technology or potential fit for our needs:

- Ceramic Melter and Ex-Situ Vitrification (ESV)- Melter is used to glassify high level radioactive wastes. ESV unit in construction at MSW incinerator for ash in western WA.

- In Situ Vitrification - Same technology as licensed to GEOSAFE. They are very interested in licensing to us as well.

- In Situ Heating - Lower temperature approach $\left(-212^{\circ} \mathrm{F}\right)$ used in conjunction with soil vapor extraction for removal of volatile organics from soils. Claims to have very favorable economics $(<\$ 50 /$ ton). We will evaluate.

- Electro Corona Destruction - Uses high voltage corona to oxidize organics in gas streams and shows potential as adjunct/alternative to carbon and/or catalytic oxidation. Low temperature $\left(<100^{\circ} \mathrm{C}\right)$, no moving parts, virtually instant on/off, etc. Late bench scale phase.

- Bioremediation - They are doing in situ studies for cleaning up Hanford. But area of most interest was "landfill husbandry" or stimulating production of methane from landfills by nutrient addition, leachate pumparound, etc.

- Waste Minimization - They are approaching this from a policy level looking at Why? something is produced as much as how to minimize the in-process waste production.

- Petroleum Sludge Treatment - Possible backup technology to enzymes/surfactants for treatment of API separator sludge. Uses heat and pressure to break emulsion resulting in distinct oil/water/solid phases. Needs scale-up to continuous process and BDAT testing of effluents.

- TEES Process (Catalytic gasification) - Catalytic technique which produces methane from bio wastes (cellulosic, food processing, etc.). Works as much as $\mathbf{4}$ orders of magnitude faster than anaerobic digestion. Liquid/slurry phase process at high temp $\left(-400^{\circ} \mathrm{C}\right)$ and pressure. 
- Catalyst materials - Possible consulting to Advanced Waste Technology and/or ARI for alternatives to expensive precious metals for waste treatment and new catalyst design and testing.

- Supercritical fluid applications - These are aimed at cleaning technologies to replace the currently used freon solvents (Boeing is involved in this).

- Waste Acid Recovery - Acid distillation process to recover clean acids. Applications also for highly corrosive environment materials of construction.

- Advanced Simulation System Project - Next generation program to advance the industry into the use of object oriented techniques.

- RAAS/REOPT - Remedial investigation technology evaluation expert system software. Designed to help RI/FS studies at DOE facilities. Possible extensions include DOE/DOD RFP preparation, RSG proposal preparations, automated proposal review, etc.

- "Smart Plants" - Employing fuzzy logic to advise operators on corrective control actions to mitigate process upsets and prevent permit excursions. We have been proposing something like this for our incinerators.

This is a summary list of some of the technologies that were presented to me during my stay. I will be going back in November, with Abid Bengali, to do a more intensive review of the processes available for license and prepare decision summaries for each potential technology, describing the process, state of research (concept, bench, pilot, full etc), licensing potential and estimated treatment/development costs.

We also have been asked to give a seminar to the computational chemistry staff at PNL about the problems faced by our chemists. They need this to direct and prioritize their research for DOE. This is a good opportunity for us to gain some visibility in this effort at PNL and establish technical relationships between our scientists $\approx$.ud theirs.
Cc: D. Ayen
S. Baker
A. Bengali
P. Dent 
Appendix B

Portion of Memo to Wheelabrator 


\section{Pacific Northwest Labs Technology Transfer January 14, 1993}

Several technologies from PNL that have potential applicability within Wheelabrator. They are summarized here for your information:

TEES -- Catalytic Gasification for organic wastewaters and biomass

- System uses $1500-3000 \mathrm{psi}$ and $300-400^{\circ} \mathrm{C}$ to produce a medium btu gas

- Estimated costs \$6-8/MMBtu gas produced from biomass and 4-12 cents per gallon for organic wastewaters.

- $\quad$ Potential applications: water treatment at our recycling facilities, yard waste at WMNA landfills, wood and paper pulp from recycled paper manufacture, brewery effluent treatment, etc.

- System is already licensed to small company, but they are very willing to work with us or sellout.

- PNL will run bench tests for us on candidate streams for $\$ 1,000$ per test (pilot scale $(.5 \mathrm{gpm})$ at $\$ 5,000 /$ test).

PST -- Petroleum Sludge Treatment

- System uses $1500-2500 \mathrm{psi}$ and $-300^{\circ} \mathrm{C}$ to break water based emulsions.

- Tested on K048-52 wastes from refineries, breaks emulsion into three phases, oil layer returned to refinery, water layer to refinery water treatment and solids (while appearing visually clean) have not been tested for BDAT.

- System has not yet been licensed to anyone. We have the opportunity to go for pilot scale-up with \$50K WTI and \$300K DOE (RFP due to DOE by Mid. January 1993). Ultimate industry (Wheelabrator) funding in later phases averages to $50 \%$ of total cost.

- Treatment cost estimated at $\sim \$ 25 /$ raw ton or $\sim \$ 100-125$ per filter cake ton (this needs to be confirmed in scale-up tests).

- $\quad$ PNL will run tests for us on bench scale batch system for $\$ 1,000$ per test (does not include BDAT analyticall.

In general we can license these and other technologies for around $50 \%$ funding. However, most of the industry portion can be satisfied by "services in kind" and this allows us to put a value on testing, obtaining samples, etc. Additionally, the time that we spend evaluating and implementing the technology can count in our favor at full billable rates. 


\section{Appendix C}

Technologies Used by RUST 


\section{PROCESS DESCRIPTION}

The PY*ROXTM technology is a transportable incineration process for treating contaminated soils. The system consists of a rotary kiln incinerator, followed by a high temperature secondary combustion chamber for complete destruction of a wide range of organic contaminants. The flue gas from the process is passed through air pollution control equipment prior to release to the atmosphere.

The PY*ROXTM system utilizes a refractory-lined rotary kiln incinerator, operating at relatively high temperatures $\left(1200^{\circ} \mathrm{F}\right.$ to $\left.1600^{\circ} \mathrm{F}\right)$, to effect the desorption of even the most stable organic contaminants out of the soil. The rotary kiln is heated by an oxy-fuel burner which fires directly into the kiln, co-current to the direction of soil movement. The oxy-fuel burner provides optimum temperature distribution and heat transfer in the kiln, and minimizes the amount of flue gas and entrained dust which enter downstream equipment. The treated soil exiting the rotary kiln falls into an enclosed ash conveyor, where water is added to cool and dedust the soil.
Flue gas exiting the kiln is directed to a refractory-lined cyclone separator for removal of entrained particulate matter. The flue gas exits the cyclone separator and enters the secondary combustion chamber (SCC), where the organic contaminants are destroyed at elevated temperature. The SCC is a refractory-lined, vertical vessel equipped with a burner which is capable of raising the flue gas temperature as high as $2200^{\circ} \mathrm{F}$ (for PCBs and dioxins) to ensure complete destruction of the organic constituents.

The hot flue gas exiting the SCC next enters the quench tower, where it is cooled to $400^{\circ} \mathrm{F}$ by water spray nozzles. The flue gas is next passed through a baghouse for the removal of fine particulate matter. The baghouse is equipped with high temperature, reflon-coated, iabric bags. Finally, the flue gas passes through a horizontal packed bed scrubber for the removal of acid gases. The cleaned flue gas exiring the scrubber is continuously monitored and discharged to atmosphere viz a short vent stack.

Figure 1. PY'ROX tim Process Flow Diagram

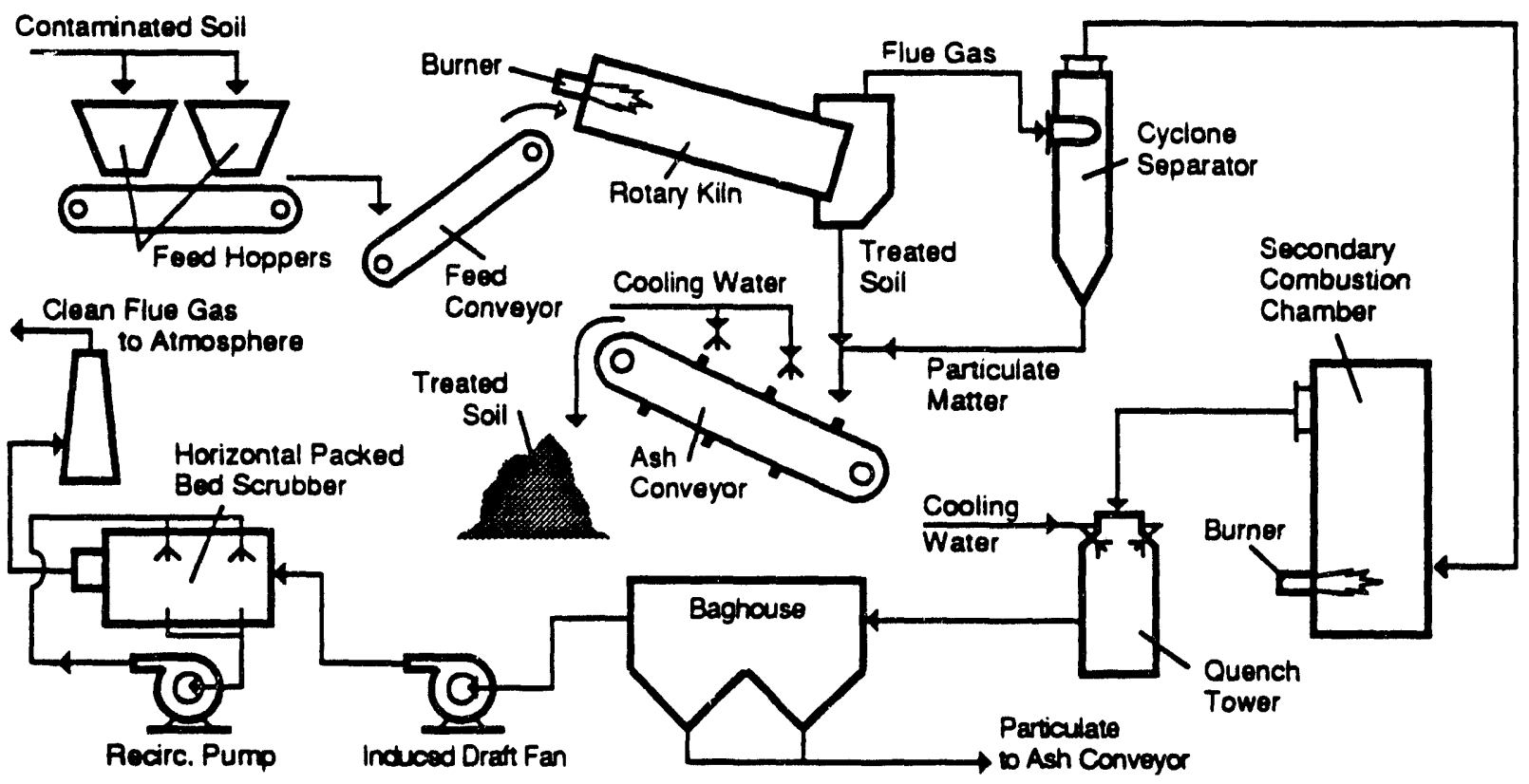




\section{APPLICABILITY}

Contaminants Treatedi

- Halogenated VOCs/SVOCs.

- Non-halogenated VOCs/SVOCs.

- PCBs, pesticides, herbicides

\section{Media Treatedi}

- Soils and other solids.

- Sludges and liquids

\section{Backaround Datai}

- Treated soil meets Land Ban requirements with respect to organic contamination.

- At least $99.99 \%$ destruction/removal efficiency for RCRA-listed organic contaminants.

- Atleast $99.9999 \%$ destruction/removal efficiency for TSCA-listed organics (PCBs/dioxins).

- Particulate loading (emissions) of $0.02 \mathrm{gr} / \mathrm{dscf}$ or less in stack gas.

- $\mathrm{HCl}$ removal of $99 \%$ or better.

- $\mathrm{SO}_{2}$ removal of $90 \%$ or better.

\section{Limitations:}

- Pretreatment required for soil particle sizes $>2 "$.

- Maximum soil moisture content of $50 \%$, with $<25 \%$ preferable.

\section{STATUS / CAPABILITIES}

RRS owns and operates two PY*ROX'TM Transportable Rotary Kiln Incineration systems and is preparing to build a third system. The PY*ROX'M 8200 is currently deployed at the Old Midland Products Superfund project. The PY*ROX'M 100 is a small, trailer mounted mobile system, recently used during the Operation Desert Storm cleanup in Saudi Arabia. The PY*ROX'M 8212 is currently in the preliminary design stage, and will have twice the capacity of the PY*ROX'M 8200 .

\section{PY*ROXTM 8200 Specifications:}

- 20-25 ron/hr soil throughpur.

- $82 \mathrm{MM} \mathrm{Btu/hr}$ overall thermal rating.

- $125^{\prime} \times 200^{\prime}$ space requirement.
PY"ROXTM 8212 Specifications: (Planned)

- 40-50 ton/hr soil throughpur.

- $160 \mathrm{MM}$ Btu/hr overall thermal rating.

- $150^{\prime} \times 225^{\prime}$ space requirement.

PY"ROXTM 100 Specifications:

- Mobile system; entirely trailer mounted.

- 1-2 ton/hr soil throughpur.

- $10 \mathrm{MM}$ Btu/hr overall thermal rating.

- $50^{\prime} \times 75^{\prime}$ space requirement.

- Flow scheme stlightly different than shown in figure on page 1: counter-current kiln; no cyclone; no baghouse.

\section{EXPERIENCE}

Bog Creek NPL Site. Howell Township. NW:

- Treated 25,000 tons of soil contaminated with paint wastes and industrial solvents.

- $99.99 \%$ DRE demonstrated on naphthalene \& carbon tetrachloride.

- Customer Contact:

- George Buk 908/389-3040 US Army Corps of Engineers

\section{Qld Midland Products NPL Site, Ola AR:}

- Treated 103,000 tons of soil contaminated with wood treating wastes (PCP, PAHs).

- $99.9999 \%$ DRE demonstrated on naphthalene \& trichlorobenzene.

- Customer Contact:

- Carlos Sanchez 214/655-6710
USEPA Region 6

Brio Refinina NPL Site, Friendswood TX:

- 120,000 tons of soil contaminated with petroleum refining wastes (tars, PAHs).

- $99.99 \%$ DRE to be demonstrated on naphthalene $\&$ chlorobenzene.

- Customer Contact:

- Ed Dondzila 713/996-8321

Project Manager - BRIO Site Task Force 


\section{PROCESS DESCRIPTION}

The $\mathrm{LT}^{*} \mathrm{X}^{\mathrm{TM}}$ Low Temperature Thermal Desorption technology (see diagram below) is a waste treatment process that thermally separates or "desorbs" organic contaminants from soils, sludges, or other solid media. The volatilized organic contaminants are subsequently oxidized and the resultant flue gas is passed through air pollution control equipment prior to release to the atmosphere.

The $\mathrm{LT}^{*} \mathrm{X}^{\mathrm{TM}}$ system incorporates a rotary dryer primary treatment unit (PTU) operating at relatively low temperatures $\left(350^{\circ} \mathrm{F}\right.$ to $\left.700^{\circ} \mathrm{F}\right)$ to effect the desorption of the organic contaminants into the flue gas. The PTU is heated by a burner which fires directly into the unit. The plural flights inside the PTU lift and shower the soil through the hot burner exhaust and down the length of the drum in a co-current direction. The treated soil exiting the PTU falls into an enclosed pugmill, where water is introduced to cool and dedust the soil.

RUST Remedial Services Inc.

Flue gas exiring the PTU, laden with desorbed organics and entrained particulates, is directed to high-efficiency cyclone separators for removal of most of the particulates. The flue gas passes from the cyclone separators to the secondary treatment unit (STU). The STU is a refractorylined, horizontal drum equipped with a burner. It is designed to raise the flue gas temperature to approximately $1800^{\circ} \mathrm{F}$ to ensure complete destruction of the organic constituents.

The hot flue gas exiting the STU next enters the quench tower, where it is cooled to $375^{\circ} \mathrm{F}$ by water spray nozzles. The flue gas is next passed through a baghouse for removal of fine particulate matter. The baghouse is equipped with high temperature, teflon-coated fabric bags. Finally, the flue gas passes through a horizontal packed bed scrubber where acid gases are removed. The cleaned flue gas from the scrubber is continuously monitored and discharged to atmosphere via 2 shor stack.

\section{$\mathrm{LT}^{*} \mathrm{X}^{\mathrm{TM}}$ Process Flow Diagram}

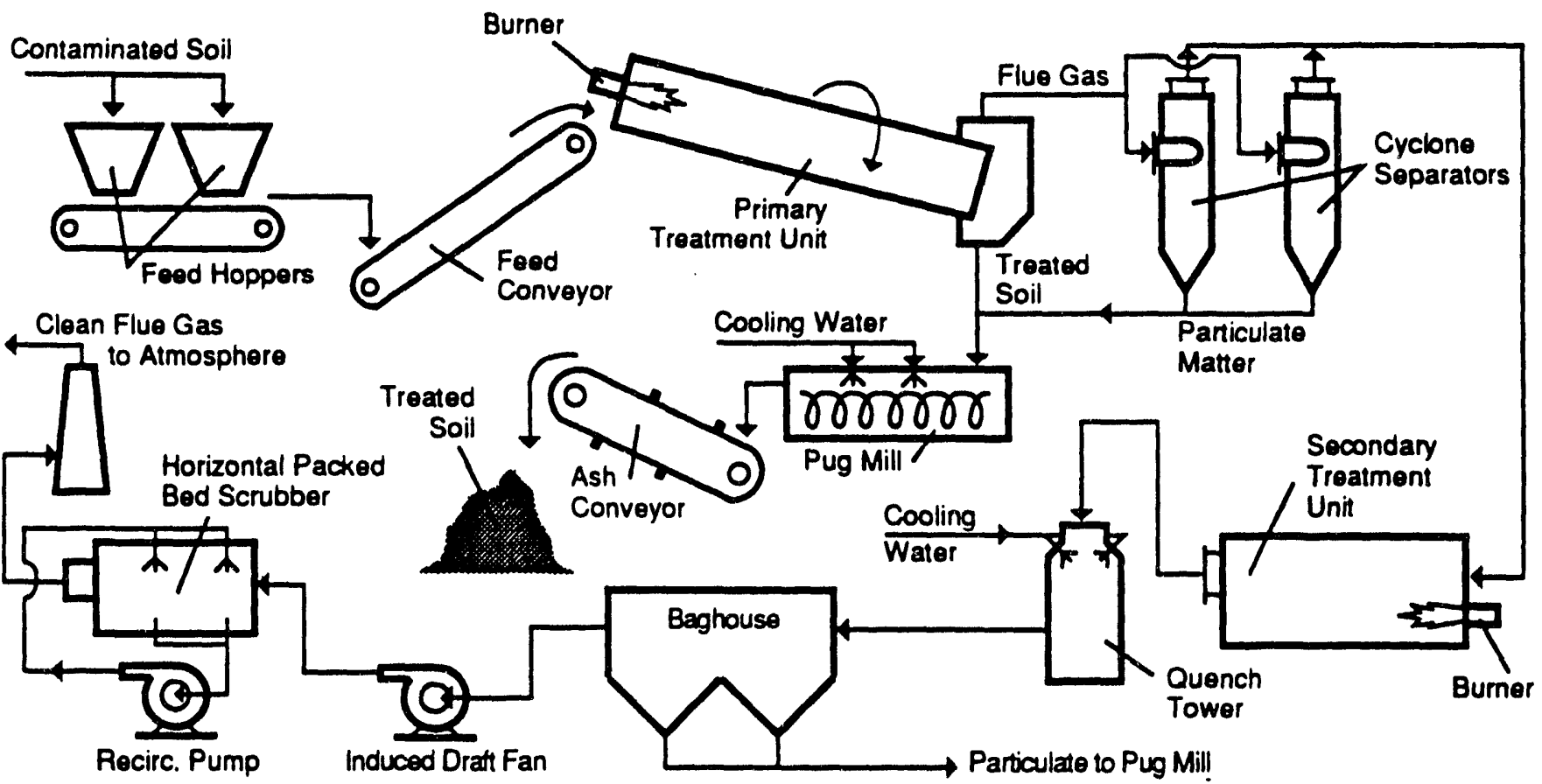




\section{APPLICABILITY}

\section{Contaminants Treatedi}

- Halogenated VOCs/SVOC's.

- Non-halogenated VOCs/SVOCs.

Media Treatedi Soils and other solids.

\section{Backaround Datai}

- Treated soil meets Land Ban requirements with respect to organic contamination.

- At least $99 \%$ destruction/removal efficiency for organic contaminants.

- Particulate loading (emissions) of $0.02 \mathrm{gr} / \mathrm{dscf}$ or less in stack gas.

- $\mathrm{HCl}$ removal of $99 \%$ or better.

- $\mathrm{SO}_{2}$ removal of $90 \%$ or better.

\section{Limitationsi}

- Not applicable to TSCA wastes.

- Pretreatment required for soils with particle sizes greater than 2".

- Maximum organic concetıtration of $5 \%$.

- Meximum soil moisture content of $50 \%$, with < $25 \%$ preferable.

- For economic reasons, site should have at least 5,000 tons of material.

\section{STATUS/CAPABILITIES}

The $\mathrm{LT}^{*} \mathrm{X}^{\mathrm{TM}}$ technology is fully commercial, with RRS currendy operating one system. The system was built in 1992, commissioned in early 1993, and scheduled to begin its first on-site remediation in May, 1993.

\section{LT"XTM Equipment 8: Performance Specs.:}

- 30-35 ton/hr soil throughput.

- $50 \mathrm{MM}$ Btu/hr PTU thermal rating.

- $55 \mathrm{MM}$ Btu/hr STU thermal rating.

- 7-10 minutes soil residence time in PTU.

- $400-500^{\circ} \mathrm{F}$ soil exit temperature from PTU.
- 1.9 second flue gas residence time in STU.

- $1,800^{\circ}$ F STU gas exit temperature.

- Propane or natural gas fuel.

- Fully automated PLC based control system.

- $125^{\prime} \times 125^{\prime}$ space requirement.

\section{EXPERIENCE}

Waldick Aerospace Devices NPL Site, Wall Township. Nd:

- First deployment of the $\mathrm{LT}^{*} \mathrm{X}^{\mathrm{TM}}$ system, with anticipated startup in May, 1993.

- Remediation of 3,000 cubic yards of soil contaminated with chlorinated volatile organic compounds.

- Estimated 40 days of $\mathrm{LT}^{*} \mathrm{X}^{\mathrm{TM}}$ operations, based on a 10 hour/day, 6 day work week.

- Project being administered by the U.S. Army Corps of Engineers.

- Air emissions and monitoring to comply with all conditions of a New Jersey Department of Environmental Protection Air Permit Equivalency document.

- Treated soil will be required to meet Land Ban requirements associated with F001 - F005 wastes, and will be transported off-site to 2 RCRA landfill for disposal.

- Customer Contact:

- George Buk 908/389-3040

Area Engineer, NJ Area Office

US Army Corps of Engineers 


\section{PROCESS DESCRIPTION}

The $\mathrm{X}^{*} \mathrm{TRAX}^{\mathrm{TM}}$ technology (see diagram below) is a thermal desorption process designed to remove organic contaminants from soils, sludges, and other solid media. It is not an incinerator or a pyrolysis system and does not form $\infty$ mbustion by-products. The organic contaminants are removed as a condensed liquid, characterized by a high heat (Btu) rating, which may be either destroyed in a permitted incinerator or used as a supplemental fuel. Because of low product temperatures (450 to 800 degrees Fahrenheit) and gas flow rates, this process is usually less expensive than incineration, and generally more acceprable by the public

An externally-fired rotary dryer is used to volatilize the water and organic contaminants into an inert carrier gas stream. The processed solids are then cooled with treated condensed water to eliminate dusting. The solids are ready to be placed and compacted in their original location.
The organic contaminants and water vapor driven from the solids are transported out of the dryer by an inert nitrogen carrier gas. The carrier gas flows through a duct to the gas treatment system, where organic vapors, water vapors, and dust particles are removed and recovered from the gas. The gas first passes through a cyclone and a high-energy scrubber. The gas then passes through two condensers in series, where it is cooled to less than $40^{\circ} \mathrm{F}$.

Most of the carrier gas is reheated and recycled to the dryer. Approximately 5 to 10 percent of the gas is cleaned by passing is through a particulate filter and 2 carbon adsorption system before it is discharged to the atmosphere. The volume of gas released from this process vent is approximately 100 to 200 times less than an equivalent capacity incinerator. This discharge helps maintain a small negative pressure within the system and prevents potentially contaminated gases from leaking. The discharge also allows makeup nitrogen to be added to the system, to keep oxygen concentrations between 0 and $4 \%$.

\section{X*TRAXTM Process Flow Diagram}

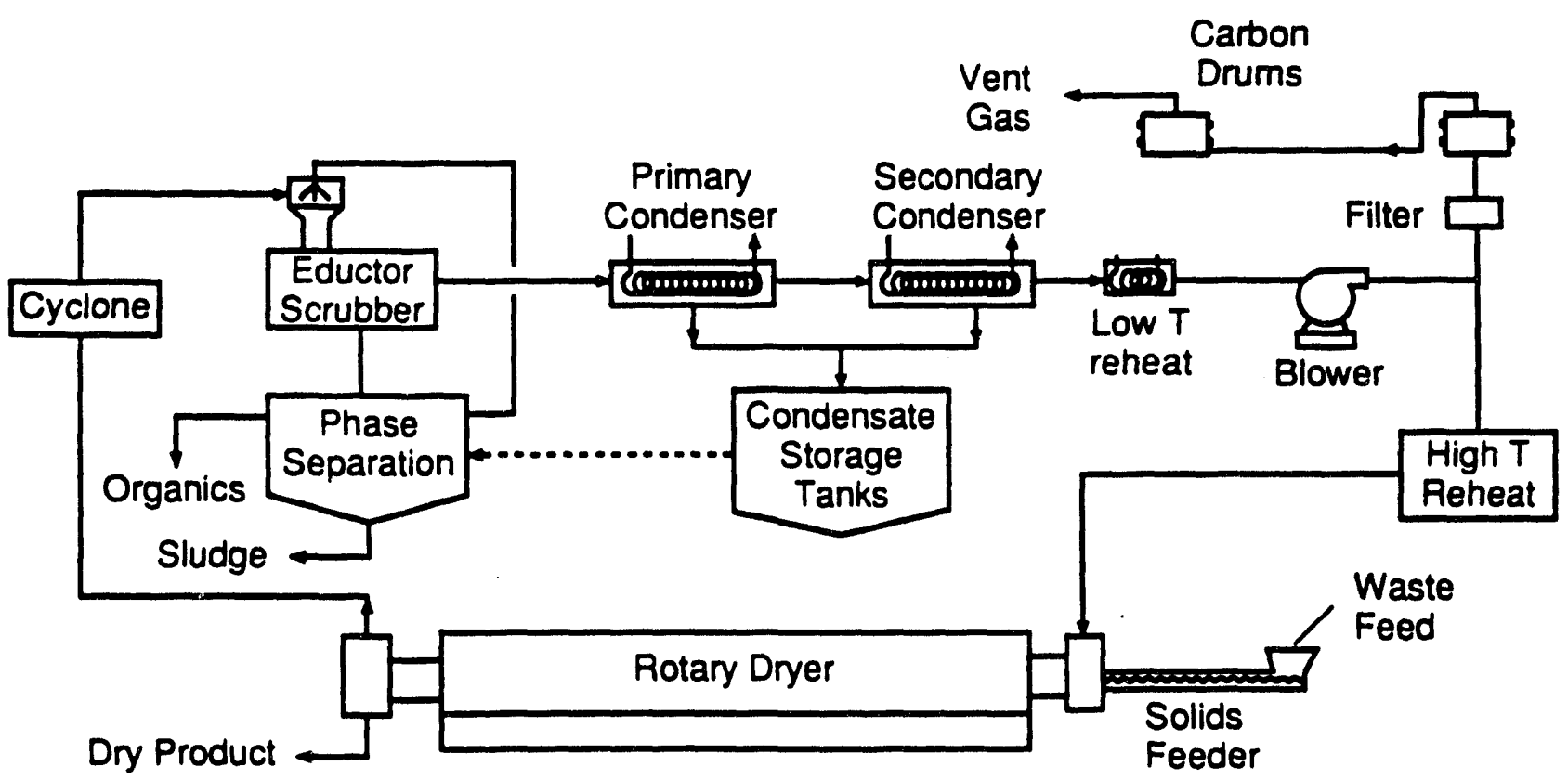




\section{APPLICABILITY}

\section{Contaminams Trented:}

- PCBs, pescicides, herbicides.

- halogenated/non-halogenated VOCs/SVOCs.

- mixed wastes (organid radioactive).

- mercury.

Media Treatedi Soils, sludges, other solids.

\section{Backoround Data:}

- Demonstrated on a variety of soils - from sand to very cohesive clays.

- VOCs typically reduced to < 1 ppm (BDL in many cases). SVOCs typically reduced to $<10 \mathrm{ppm}$, frequently to $<1 \mathrm{ppm}$.

- $3,000 \mathrm{ppm}$ PCBs in soils reduced to < $2 \mathrm{ppm}$. Demonstrated removal efficiencies of $96-99+\%$ for pesticide contaminated soils.

- Soil mercury contamination reduced from $5,100 \mathrm{ppm}$ to $1.3 \mathrm{ppm}$.

\section{Limitntions:}

- Precreament to $<2^{n}$ particle size.

- Maximum organic concentrations of $20 \%$.

- Maximum soil moisture contents of $50 \%$, with < $25 \%$ moisture preferable.

- Acceprable resules may not be achievable for some contaminants in clayey soils.

- For economic reasons, site should have at least 5,000 tons of material, with sites $>20,000$ tons preferable.

\section{STATUS / CAPABILITIES}

The X*TRAXM technology is a product of $100 \%$ internal Company development - from laboratory conceptual studies through the deployment of the full-scale commercial unit. We currently have three different $X^{\text {"TRAXMN }}$ systems available for use and tescing:

\section{Laboratory Scale:}

- Two systems available for treatability studies on RCRA, TSCA, or mixed wastes at RRS' Clemson Technical Center.

- Small, continuous flow systems (2-5 lbs per hour) that simulate the pilot and full scale hardware in almost every feature.

- More than 75 studies conducted with laboratory units since January 1988.

\section{Pilot Sarle:}

- Mobile unit mounted on two semi trailers.

- 24" diameter, $20^{\prime}$ long indirect-fired dryer - nominal capacity of 5 tons per day.

- Fully engineered off-gas collecrion and treatment system.

- Initially used to provide design data for full soale system. Still used for larger scale treatability studies and demonstrations.

- Over 90 tons of material processed since start up in 1988, including mixed wastes, PCB contamirated soils, and RCRA materials.

\section{Eull Scale:}

- $\mathrm{X}^{*} \mathrm{TRAX}^{\mathrm{m}}$ Model 200 - transportable production unit for on-site cleanup of contaminated soil.

- Nominal capacity of 125 tons per day of contaminated soil (at 20\% moisture).

- Indirect-fired rotary dryer with gas collection and treatment system.

- First Model 200 completed in early 1990, tested through 1992.

\section{EXPERIENCE}

\section{BeSolye NPL Site. North Dartmouth. MA:}

- First project for the X"TRAX'M Model 200 - for remediation of over 35,000 tons of $P C B-c o n t a m i n a t e d$ soil.

- Proof-of-process test and USEPA SITE demonstration were both successfully conducted at ReSolve in May/ June, 1992.

- Operating at throughput rates of 120-150 tons per day, treated soil PCB concentrations were an average of 0.25 PPm, from a starting concentration range of $180-515$ Ppm PCBs.

- Other organic contaminants, e.g. - TCE and TPH, were reduced below derectable leveis.

- Recently issued EPA SITE Bulletin on the ReSolve demonstration is attached.

- Customer Contacts:

- Michael Worthy 508/635-9500

ReSolve PRP Committee Proj. Coord.

ENSR Consulting and Engineering

- Paul R dePercin 513/569-7797

EPA Project Manager

USEPA Risk Reduction Engineering Lab 


\section{PROCESS DESCRIPTION}

The VAC*TRAX process is designed to separate organic contaminants from soils and sludges, with applicability to both mixod and un mixed wastes. In mixed waste (organic and radioactive contaminants) applications, the VAC TRAX process generates product streams that are amenable to further treatment and/or disposal via conventional methods. VAC'TRAX is similar in concept to the $X^{*}$ TRAX'M thermal desorption process, except that a vacuum environment is used to lower the process operating temperature. The intended application of this technology is the remediation of sites with smaller quantities of contaminated soil. Most existing thermal separation systems carry large overhead and set up costs, which limit their feasibility for smaller sites. VAC"TRAX is an economical alternative because the system is small, mobile, and requires minimal mobilization and demobilization activities.

The primary component of the VAC TRAX system is a stirred and jacketed batch dryer. An external heater unit circulates hot oil through the jacket and stirring paddles. A heared filter attached to the vapor outlet of the dryer separates particulate from the vapors - keeping all solids in the dryer. After exiting the filter, the vapor phase passes through a series of three condensers, a vacuum pump, a secondary particulate filter, and a carbon adsorption canister to capture volatilized organic compounds. A low flow of nitrogen inerts the dryer and carries the contaminants through the vapor handling system.

\section{APPLICABILITY}

\section{Contaminants Treated:}

- halogenated/non-halogenated VOCs/SVOCs.

- mixed wastes (organidradioactive).
Medis Treated: Soils, sludges, other solids.

\section{Backaround Data:}

- Bench-scale VOC removal efficiencies in excess of $99 \%$.

\section{Limitations:}

- Maximum organic concentrations of $20 \%$.

- Optimum moisture content $<25 \%, 50 \%$ maximum

\section{STATUS / CAPABILITIES}

The VAC*TRAX technology is currently in the developmental stage. In late 1992, RUST was awarded a contract through the USDOE Program Research and Development Announcement (PRDA) program to fund this development. Pilot-scale testing of the VAC TRAX technology will begin shortly at RRS' Clemson Technical Center. Successful treatment of surrogates and mixed wast's at this level will lead to the construction, testing, and commercialization of a full-scale mobile treatment system. This system will be available for the remediation of hazardous and mixed wastes at contaminated DOE, DOD, and commercial sites.

\section{EXPERIENCE}

Due to the relative infancy of this technology, experience to date consists of the initial laboratory studies on the process and the extensive data collected on the similar $X^{*} T R A X$ process. It is anticipated that the PRDA program will result in the development of a commercial VAC ${ }^{*}$ TRAX system within the next two years.

- Customer Contact:

- William Huber 304/291-4663 USDOE - Morgantown Energy Technology Center

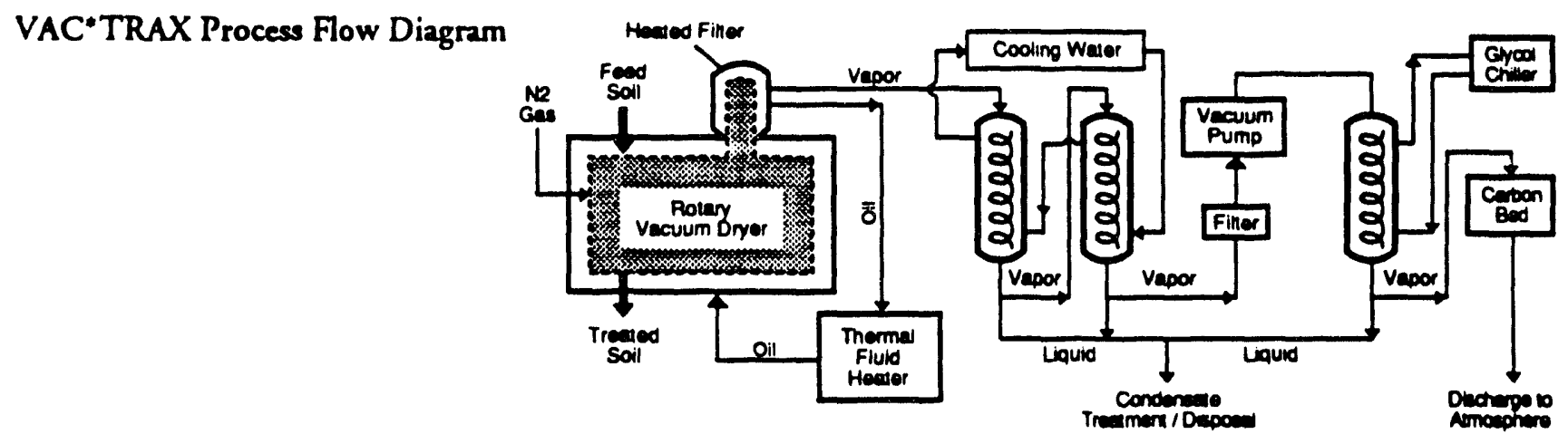




\section{PROCESS DESCRIPTION}

The Chem ${ }^{*}$ Matrix ${ }^{5 \mathrm{M}}$ treatment system was developed by the company to provide a flexible treaiment process to meet the challenges in stabilizing the wide variety of industrial waste streams and contaminated materials to regulatory standards. While the treatment system employs conventional equipment and unit operations, its uniqueness stems from its design ability to "mix and match" various physical and chemical process operations to meet the specific characteristics and associated requirements of the incoming waste stream (see diagram below).

The collective process consists of two basic modules, each containing a number of unit operations that can be selected in the design to meet projected waste characteristics for a specific application, or combined to provide a high degree of variability.

The pretreatment module involves capability for size reduction, debris removal/destruction, and chemical pretreatment, the latter for wastes containing hazardous

\section{Chem ${ }^{*}$ Matrix ${ }^{S M}$ Process Flow Diagram}

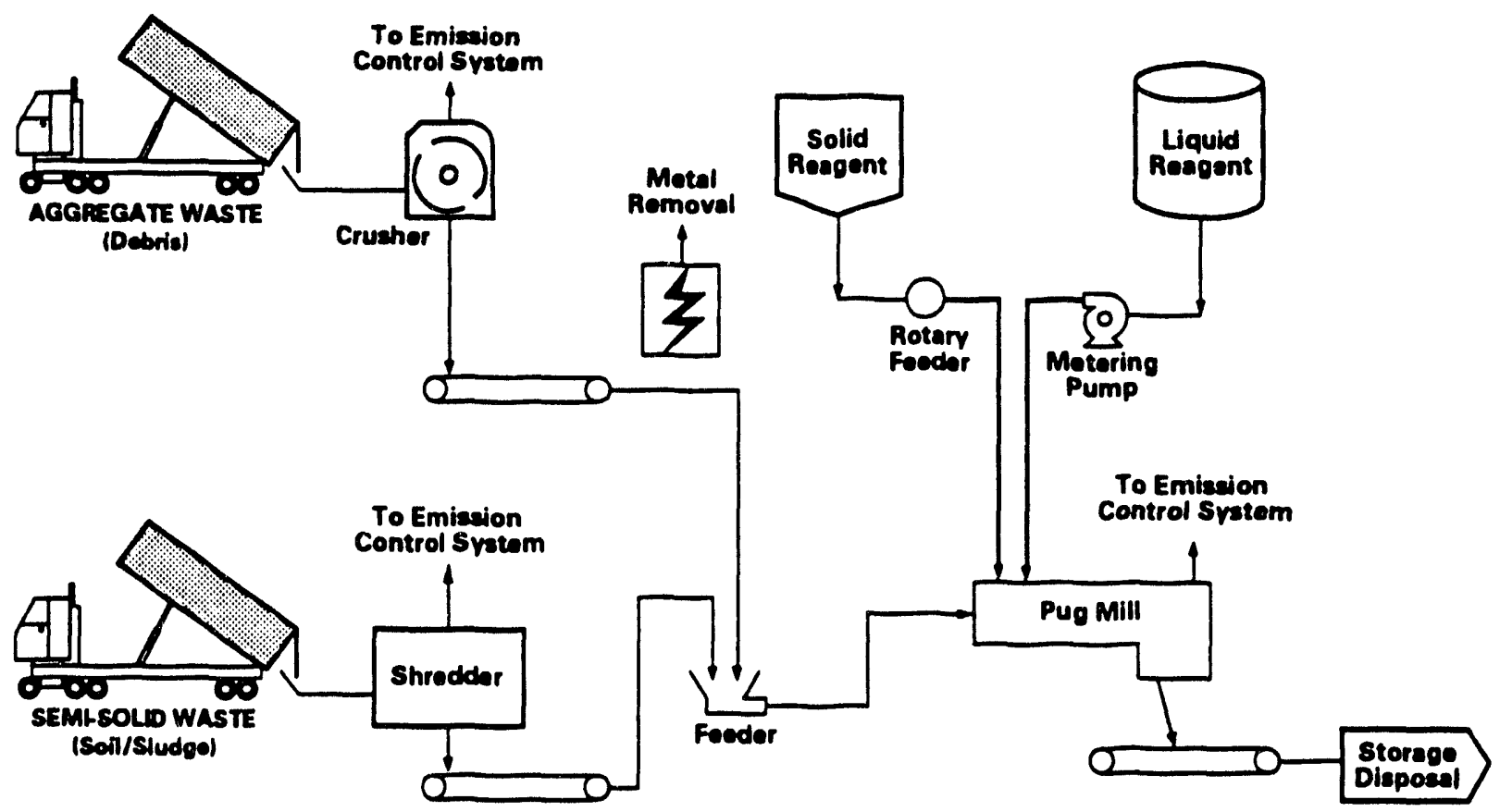

components not immobilized by normal stabilization using hydraulic binders $\&$ additives. The pretreatment process may handle liquid, semi-solid, aggregated and powdered wastes and can be operated as a continuous or batch process.

The various feed and discharge modules accommodate variable waste forms. These modules are reinforced with a sophisticared process control system designed to replicate the stabilization formulation developed in thelaboratory.

Equally critical is the mixing module. Mixing is provided by a high intensity, high shear continuous pugmill with high throughput capability for efficiently mixing various waste forms including solids, sludges, filter cake and liquids. 


\section{APPLICABILITY}

\section{Contaminants Treatedi}

- Heavy metals \& radionuclides.

- Volatile \& semivolatile organics (low concentrations).

\section{Media Treatedi}

- Soils, sludges, oily and tarry substances.

- Powdered and aggregated wastes.

- Liquids and semi-solid materials.

\section{Backoround Datai}

- Mobile or fixed basi: operation.

- Can process foreign debris, in waste stream, such as wood, concrete, rubble, and metallic objects.

- Can handle wastes with high variability in particle sizes, down to furnace dust.

- Units typically sized at 100 tons/hr processing capacity.

- Highly automated system to facilitate replication of stabilization formulation developed in laboratory for specific waste materials.

- Interferences encountered can be controlled.

\section{Limitations;}

- Practical limitation - waste materials must be amenable to pretreatment size reduction to 2 " or less.

\section{STATUS/CAPABILITIES}

Chem "Matrix ${ }^{S \mathrm{M}}$ is an accumulation or combination of various unit operations that provides a comprehensive commercial approach to transportable stabilization and immobilization treatment. RUST can also perform comprehensive treatability studies at its Clemson Technical Center, to determine the optimum formulation for the stabilization of a particular waste stream.

- Various pretreatment processes and reagent addition schemes can be implemented, depending on the physical and chemical characteristics of the waste.
- Three full-scale, transportable systems available, each with a nominal capacity of 100 tons/hour.

- Four fixed units exist, one each at Chemical Waste Management's TSD facilities at Emelle, AL; Model City, NY; Menomonee Falls, WI; and CID (Chicago, IL).

\section{EXPERIENCE}

\section{Ed DuPont de Nemours, Pomoton Lakes. Nli}

- Remediation of approximately 50,000 tons of lead and mercury contaminated soils and "shooting ponds", where off-spec blasting caps, fuses, wires, etc. had been disposed and exploded.

- Excavation and pretreatment (crushing, screening, etc.) performed on-site.

- Prepared material shipped to Model City facility (CWM) for stabilization by Chem ${ }^{*}$ Matrix $^{\mathrm{SM}}$ system, followed by disposal in secure landfill.

- Project completed May, 1992.

- Customer Contact:

- Bob Decker 201/835-1300

E.I. DuPont de Nemours

- Company Contact:

- Jesse Conner 803/646-2413

RUST Remedial Services Inc.

Clemson Technical Center 


\section{PROCESS DESCRIPTION}

RAD*MATRIX is an ongoing control program that has resulted in a number of stabilization formulations for low level radioactive wastes.

The RAD*MATRIX program consists of several components as related to site specific, target waste streams. These components mange from the $R \& D$ solidification program supporting NUL waste form certification to the subsequent process and quality control of on-site stabilization services prior to packaging for waste form transport and disposal. R\&D activities are supported by RRS' Clemson Technical Center, program execution and process control is managed by RRS' sister company, Chem Nuclear Systems, Inc.

The ultimate objectives of the program can be summarized as follows:

- Produce a waste form that receives regulatory acceprance from the NRC.

- Produce a formulation that results in an economical, high waste-to-container ratio.

\section{RAD*MATRX Process Flow Diagrams}

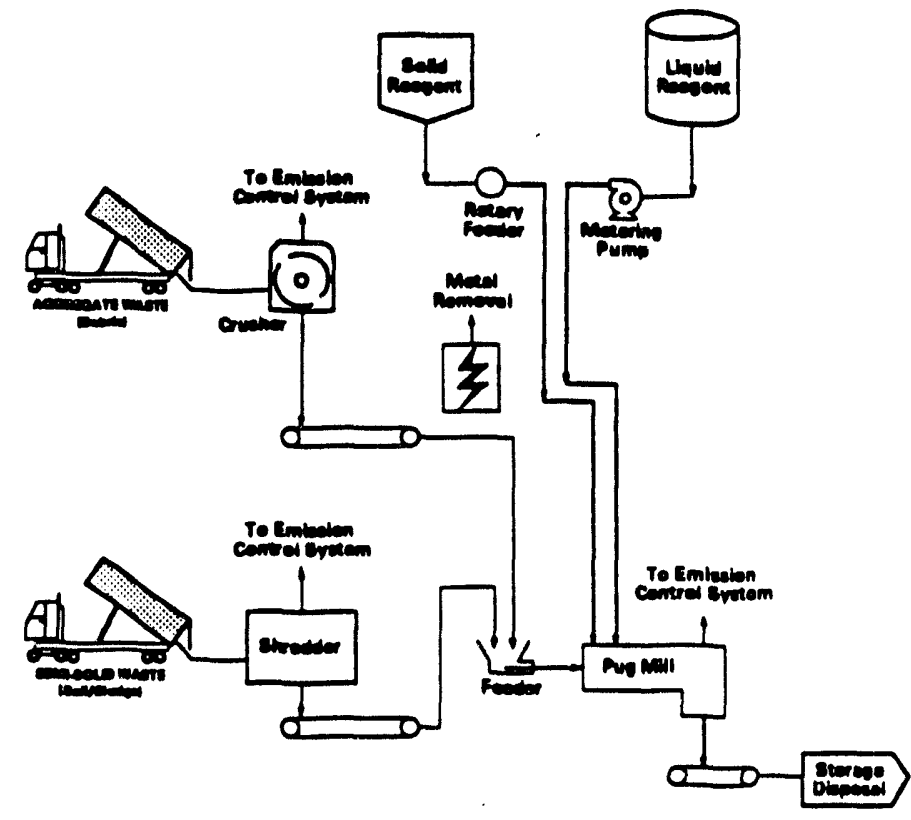

- Provide technically flexible and versatile transportable systems to accommodate all potential waste types (see diagram below).

\section{APPLICABILITY}

\section{Contaminants Treated:}

- All radionuclides

\section{Media Treatedi}

- Low level radioactive wastes classes A, B, and C. ( boric acid, resins, oils, decon solutions, etc.)

\section{EXPERIENCE}

The RAD*MATRIX program has performedsince 1974 and project examples are numerous, involving more than half of the nuclear power plants in the United States.

- Customer Contacts:

- Jack Torbett 315/349-2543

Rad Waste Supervisor - 9 Mile Point Niagara Mohawk Power Co.

- Art Wocha 609/971-4545

Rad Waste Supervisor - Oyster Creek GPU Nuclear

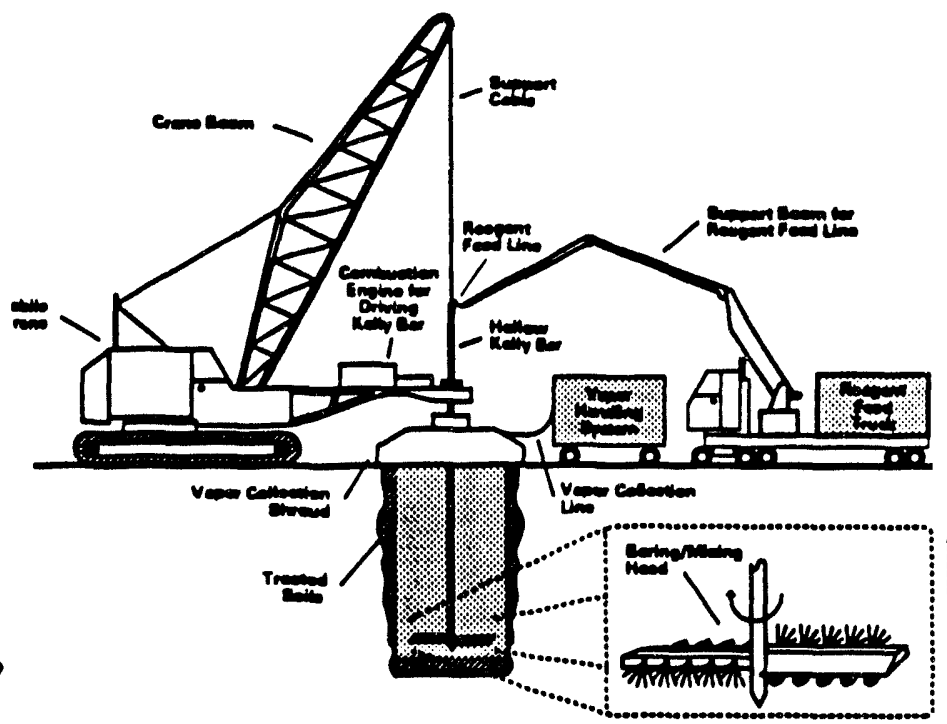




\section{PROCESS DESCRIPTION}

RUST employs the Stir-Melter ${ }^{\mathrm{TM}}$ vitrification system as a unique and emerging technology. Stir-Melter ${ }^{\text {TM }}$ transforms hazardous and radioactive wastes into an easily handled non-leachable glass waste product. This technology is made available through a licensing agreement with Stir-Melter ${ }^{\mathrm{TM}}$, Inc. and its parent company, GlassTech, Inc.

In the Stir-Melter ${ }^{\mathrm{TM}}$ process, waste materials along with glass production materials are fed into the melter retort (see diagram below). The heat to convert the feed into a stable inert glass is supplied by joule hearing, i.e. heat is produced through the resistance to an electric current passing through the molten glass bath.
The molten bath is continuously stirred at a high rate to assure uniformity of the material and heat distribution and to accelerate melting through the shearing action of the impeller. The nature of the process creates a quiet zone within the melter which allows gases to escape, producing a final molten glass product that is at maximum density and lowest volume. The molten glass is chilled in a water bath into easily handled coarse glass granules.

The: Stir-Melter ${ }^{\text {TM }}$ design offers high throughput efficiency compared to competing technologies, lower melting temperatures and minimized off-gas volumes. The small size of the unit enhances the practicality of a portable unit or facilitates its installation within an existing plant.

Stir-Melter ${ }^{\text {TM }}$ Process Flow Diagram

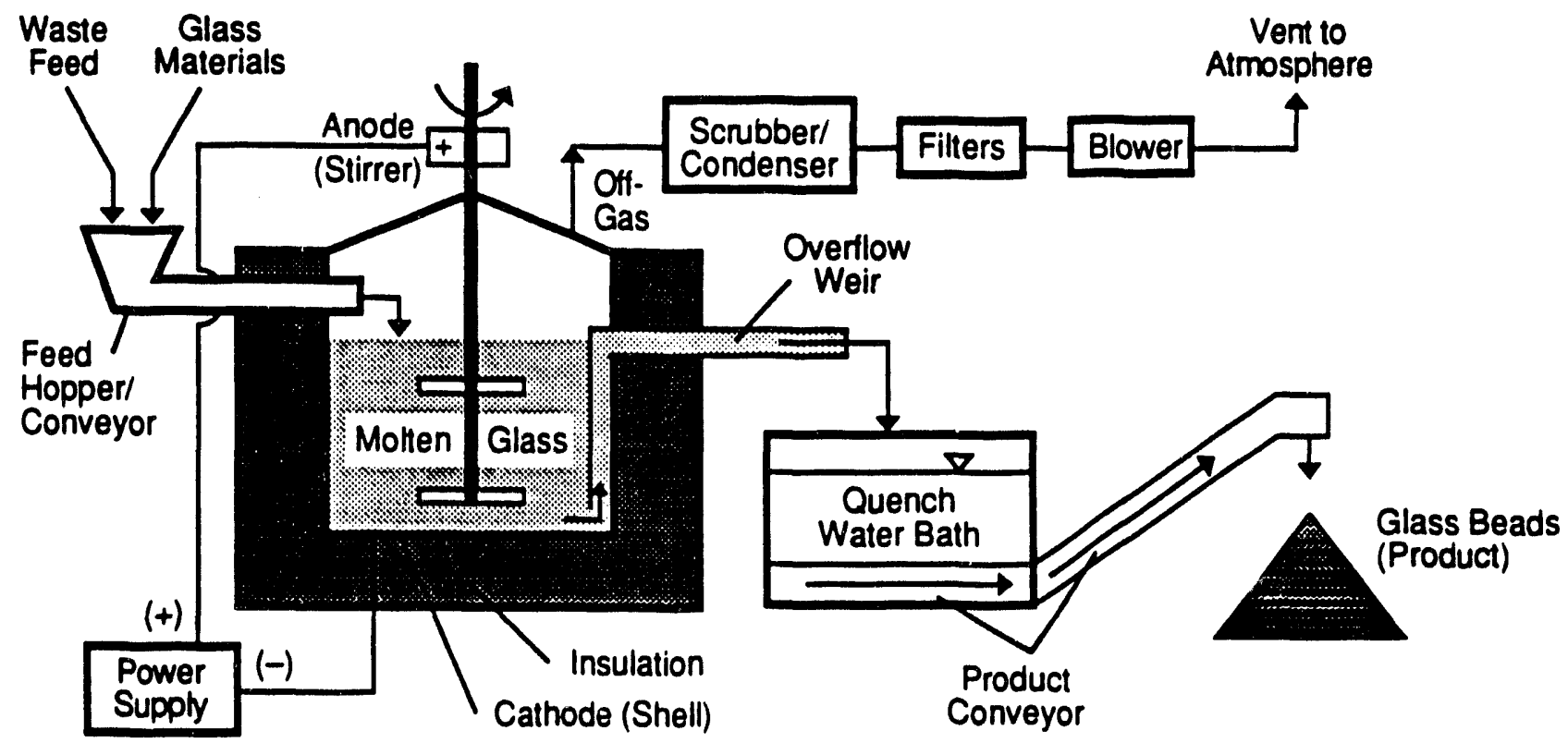




\section{APPLICABILITY}

\section{Contaminants Treatedi}

- High level/low level radionuclides.

- All organics.

- All metals.

\section{Media Trented:}

- Liquids.

- Solids/semi-solids.

\section{Backaround Datai}

- Incorporates waste into glass matrix.

- Stirred concept allows higher processing rates per vclurne of melter.

- Meets TCLP and other leach standards.

\section{Limitations:}

- Media size required to be small enough for melter feeder (typically < 1/4").

- Glass temperature restricted to $<2200^{\circ} \mathrm{F}$ by materials of construction of stirrer and melter (Inconel-690).

\section{STATUS/CAPABILITIES}

Vitrification is an emerging technology for immobilizing wastes. Although this process has been successfully used by the US DOE to stabilize high level radioactive wastes, it has received little attention to date for its potential application to other hazardous low level radioactive or mixed wastes. The Company believes, however, that the basic vitrification technology offers many benefits to mixed waste management issues. In addition to the stabilization advantages, the technology offers significant potential for waste volume reduction, the destruction of organics, and the recovery of metals (precious and other). It will also produce a final waste form that is highly manageable.
To further advance the application and commercialization of this technology, RRS' Clemson Technical Center has joined in a research partnership consisting of Westinghouse Savannah River Technology Center, Clemson University, and two commercial manufacturers. This partnership will focus on research to refine the technology for improved applicarion to the environmental restoration industry. Research will address concerns such as applicable waste composition, glass chemistries, optimum melter furnace design, energy requirements, metallurgical factors, emission controls, and the stabilization of the final waste form.

Bench and pilot-scale units (up to one ton of glass production per day) are available for application testing through RRS' Clemson Technical Center. Full-scale field units are not currently available.

\section{EXPERIENCE}

- Treatment of several non-radioactive surrogate samples has been demonstrated in a 1 sq. fr. pilor unit, with approximately 4,000 hours of total operation.

- A mini-pilot unit (1/4 sq. $f$.) is available for testing, and is currently involved in a research program with Clemson University and Westinghouse - Savannah River Plant.

- Customer Contact:

- John Plodinec 803/725-2170

Westinghouse Savannah River Co.

- Company Contacts:

- Ray Richards 419/536-8828

Stir-Melter, Inc.

- Bob Hemmings 803/646-2413

RUST Remedial Services, Inc.

Clemson Technical Center 


\section{PROI SS DESCRIPTION}

The Dr hor/KGME process is designed to chemically dehalogenate liquid wastes containing PCBs, dioxins, furans, and other halogenated aromatic and aliphatic compounds. It is a batch process, with the waste and reagents added to a jacketed and mixed reactor, in quantities determined by the concentration of the halogenated species. A thermal fluid heater is used to pump hot oil through the jacket, heating the mixcure to the design temperature, whereit is held for a preset time (3-9 hours). When the reaction mixture has cooled to abour $200^{\circ} \mathrm{F}$, water is added to quench the reaction. The contents of the reactor are then transferred to a decantation tank, where the organic and aqueous phases are allowed to separate. These two streams are pumped inco separate storage tanks or drums to await ulamate disposal. All vapors from the reactor pass through a refrigeraned condenser $\left(40^{\circ} \mathrm{F}\right)$ and a series of carbon canisters prior to discharge to the aumosphere. A process schematic is shown below.

\section{APPLICABILITY}

\section{Contaminants Treated:}

- PCBs, dioxins, furans (halogenated organics).

\section{Media Treatedi}

- Organic phase liquids.

- Low-moisture soils (developmental).

\section{Backoround Data:}

- Bench/pilot scale experiments on PCB-contaminated oils and surrogates show destruction efficiencies $>99.8 \%$, even for concentrations $>150,000$ ppm.

\section{Limitations:}

- Works best on highly chlorinated species, e.g. - Arodor 1248, 1254, or 1260. Lighdy chlorinateds require more reagent, higher temperatures, and longer processing times.

- Maximum moisture content of $5 \%$.

\section{STATUS / CAPABILITIES}

The DeChlor/KGME chemistry and process is a product of $100 \%$ internal Company development. Numerous bench-scale studies have been conducted on PCBs, surrogates (chlorobenzenes), and other halogenated organic compounds. A pilor system was designed and assembled for use at the ReSolve NPL site proof-of-process demonstration. Current capabilities include:
- Treatability studies available at RRS' Clemson Technical Center.

- Nominal 100-gallon, transportable, pilot reaction system available for studies, or treatment of small volume waste streams.

- Langer treatment systems can be readily designed and assembled.

\section{EXPERIENCE}

\section{BeSolve NPL Site. North Dartmouth MA:}

- Nominal 100-gallon pilot system used to dechlorinate PCB-contaminated oils that were thermally desorbed from the ReSolve soil by the RRS' X'TRAX process.

- Proof-of-process demonstration successfully compleced in June, 1992.

- In one treatunent batch, $P C B$ concentration in the oil was reduced from $44,000 \mathrm{ppm}$ to $110 \mathrm{ppm}$, giving a DRE of 99.75\%.

- DeChlor/KGME proven to be effective, but not required, for this application. Will not be used during full-scale remediation.

- Customer Contacts:

- Michael Worthy 508/635-9500

ReSolve PRP Commitree Proj. Coord.

ENSR Consulting and Engineering

- Paul R. dePercin 513/569-7797

EPA Projecr Manager

USEPA Risk Reduction Engineering Lab

DeChlor/KGME Chemical Dechlorination Process Schematic

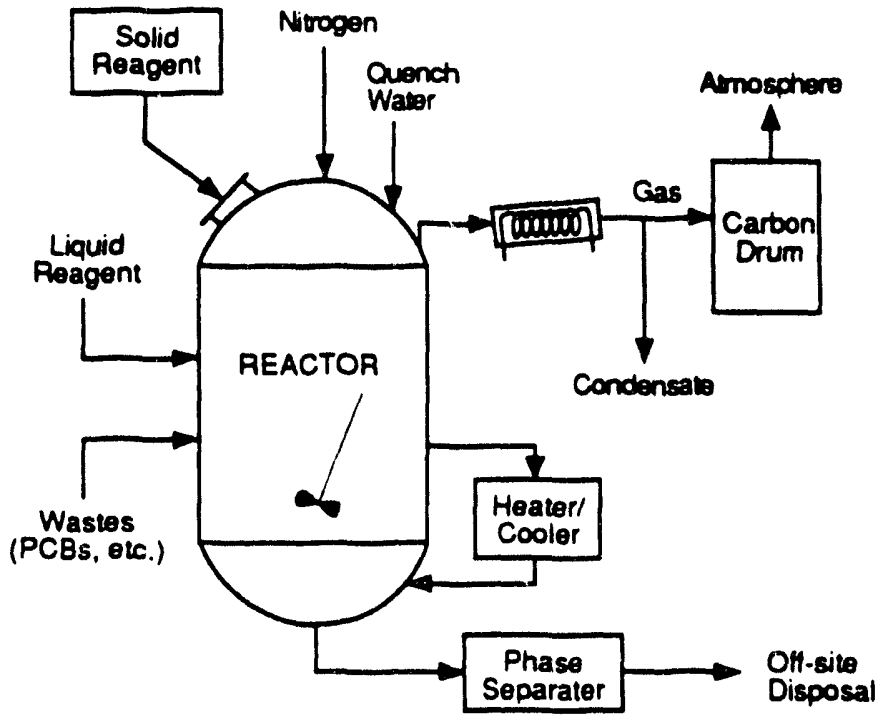




\section{PROCESS DESCRIPTION}

$\mathrm{ACT}^{*} \mathrm{DE}^{*} \mathrm{CON} \mathrm{N}^{\mathrm{SM}}$ is a reagent technology developed to facilitate the chemical extraction process in the treatment of soils and other solid materials contaminated with radionuclides. The associated $A C T^{*} D^{*} \mathrm{CON}^{\mathrm{SM}}$ process (see diagram below) combines dissolution with dilute selective solvents, contaminant recovery and solvent regeneration to provide a continuous recirculating treatment process for the treatment of solid wasteforms to remove multiple radionuclides, including transuranics, and heavy metals. The process may be applied either insitu or $\mathrm{ex}$-situ. In either application, the unique element of the process is the solvent chemistry, i.e. - the $A C T^{*} D E^{*} C O N^{5 M}$ reagent, which combines carbonate recovery chemistry with a chelating agent (EDTA) and an oxidant $\left(\mathrm{H}_{2} \mathrm{O}_{2}\right)$.

In treating soils ex-situ, the contaminated soil is fed to a dual stage (minimum) counter current solvent extraction system. The number of extraction stages and the related contact time is indexed to the soil contamination level and the final treatment objectives. The treated material (slurry) flows from the last extractor stage to a pressure filter; the resulting filter cake subsequently is flushed with fresh solvent and clean water prior to disposal or return. The contaminated solvent, containing dissolved carbonate complexes from the extraction process is recovered by anion exchange and recycled to the treatment process after fortification to account for depleted oxidant, chelate and carbonate ions. Contaminants removed by the ion exchange process are typically recovered in a highly concentrated form by elution in nitricacid followed by evaporation.

In treating soils in-situ, the same process principles as in the ex-situ form apply. However, the recovery step is modified to accommodate high flow rates and the potential presence of soil fines in the solvent. This is accomplished by replacing the recovery ion exchange system with the company's Magnetic Separation (MAG*SEPTM ) technology. For in-situ applications, the soil to be treated is surface flushed with the $A C T^{*} D E^{*} C O N^{S M}$ solvent with solvent recovery through horizontal recovery wells. The solvent chemicals are environmentally benign. Therefore, no residual contamination will result from in-situ applications.

$\mathrm{ACT}^{*} \mathrm{DE}^{*} \mathrm{CON}^{S M}$ Radionudide Extraction Process Flow Diagram

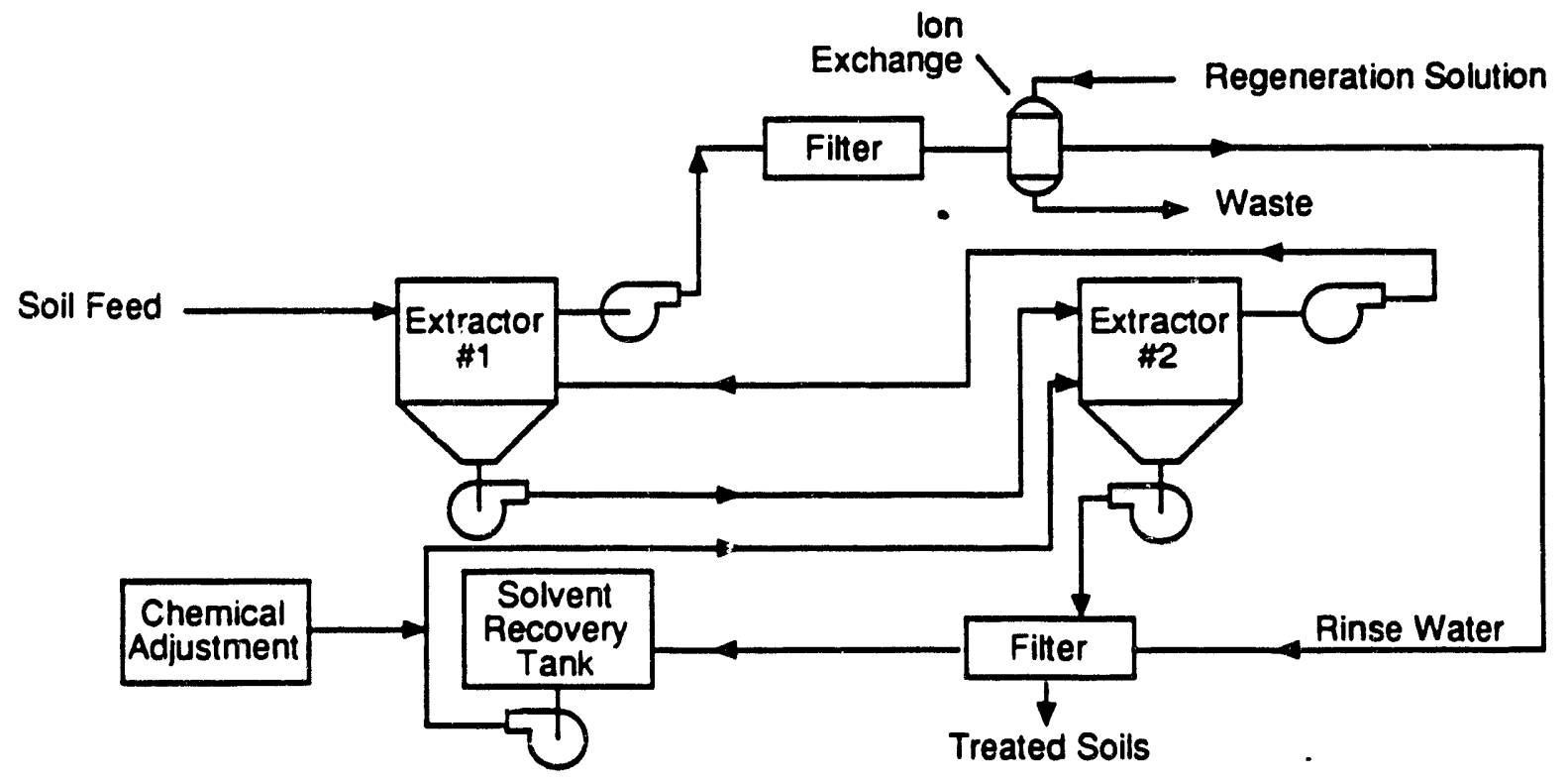

\section{RIST}




\section{APPLICABILITY}

Contaminants Treated;

- Strontium, cesium, technetium, radium.

- Actinides (uranium \& transuranics).

- Metals (barium, mercury, lead).

Media Treatedi

- Soils.

- Construction debris \& production vessels.

- Military vehicles (depleted uranium).

\section{Backuround Datai}

- Performance levels to $<35 \mathrm{pci} / \mathrm{g}$ for uranium \& $<25 \mathrm{pci} / \mathrm{g}$ for plutonium.

- Not affected by soil type or particle size.

- Demonstrated on a variety of soils - from sands to cohesive clays.

\section{Limitations:}

- Presence of organic contaminants will require some adjustments in chemistry.

- Variability in the characteristics and behavior of various soil types does require pre-testing to confirm exact formulation.

\section{STATUS / CAPABILITIES}

The $A C T^{*} D E^{*} C O N^{T M}$ reagent technology was developed by Bradtec, Inc. (United Kingdom) to support the CEGB's fuel debris treatment program. The technology is available to RUST for environmental restoration services through an exclusive license. The $A C T^{*} D^{*} C^{*} N^{s M}$ technology is currently being blended with other proprietary and conventional RUST technologies for adaptation to site remediation work on DOE and other sites.

\section{Laboratery Scale:}

- The first laboratory-scale continuous flow system (rated capacity of $100 \mathrm{lb} / \mathrm{hr}$ ) for application to soils \& radioactive landfill debris is under construction at RRS' Clemson Technical Center for application on the INEL-Pit 9 Project.

\section{Pilot \&. Full Scale:}

- Neither pilot-scale nor full-scale systems are immediately available. Successful completion of the proof-of-process demonstration for the Pit 9 project will result in the design and construction of a full-scale system.

\section{EXPERIENCE}

\section{Aroonne National Laboratory}

Demenstration:

- Bench scale testing of the $A C T^{*} D^{*} C^{*} N^{S M}$ reagent technology has been witnessed by $D O E$ representatives and approved by DOE's Argonne National Laboratory.

- Customer Contacts:

- Don Johnson 708/252-3392 USDOE - Argonne National Laboratory

- Clyde Frank 202/586-6382

USDOE - Office of Technology

Development

- Company Contacts:

- Bob Hemmings 803/646-2413 Steve Hoeffner RUST Remedial Services, Inc. - CTC 
The PO*WW*ERTM technology (see diagram below) principally employs two conventional chemical process technologies - evaporation and catalytic oxidation. These are combined in 2 unique and synergistic manner to effectively treat wastewaters laden with both organic and inorganic constituents. The process provides significant waste volume reduction while producing a high quality and highly manageable emission or discharge.

The essence of the process is that the liquid waste is concentrated in an evaporator by boiling off most of the water and volatile compounds (organic and inorganic). Air or oxygen is injected into the vaporized fraction and the resulting mixture passes through a fluidized catalyst bed in which organic contaminants are oxidized. Acidic gases, potentially formed during the oxidation process, are removed by 2 scrubber (wet or dry). The off-gases are then cooled, resulting in an overall condensate that meets stringent discharge standards, including chronic bioassay criteria. The resulting condensate can be used as cooling tower make-up water, boiler make-up, process foed water, or it can be discharged.

In addition to the unique arrangement of these conventional chemical process rechnologies, the performance of the system is also indexed to the catalyst employed in the catalytic oxidizer. This catalyst is a proprietary metal (non-precious) oxide designed to withstand the fouling or activity suppression common to many metal oxide catalysts.

A secondary waste stream is generated by the process - a highly concentrated waste $(60-70 \%$ total solids). This brine, which represents only a small portion of the original waste volume, typically can be treated through stabilization to below TCLP characteristic limits.

PO*WW*ERTM Wastewater Treatment Process Flow Diagram

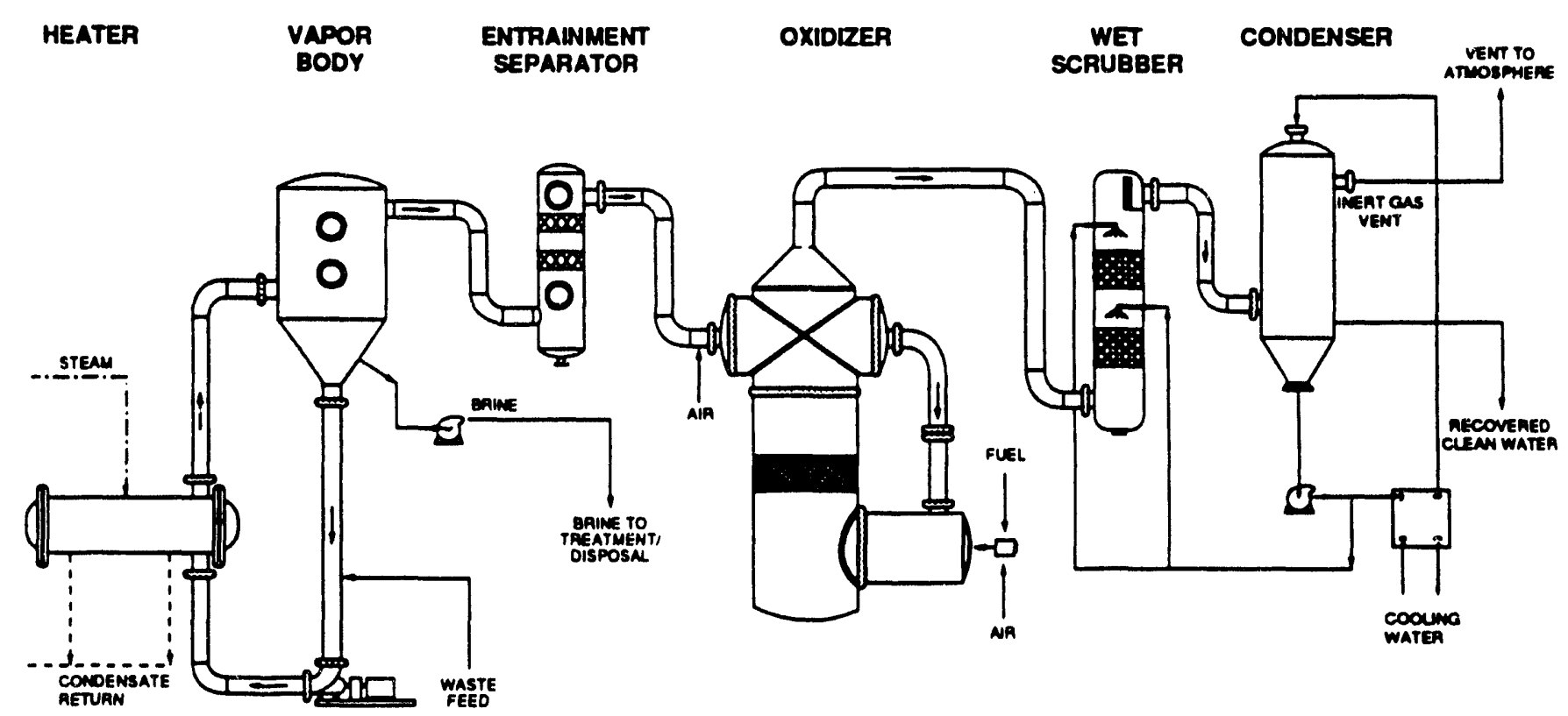




\section{APPLICABILITY}

\section{Contaminants Treated:}

- PCBs, Pesticides, Herbicides.

- Halogenated/non-halogenated VOCs/SVOCs.

- Mixed wastes (organic/ inorganic / radioactive).

- Mercury and various inorganic salts.

\section{Media Treatedi}

- Wastewaters.

- Leachates.

- Groundwater.

- Process waters and other aqueous wastes.

\section{Backaround Data:}

- Concentration ratio (brine) from a feed of 0.5 to 2.0 wr\% TDS to a concentrated slurry of 60 to $70 \mathrm{wr} . \%$.

- TOC oxidation efficiencies to $99.9 \%$, with specific compound oxidation efficiencies to 99.99\%, starting from feed TOCs of 500-3000 ppm.

- Priority pollutants in product water typically non-detectable, TDS below $50 \mathrm{ppm}$, and acute toxicity tests typically successful with $100 \%$ product water.

- All metals in brine solution typically stabilized below TCLP limits with conventional stabilization technology; no priority pollutants typically identified in TCLP leaching solution.

- Typical commercial systems range in capacity from 10 to $1000 \mathrm{gpm}$.

\section{Limitations:}

- Pretreatment may be required to control foaming tendencies of some wastes.

\section{STATUS / CAPABILITIES}

The PO*WW $W^{*} E R^{T M}$ technology is a product of $100 \%$ incernal company development. We currently have one laboratory scale unit and one pilot scale unit for use in testing this technology.

\section{Laboratory Scale:}

- One system available for treatability studies on RCRA, TSCA or mixed wastes at RRS' Clemson Technical Center.

- Actually a small, continuous flow, pilot plant (capacity of $1 \mathrm{gph}$ ) that simulates the pilot-scale hardware.

\section{Pilot Scale:}

- Pilot-scale system, capable of continuous flows of $15 \mathrm{gph}$, is available at Chemical Waste Management's Lake Charles, LA facility.

\section{Eull Scale:}

- Commercial system (3000 gph) is nearing completion at the WMI's new hazardous waste TSDF in Hong Kong. Anticipated start up in May, 1993.

\section{EXPERIENCE}

The PO*WW*ERTM technology has been tested on landfill leachates, process wastewaters, and other aqueous waste at the company's Lake Charles, Louisiana facility. The pilot unit was first placed in operation in 1988, and over 20 pilot scale demonstrations have been completed. A successful EPA SITE program demonstration was recently conducted with the pilot system at Lake Charles.

- Customer Contact:

- Randy Parker 513/569-7271 USEPA Risk Reduction Engineering Lab

- Company Contact:

- Bob Hemmings 803/646-2413

RUST Remedial Services, Inc. Clemson Technical Center 


\section{PROCESS DESCRIPTION}

The SOIL*EXTM technology (see diagram below) incorporates constituent specific, aqueous based chemical extraction with solids separation, evaporation and catalytic oxidation collectively designed to separate and remove radionuclides and metals from solid mixed waste materials, e.g. soils and debris, while destroying volatile organic compounds. The process incorporates three integrated process modules or subsystems: chemical extraction, extraction blowdown treatment and extraction sludge dewatering.

The extraction process utilizes the company's $A C T^{*} \mathrm{DE}^{*} \mathrm{CON}^{\mathrm{SM}}$ solution and non-ionic surfactant chemistry to promote mass transfer of specific bound contaminants (e.g. actinides, VOCs, toxic metals) into an aqueous phase for subsequent concentration of nonvolatile constituents and oxidation of the volatile components (organic and inorganic). The extraction chemistry is waste specific, with the extraction process supported by an innovative two-stage counter-current extraction and separation system, consisting of cyclone separation and solid/liquid extraction units. The extraction process is preceded by a waste preparation phase incorporating a pulper-type mixer to process the waste materials into a slurry to advance extraction efficiency. Debris not sized by the pulper rotors is collected in a debris trap for special handling and washing using recycled (treated) process waters.

The extraction process results in a contaminate-laden liquid blowdown which is processed to the PO*WN*ERTM subsystem. Evaporation of the blowdown resules in volume reduction of 1:100 with the resulting vapors treated by the unit's catalyric oxidizer in which volatile compounds, including chlorinated compounds, aromatics, sulfides, ammonia, cyanides, etc. are completely oxidized. Second stage vapors are

Figure 1. SOIL“EXTM Radionuclide Extraction Process Flow Diagram

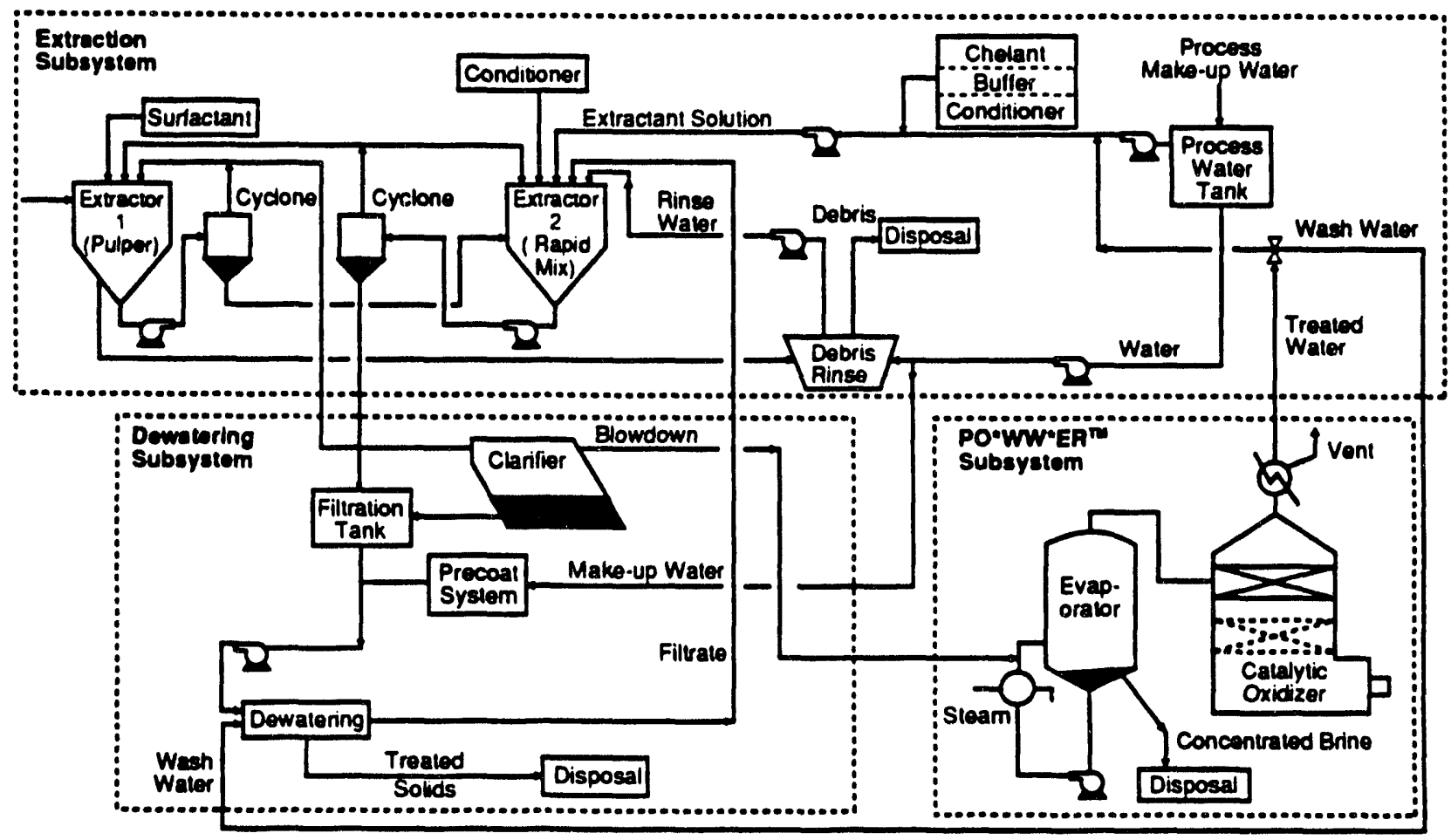


treated by conventional scrubbers positioned between the oxidizer and condenser with scrubber blowdown returned to the evaporator. High quality condenser (product) waters are recycled to the extractor and/or used in the dewatering process for washing of non-sized debris.

The dewatering subsystem utilizes clarification for liquid extraction blowdown pretreatment prior to introduction to the PO*WW*ER system and a plate \& frame pressure filtration (or centrifugation) system for treatment of slurry sediments from the separator and clarification units. The final waste product is a decontaminated dewatered sludge that may be disposed or recycled to other uses.

\section{APPLICABILITY}

\section{Contaminants Treated:}

- Heavy metals.

- Radionuclides.

- Volatile organics.

\section{Media Treated:}

- Soils (all types).

- Debris \& sludges.

\section{Backoround Data:}

- Typical volume reduction $>95 \%$.

- Treated waste forms reflect:

- $99 \%$ organic reduction.

- 200:1 reduction in heavy metals.

- Process has distinct advantage over conventional soil washing, acid dissolution and solvent extraction systems due to contaminant selectivity.

- System flexible to accommodate wide variations in feed contaminant levels.

- No secondary waste generated that requires further treatment.

\section{Limitations:}

- Organic loading over $15-20 \%$ may require pretreatment.

- Some volatile compounds may require special additives.

\section{STATUS/CAPABILITIES}

SOIL ${ }^{*} X^{T M}$ technology is a marriage of existing company proprietary technologies - $A C T^{*} D E^{*} C O N^{S M}$ and $P^{*} W^{*} W^{*} E R^{T M}$ and non-proprietary readily available conventional systems. The first fully integrated continuous flow pilor scale unit is under construction at RRS' Clemson Technical Center and will initiate service during 1993.

\section{EXPERIENCE}

- Both the PO*WW*ERTM and ACT*DE*CON ${ }^{5 M}$ processes have been successfully demonstrated individually.

- Idaho National Engineering Laboratories (INEL) has selected the SOIL EXTM process for demonstration in the remediation of INEL's Pit 9 soils \& sludges, contaminated with radionuclides, organics, and metals.

- Proof-of-process demonstration for Pit 9 to begin in mid-1993 at RRS' Clemson Technical Center.

- Customer Contact:

- Doug McKenzie 208/526-2977 Idaho National Engineering Laboratories

- Company Contacts:

- Bob Hemmings 803/646-2413

RUST Remedial Services, Inc.

Clemson Technical Center

- Bob Bloom 303/243-8800

RUST Federal Environmental Services 


\section{PROCESS DESCRIPTION}

$E^{*} I^{*} X^{n M}$ is a process designed to remove and destroy nitrates in wastewater effluents, process waters, and groundwaters. The process combines the well-known nitrate removal effectiveness of ion exchange with the desirable waste form advantage of electrical regeneration of the resin. This produces nearly complete destruction of the nitrates so nitrogen and water. Therefore, the process eliminates the waste management problems associated with traditional brine regeneration of the ion exchange resin.

In the process, waste effluent or groundwater is pumped through selective anion exctrange columns where nitrates are removed, typically to levels that are approximately $1 \%$ of the original concentration. The exchange column is sandwiched berween anion permeable membranes, with an anode on one side and a cathode on the other. The continuous application of electrial current causes the nitrates to migrate from the exchange resin to the anode compartment. Here, the nitrates are subjected to redox rections to form nitrogen and water for subsequent discharge or well injection (for ground water recycle). The process is continuous flow, with concinuous on-line regeneration of the resin resulting in a steady state removal/regeneration process. A schematic of the process is shown below.

\section{APPLICABILITY}

Contaminants Treated: Nitrates.

\section{Backoround Datai}

- $99 \%$ removal and destruction of nitrates.

- Continuous flow system.

- Continuous regeneration of ion exchange resin enhances resin life.

\section{Limitations:}

- Pretreament may be required for some wastes to prevent resin plugging.

- Oxides of nitrogen may be formed at electrodes, small volumes of off-gas may require caralytic treatment.

\section{STATUS / CAPABILITIES}

The $E^{*} I^{*} X^{7 M}$ process has been developed through the pilot-sal. level by Bradtec, Inc. RUST has acquired an exclusive license for $E^{*} I^{*} X^{T M}$ development and application.

\section{EXPERIENCE}

No field projects can be referenced at this time. However. contracts are in place to progress the $E^{*} I^{*} X^{T M}$ system to full scale.

- Customer Contacts:

- Jack McKinnon 303/966-6493

George Lehmkuhl 303/966-7000

EG\&G Rocky Flats

Media Treated: Wastewaters, process waters, and groundwaters.

$E^{*} I^{*} X^{T M}$ Eleara-Chemial Ion Exchange Process Flow Diagram

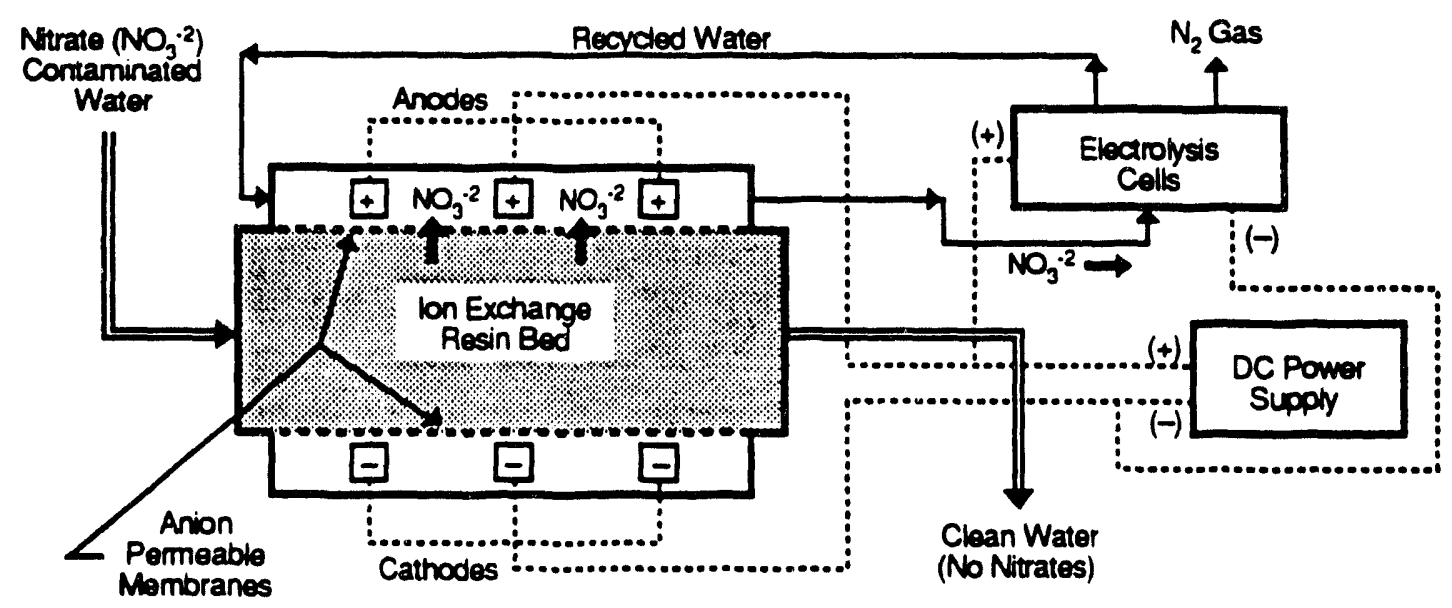




\section{PROCESS DESCRIPTION}

Magneticseparation technology combines a specialized adsorbing particle with magnetic filtration to remove inorganic constituents, such as radionuclides and heavy metals, from wastewater and groundwater. The key innovation in the MAG*SEPTM process (see diagram below) is the adsorbing resin particles, which are a composite of magnetite and various organic polymers. The polymet coating is designed to contain certain "funcrional groups", or to have selective magnetic seeds bound to the magnerite particles. The acrive sites, therefore, an be custom designed to treat 2 variety of inorganic target contaminants.

These resins have been effective in removing dissolved metals down to the ppb level. Since the adsorption of contaminants onto these particies is a surface phenomenon only, reaction kinetics are very rapid. This allows the process to be run at relatively high flow rates - up to $2400 \mathrm{gpm}$. The process uses commercially available equipment.

Typically, wastewater or groundwater is blended with the magnetite and seed materials in a mixing chamber to effect the binding of the target contaminant(s) to the magnetite. The light slurry is then pumped through a magneric filter where the magnetite (and contaminants) are removed. Periodically, the magnetic filter must be removed from service and backflushed into a recovery tank, where the magnetite/contaminant bond is chemically broken and essentially all of the magnetite is recovered for reuse. The contaminants remaining in the slurry are reclaimed, treated, or disposed. Waste volumes from the MAG*SEPrM process are considerably less than those generated by conventional treatment techniques, with decontamination factors ranging from 100 to 1000 .

\section{APPLICABILTTY}

\section{Contaminnnte Trented:}

- Heavy mecals/precious mecals.

- Radionuclides.

\section{Medin Trented:}

- Wastewaters and groundwater.

\section{Bnakground Dote:}

- Metals removal projected to below detection limits, typically < 0.1 ppm demonstrated.

- Mercury removals experienced at 99+\%.

- Multi-stage system enhances performance.

Limitation:

- Process rate apacity limired by apacity of commercially available magnetic filters.

- Specialized particle types for all posential applications not fully tested to date.

\section{STATUS/CAPABILITIES}

Magneticseparation rechnology, with respect to the environmental industry, is in the development stage. Tests to date, both continuous and batch, have been principally limited to laboratory scale, and only several specialized particle types have been tested. MAG*SEPTM has been developed through the pilot-scale by Bradtec, Inc., and is available to RUST through an exclusive license. Since commercially available equipment is used, fullscale development can proceed rapidly after testing of specific particle/wastewater chemistries.

\section{EXPERIENCE}

- Field scudies conducted for confidential client (international precious metal refiner).

- Precious metals were removed to detection limits.

- Customer Contac:

- Don Johnson 708/252-3392

USDOE - Argonne National Laboratories

\section{MAG*SEPrM Process Flow Diagram}

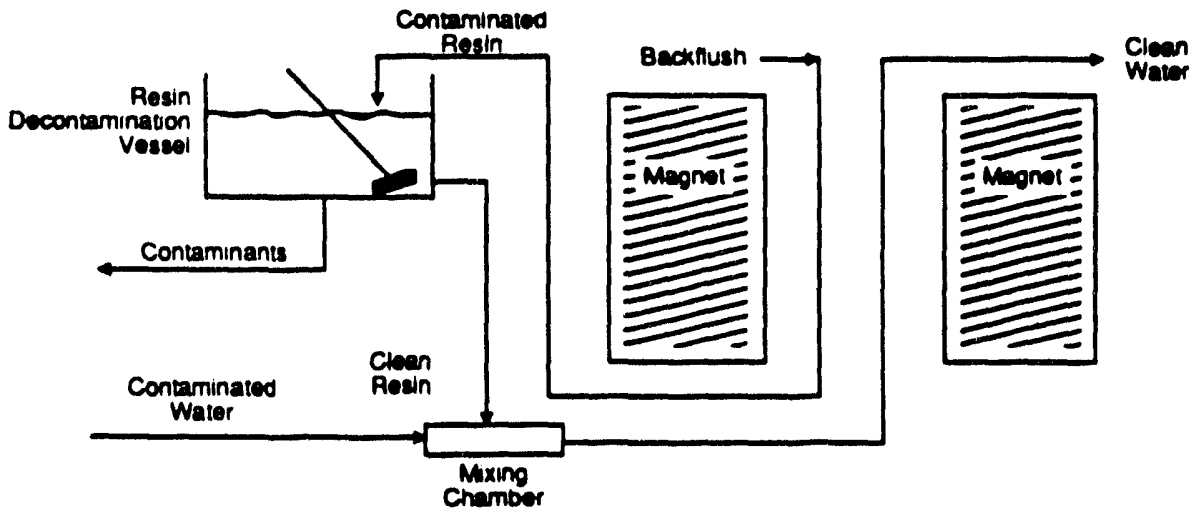




\section{PROCESS DESCRIPTION}

CRYOCELL ${ }^{T M}$ is a unique ground freezing process for the containment of radioactive and hazardous wastes. It utilizes techniques similar to those that have been used extensively in civil engineering projects for freezing unstable and saturated soils during construction tasks. CRYOCELL ${ }^{\mathrm{TM}}$ contains and isolates hazardous waste in-situ by encircling the waste area with a thick barrier of frozen/impermeable soil. The rate of diffusion through the barrier is estimated as below detectable levels over a 10,000 year span.

The cryogenic barrier is constructed by positioning two staggered rows of 6" pipes in the soil at an angle to reach below the area of contamination, forming a " $\mathrm{V}$ " much like the ribs of a canoe. A double row of pipes is also positioned vertically in the soil at both ends of the waste area to provide complete containment. Using a tube within a tube design, a 3 " pipe is placed inside the 6" pipes to provide return flow of refrigerant. Surface piping connections are made and refrigerant is supplied, providing a rapid temperature reduction to $-35^{\circ} \mathrm{F}$ along the length of the piping. Perforated (non-refrigerant) piping is installed at periodic intervals to allow moisture injection (if needed) during barrier formation, subsurface sampling, selective thawing of certain areas of frozen soil, and monitoring of the barrier temperature and pressure.

CRYOCELL ${ }^{\text {TM }}$ is not affected by ground movement from settlement, earthquakes, etc., due to a special "selfhealing" property. Internal barrier pressure will cause breaks or voids in the ice to re-freeze/fuse together. Any liquid that begins to enter a crack or void in the barrier's sub-zero environment cannot pass through the 50-75' wide barrier due to the phenomenon of "freeze purification". Further, the barrier and its "self-healing" protection requires over 10 years of continuous shutdown of the modest O\&M refrigeration system before thawing to a permeable state.

\section{CRYOCELI ${ }^{\text {TM }}$ Process Flow Diagram}

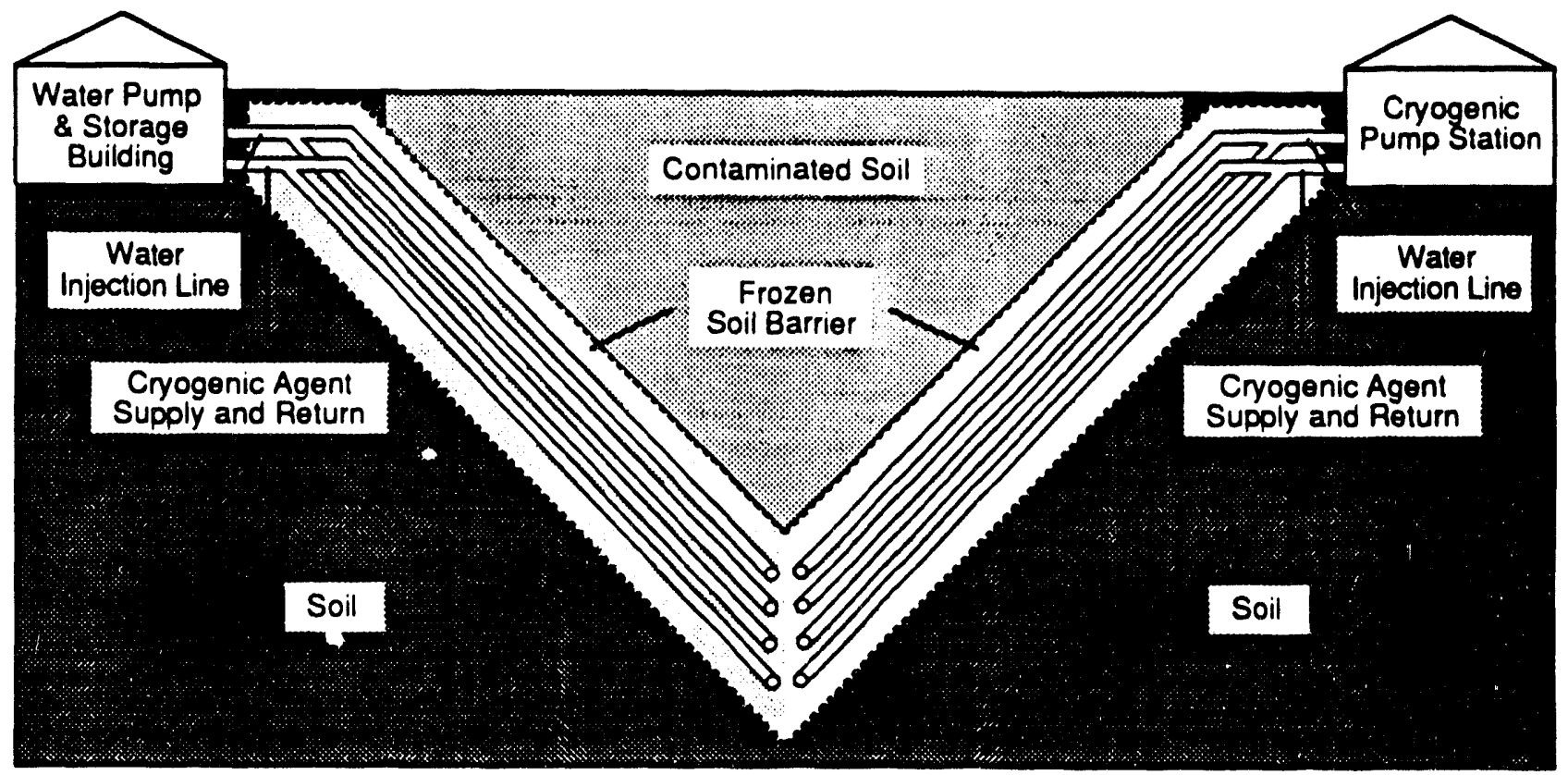




\section{APPL.ICABILITY}

\section{Contaminants:}

- Organic chemical wastes.

- Inorganic chemical wastes.

- Mixed and radioactive wastes.

Mediai Soils/solids.

\section{Backaround Data:}

- Contained area can be 1 to $>100$ acres.

- Contaminant concentrations are insignificant due to virtual zero rate of permeability.

- Not effected by soil moisture content.

\section{Limitations:}

- Limited only by ability of piping placement in soil - 1,000 foot is maximum barrier depth for most soils.

\section{STATUS / CAPABILITIES}

RUST has an exclusive licensing agreement in place with RKK, Led (owner of CRYOCELL $L^{T M}$ ), and their teaming partner, FreezeWaall, Inc., to apply this technology at certain sites. Services and/or capabilities that are available include:

\section{Pilot Scale:}

- Pilot-scale containment barrier constructed in 1990 , and operated for six months.

- Simulated full scale manifold, freeze pipes and equipment.

- Chemical analysis report verified no diffusion through the barrier.

- Ten cubic yards of soil, spiked with 0.75 gallons of motor oil, was contained.

- System was self-contained and maintained an average temperature of $28^{\circ} \mathrm{F}$.
Eull Sale:

Full scale CRYOCELL ${ }^{\text {TM }}$ systems have not yet been installed, but ase being considered at numerous DOE facilities. The following list demonstrates the different types of sites, conditions, and waste types/characteristics that this technology is being considered for:

- Oak Ridge, TN (clean site demonstration).

- Hanford Nuclear Reservation, Richland, WA.

- Mound, OH.

- Fernald, OH.

\section{EXPERIENCE}

CRYOCELL ${ }^{\text {TM }}$ rechnology research began in 1987 , resulting in the two patents listed above. During the last 13 years, dozens of successful groundwater freezing projects have been performed to client expectations by RKK's teaming partner, FreezeWall Inc. Currently, in New York City, a series of four vertical shafts each 50 feet in diameter and 240 feet deep, are under construction. This use of civil ground freezing is providing the structural strength for holding back a 200 foor head of water.

- Company Contacts:

- Chris Reno 206/653-4844 Chief Projects Manager - RKK, Ltd.

- John Donohue 201/627-3950 President - FreezeWall, Inc.

- Dr. Greg Dash 206/543-2787 Professor - Department of Physics University of Washington 


\section{PROCESS DESCRIPTION}

Oxidation is the best method to assure the destruction of both chlorinated and non-chlorinated VOCs to meet regulatory emissions standards and solve VOC related odor problems. The Econ-Abator ${ }^{\text {TM }}$ system oxidizes VOCs in contaminated air streams using a rugged low temperature non-precious metal catalyst. This design overcomes the deficiencies which exist in conventional catalytic oxidation systems which resulting from the loss of catalyst through attrition.

The estimated life of Econ-Abator ${ }^{\mathrm{TM}}$ catalyst is 17,520 hours. Catalyst is normally added on a monthly or bimonthly basis to top off the bed, which can be done without shutring down equipment. The design also overcomes the inefficient energy utilization inherent in thermal afterburner systems by operating at lower temperature and handling higher VOC loading, outweighing the smaller advantage of a thermal oxidation unit's lower pressure drop.
The heart of the Econ-Abator ${ }^{\mathrm{TM}}$ Catalytic Oxidation System (see diagram below) is the catalytic reactor, through which an organic contaminated air stream is passed for treatment prior to heat recovery/exhaust. The reactor is comprised of a thermal zone and a catalyst zone.

The thermal zone is immediately up-stream of the catalyst zone and is designed to supply catalyst pre-heat requirements. If necessary, heat input up to thermal oxidation temperature can be supplied. The catalyst zone is comprised of a few inches of moving or fluid bed catalyst. The moving catalyst bed allows any coated catalyst to circulate to higher temperature zones in the bed where the coating is oxidized.

\section{Econ-Abator ${ }^{\text {TM }}$ Process Flow Diagram}

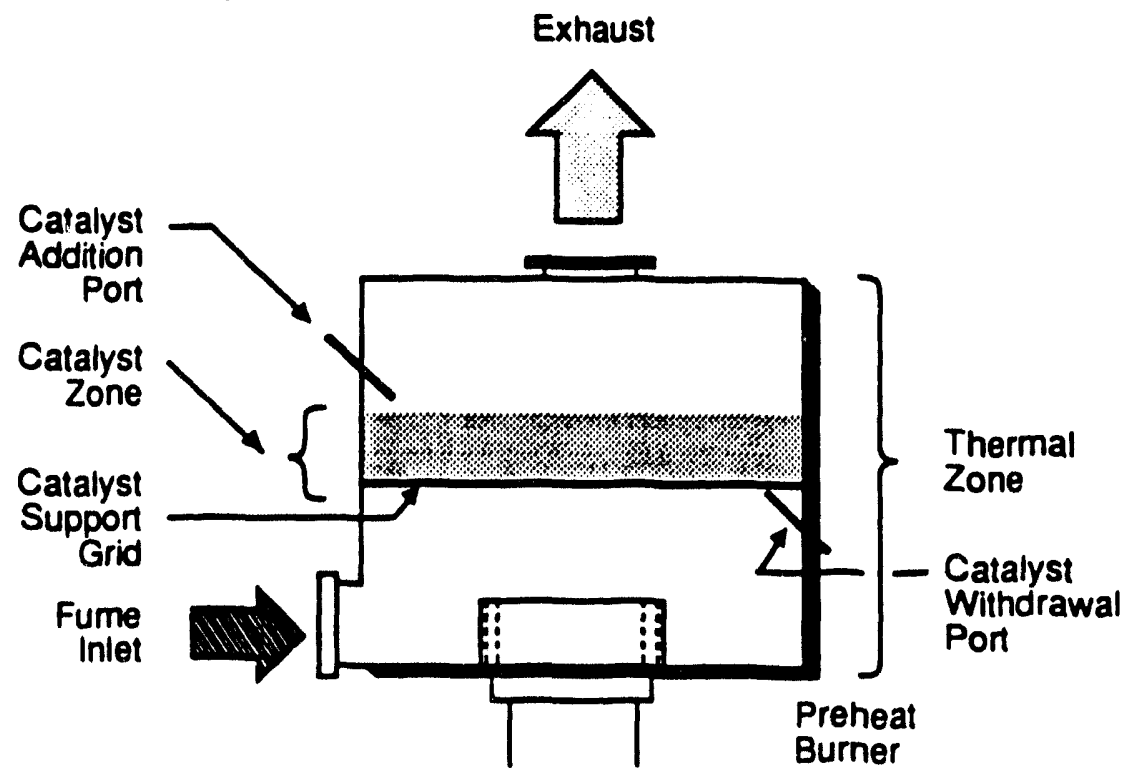




\section{APPLICABILITY}

\section{Contaminante:}

- Volatile Organic Compounds.

- Hydrocarbons (BTEX, JP4, gas, diesel, etc.).

- Alcohols.

- Esters, echers, and ketones.

- Aliphatics and aromatics.

- Chlorinated/fluorinated derivatives (freons).

\section{Modia:}

- Air streams and other gases/vapors.

\section{Backaround Data:}

- Typical operating temperature range of $600^{\circ}$ $800^{\circ} \mathrm{F}$ for $99+\%$ destruction efficiencies.

- Systems can operate at up to $1600^{\circ} \mathrm{F}$.

\section{Limitations:}

- High concentrations of chlorinated organics produce $\mathrm{HCl}$ as a reaction product, requiring a wet scrubber after the Econ-Abator ${ }^{\mathrm{TM}}$.

\section{STATUS / CAPABILITIES}

The Econ-Abator ${ }^{\text {TM }}$ Catalyric Oxidation System is the product of years of development work by ARI Technologies, a subsidiary of Wheelabrator Technologies, Inc. which holds extensive proprietary knowledge in the area of catalytic oxidation. Commercial development of full-scale Econ-Abator ${ }^{T M}$ systems is complete, with many systems in operation. Among the systems designed and installed to date, most are rated 8,000 SCFM or above. The highest volume system to date is rated at 36,000 SCFM. ARI's Econ-Abator ${ }^{\text {TM }}$ system is available to RRS for site remediation applications.

\section{EXPERIENCE}

ARI's list of references includes a significant number of major industrial firms. These companies are involved in every conceivable manufacturing sector. With respect to remedial work, ARI has built several recuperative system designs for site remediation projects involving groundwater treatment, i.e. - for the treatment of offgases from groundwater air stripping and soil remediation operations. Example remedial site applications include:

Wurtsmith AFB,Mli: Two 1,500 SCFM units used for destruction of chlorinated and nonchlorinated organics from air strippers.

Maclellan AFB, CA: 2,000 SCFM unit for chlorinated organics from air stripper.

Upiohn Companv Kalamazeo Mli Two 500 SCFM units installed at various soil venting remediation sites.

- Customer Contacts:

- George Miller 214/866-6000 Union Carbide, Garland, TX

- Joe Seranton 313/329-2274 Vacumet, Inc., St Clair, MI

- Company Contact:

- Bill Sheffer 708/359-7810 AR Technologies, Inc. 


\section{PROCESS DESCRIPTION}

Vapor phase carbon adsorption is a well known and proven technology used to remove solvents or VOCs from contaminated air streams (soil ventilation, air strippers, sprung structure ventilation, etc.), with typical removal efficiencies of up to $99 \%$. Amcec offers this technology in two types of regenerative adsorption processes - the HYBRJD system and a deep static bed system.

Amcec's innovative HYBRJD process provides the lowest operating cost for on-site removal and destruction of VOCs from high volume/low VOC concentration (< $500 \mathrm{ppm}$ ) air streams. The process eliminates the possibility of VOC "breakthrough" by combining two proven technologies, carbon adsorption and oxidation (see diagram below). HYBRID's design is based on a ceramic fiber honeycomb wheel, impregnated with activated carbon. As VOC-laden air streams pass through the rotating wheel (turning at 1 to 3 revolutions per hour), the VOCs are retained on the activated carbuin, with an efficiency which is typically about $95 \%$. While rotating, the wheel passes through a regeneration sector where a hot air stream (10 to 20 times lower in volume than the main air stream) removes and concentrates the VOCs, simultaneously regenerating the carbon. The regeneration air stream is then passed io a deep bed carbon adsorption system or small thermal/catalytic oxidation unit for final treatment.

If extremely high VOC concentrations and stringent removal efficiency requirements disallow the use of HYBRID, Amcec's custom designed, conventional deep static bed carbon adsorption and regeneration system can be urilized. Through adsorption/desorption cycle: monitored by on-line analyzers and computer, each bed is periodically regenerated. A counter flow of steam heats the carbon bed and carries the desorbed VOC vapors to a condenser and liquid separation unit, for segregation and ultimate disposal.

Amcec "HYBRID" and Static Bed Carbon Adsorption Process Flow Diagram

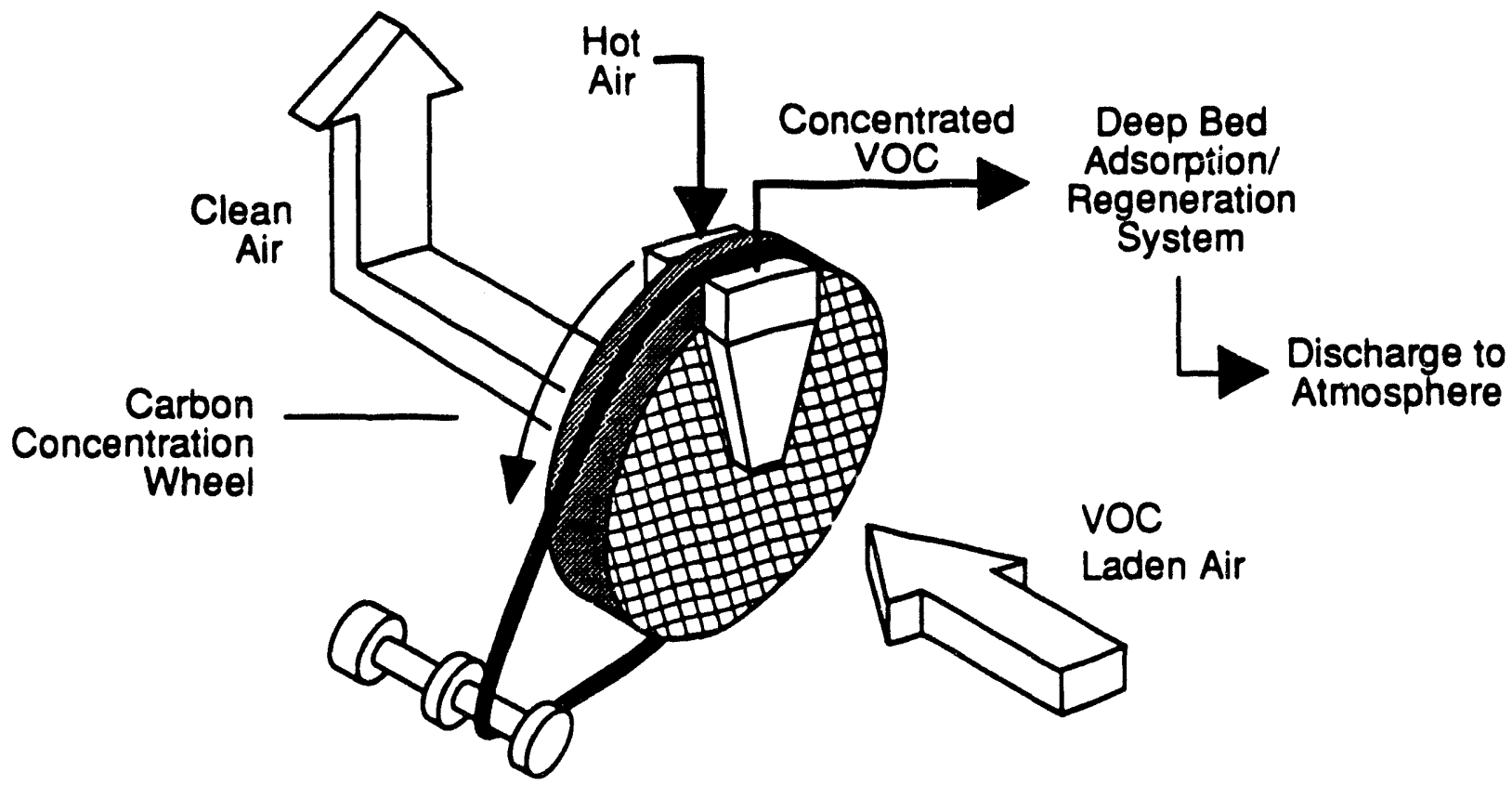




\section{APPLICABILITY}

Contaminants:

- Solvents or VOCs.

- Hydrocarbons (BTEX, JP4, gas, diesel, etc.).

- Alcohols.

- Esters, echers, and ketones.

- Aliphatics and aromatics.

- Chlorinated/fluorinated derivatives (freons).

Media: Air streams and other gases/vapors.

\section{Backoround Data:}

- Amcec deep static bed carbon adsorption systems (regenerated on-site with steam) range from 300 to 500,000 SCFM air flows.

- HYBRID system (regenerated on-site with hot air) is cost-effective for large air flows with VOC concentrations $<500 \mathrm{ppm}$.

\section{Limitations:}

- Sacrificial carbon beds may be required upstream of any carbon adsorption unit for capturing high boiling point compounds (semivolatiles).

\section{STATUS / CAPABILITIES}

Amcec, Inc., a RUST affiliate company, has 60 years experience in the application of carbon treatment technology, and holds proprietary knowledge in the engineering of the processes described herein. These processes and services are readily available to RRS for site remediation applications.

\section{Pilot Scalei}

- A pilot scale system is available for testing purposes.

\section{Eull Scale:}

- Numerous systems, both HYBRID and conventional, are in operation, and more are under construction.

- Majority of systems are at customer's fixed manufacturing facilities.

- Ten of the installed systems are rated 100,000 SCFM or above. Site visits can be arranged upon request.

\section{EXPERIENCE}

Amcec's list of references includes $15 \mathrm{major}$ industrial firms involved in printing, packaging, pharmaceuticals, chemicals, refining, etc., that require the treatment or recovery of solvents and/or VOCs. With respect to remedial work, Amcec has designed and built several regenerative systems for site remediation projects involving ground water treatment. These systems were used to treat the off-gases from groundwater air stripping processes.

\section{WWW Engineerina Groundwater Projects:}

- 4,500 SCFM system for use at Rexair facility in Cadillac, MI.

- 3,000 SCFM system for Goetz facility in Muskegon, Ml currently under construction.

- Customer Contact:

- Peter Lundquist 616/942-9600

W.W. Engineering

Quad Graphics, Lomira Wli:

- Static deep bed system at fixed printing facility, rated at 500,000 SCFM.

- Customer Contact:

- Mike Krzykowski 414/269-4700

Quad Graphics 


\section{PROCESS DESCRIPTION}

Since 1984, Wheelabrator Environmental Systems, Inc., a subsidiary of Wheelabrator Technologies, Inc. (WTI), has researched and developed practical technologies for the immobilization of heavy metals in ash and other wastes. The culmination of this effort is WES-PHix ${ }^{\text {TM }}$, a cost-effective and reliable heavy-metal immobilization process that is up to 300 times more effective than cement-based processes at controlling lead leaching. WES-PHix ${ }^{\mathrm{TM}}$ also reduces disposal costs by eliminating the waste bulking and weight gain associated with the cement/silica-based stabilization methods.

The WES-PHix ${ }^{\text {TM }}$ process immobilizes heavy-metals so that the resulting treated wastes test as non-hazardous under the USEPA TCLP, the California WET, and other state and foderal leaching tests. Furthermore, WES-PHix ${ }^{\text {TM }}$ has been confirmed as highly effective by the USEPA and various independent labs.
The WES-PHix ${ }^{T M}$ process can treat waste in-situ or in a batch mode or continuous flow, in-line system which is totally enclosed, eliminating unnecessary exposure (see processes below). A small quantity of proprietary liquid reagent is injected and intimately mixed with lead-and/or cadmiumbearing wastes to form highly insoluble, mineralized metal complexes. Occasionally, a form of alkali must beadded to the waste to maintain the optimum $\mathrm{pH}$ conditions for the WESPHix ${ }^{\text {TM }}$ chemical reaction to occur.

The treated waste stream from the WES-PHix ${ }^{T M}$ process retains similar physical and material handling characteristics as that of the waste feed. The treated waste does not cure into a brick-like consistency, as is the case with many waste streams treated with high dosages of cement/silica reagent admixtures.

WES-PHix ${ }^{T M}$ an be applied using these RUST Remedial Services immobilization processes

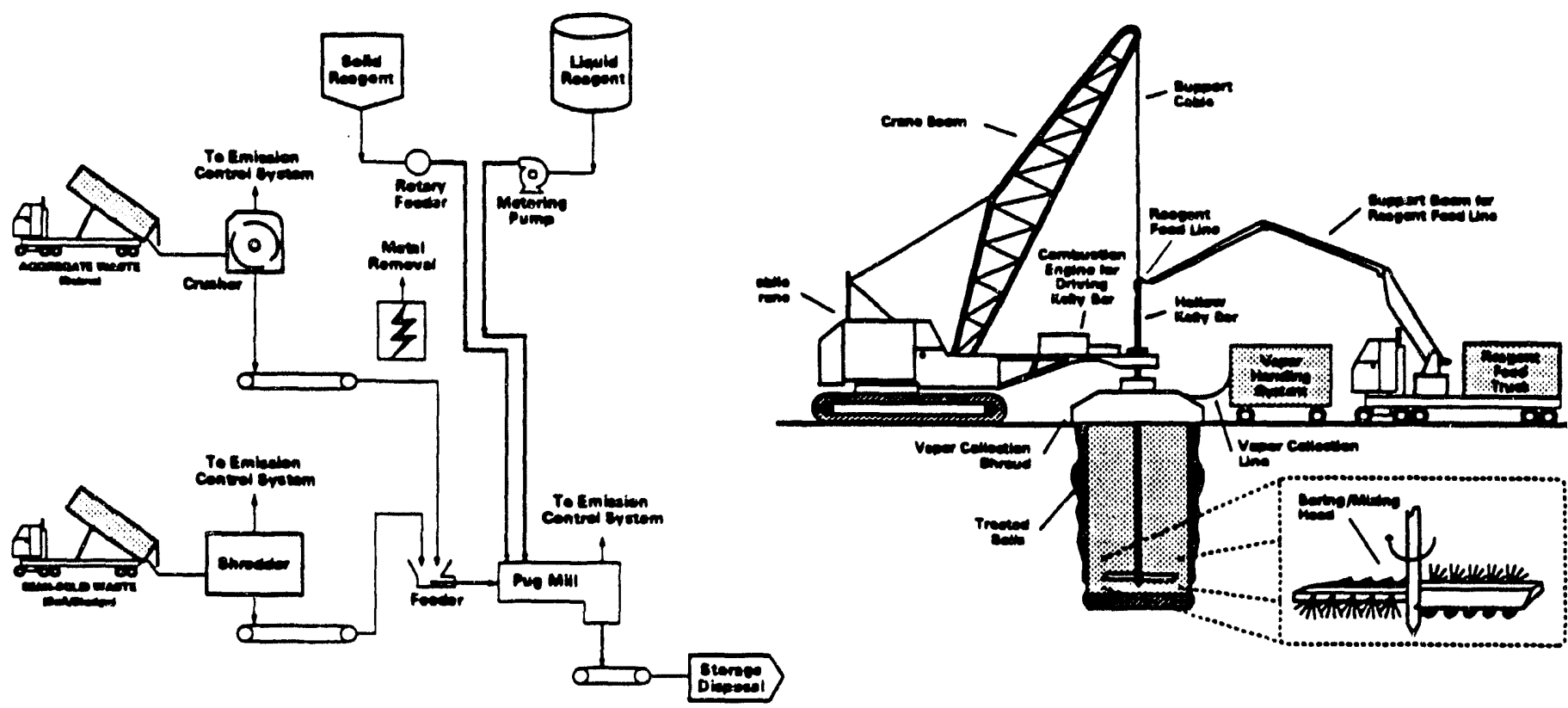




\section{APPLICABILITY}

Contaminants Treatedi Lead, cadmium, zinc, and copper.

\section{Media Trented:}

- Soils, sludges, and slags.

- Incinerator ash and baghouse dusts.

- Scrap metal processing wastes.

\section{Backoround Date:}

- Demonstrated on a variety of solids, from ash to metals contaminated sludges.

- Heavy metal leaching reduced to 1 ppm or less.

- Effective over a wide $\mathrm{pH}$ range (4 to 12).

\section{Limitations:}

- Maximum contaminant concentration limit is theoretically unlimited - to date 130,000 ppm has been tested.

- Soils/solids $3 / 8^{n}$ or greater must be size reduced in 2 crushing, shredding, or screening operation.

\section{STATUS / CAPABILITIES}

Results from full scale operations and laboratory treatability studies are available upon request. In addition, an EPA research program on the usage of the WES-PHix ${ }^{\text {TM }}$ process was complered in 1992.

\section{Laboraton Scale:}

- Bench-seale system in operation as Wheelabrator's contract laboratory facilities.

\section{Pilot Sarle:}

- On-site pilot studies can be arranged.

EullScale: Full-scale WES-PHix ${ }^{\mathrm{TM}}$ ash immobilization systems are in operation at many WTI refuse-to energy facilities and external licensee facilities. RUST Remedial Services, as an affiliate, offers the capability of performing either ex-situ or in-situ WES-PHim immobilization at a customer's site, using our proprietary applications and technologies as follows: MecToolin In-situ Remediation:
- Deep soil mixing tool, with reagent application by injection through tool head.

- Treatment to depths > 100 feet.

Chem-Matrix St Stabilization:

- Transportable pug-mill system.

- Capable of treating up to 100 tons per hour, depending on waste characteristics.

- Enclosed mixing system with waste material weigh belt and reagent metering.

\section{EXPERIENCE}

The WES-PHix ${ }^{\mathrm{TM}}$ process was patented in 1988 and has been operated on a commercial basis since 1986 . The first full-scale installation of WES-PHix was at WTI's refuse-to-energy facility in Claremont, NH, with continuous operations since installation. Treated ash has been subjected to daily and weekly EP Toxicity testing to meet stringent state requirements. The Company's Gloucester, NJ refuse-to-energy facility has even more stringent testing requirements. Treated ash is sampled each hour and composited on a semi-daily, daily, weekly, and monthly basis for EP/TCLP analysis.

To date, WES-PHix TM has successfully treated over two million tons of waste. Wheelabrator has installed WESPhix ${ }^{\text {TM }}$ processes at four refuse-to-energy facilities, and seven commercial installations. WES-PHix ${ }^{\mathrm{mM}}$ reagent has been used for immobilization at a Superfund site remediation project in New Jersey. This project utilizes WES-PHix ${ }^{T M}$ reagent and portland cement to treat 13,720 tons of lead slag. The lead concentration isreduced from approximately 130,000 Ppm to 5 ppm. Treated waste is sampled and analyzed via TCLP prior to disposal.

- Customer Contact:

- Cariton Wiles 513/569-7795

Project Manager - EPA Ash Solidification/ Stabilization Study USEPA Risk Reduction Engineering Lab

- Company Contact:

- Mark Lyons 603/929-3000

Wheelabrator Environmental Systems, Inc. 


\section{PROCESS DESCRIPTION}

Wheelabrator Technologies, Inc. (WTI), through its Bio Gro Systems, Inc. subsidiary, offers a pollution-free, odor-free process to convert municipal wastesludges (bio-solids) into pathogen-free fertilizer, soil amendment pellets, or clean-burning pellerized fuel. The Bio Gro process may also be applicable for cerrain types of hazardous wastesludges. The primary feature of the patented Bio Gro-Seghers Pelletech® process is the innovative Pelletech (1) unit - an enclosed, vertical, indirect dryer that heats/dries sludge at $212^{\circ} \mathrm{F}$ by circulating steam or thermal oil in a separate closed loop. The pellets are formed during this one-step drying process, so that separate mechanical pelletization equipment is not required. Because the sludge never contacts flames or superheated gases, the unit needs no costly add-on pollution or odor control equipment. Microorganisms that are commonly found in wastewater are also eliminated during the drying process.
The pellets generally comprise less than 10 percent of the original feed sludge. The pellets are round in shape, 0.5 $6.0 \mathrm{~mm}$ in diameter, and contain about $5 \%$ moisture by weight. Aside from being directly marketable as a fertilizer, the pellets can also be burned in an innovative "Zerofuel" combustor. This unit does not require supplemental fuel (natural gas, propane, erc.), and provides the heat for the sludge drying/pelletizing process in the Pelletech (1) unit. This provides a very cost-effective energy recycle loop for the overall sludge management process. The combusted pellet ash generally comprises less than $2 \%$ of the volume of the initial sludge.

\section{Bio Gro Sludge Reuse Process Flow Diagram}

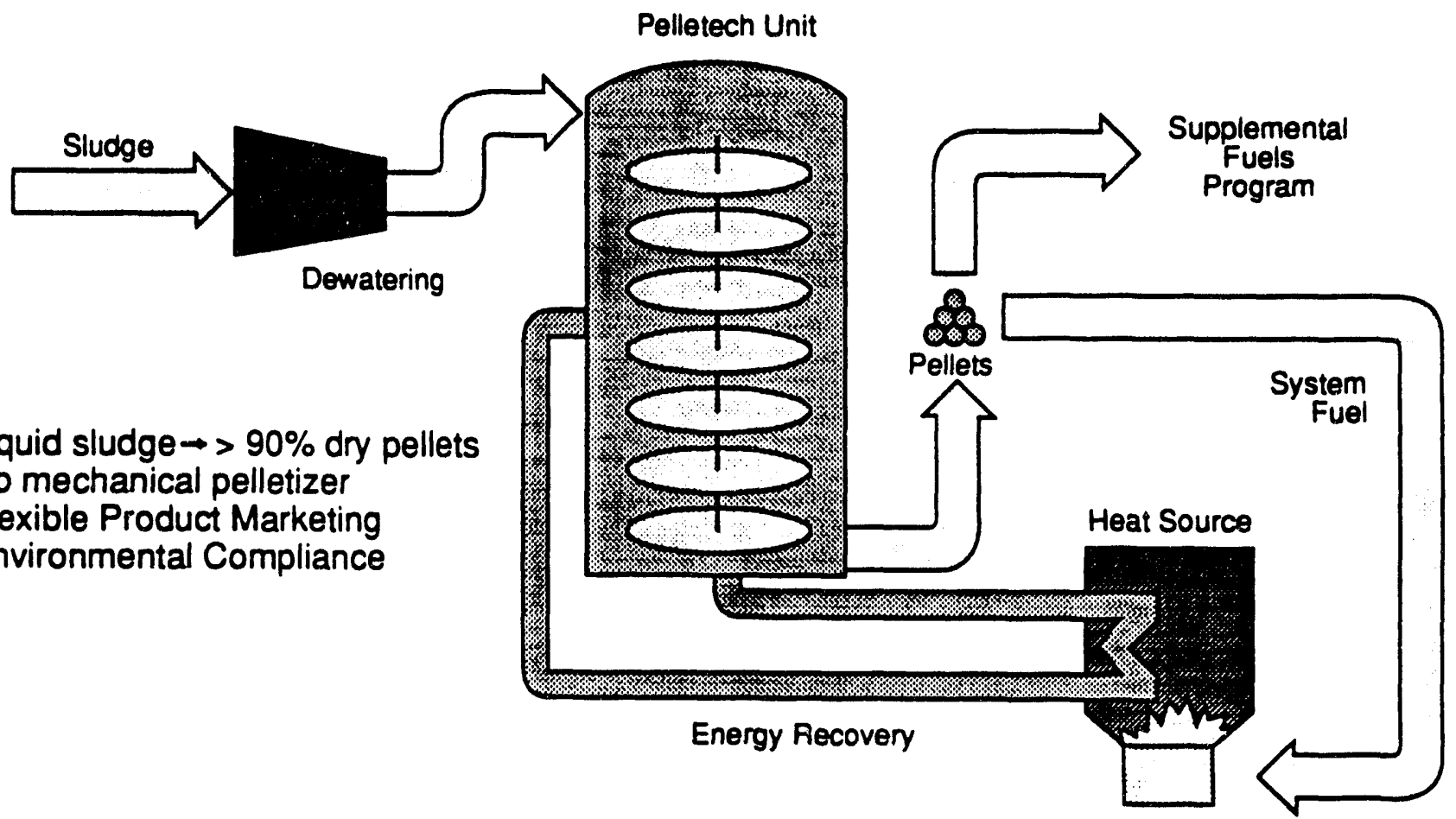

- Liquid sludge $\rightarrow>90 \%$ dry pellets

- No mechanical pelletizer

- Flexible Product Marketing

- Environmental Compliance 


\section{APPLICABILITY}

The current application of the Bio Gro technologies is limited to the drying, pelletization and general management of municipal wastewater treatment plant (WWTP) sludges, which are essentially non-hazardous and non-regulated materials. The application information given below refers only to the treatment of these materials. However, the process may be applicable to cerrain types of hazardous waste sludges that could be transformed into supplemental solid fuels for cement kilns and/or BIFs. This would require an upgrade of the air pollution control system on the Pelletech unit, and extra monitoring to assure that permit requirements would be met.

\section{Media Treated:}

- Municipal sludges and similar bio-solids.

\section{Backoround Data:}

- System capacities range from 5 to greater than 100 dry tons per day.

\section{Limitations:}

- Hazardous contaminant concentrations in the sludge must be within regulatory limits.

- Foreign material must be screened and removed prior to processing.

\section{STATUS / CAPABILITIES}

Bio Gro Systems, Inc. markets and distributes the Pelletech $\otimes$ process and "Zerofuel" combustor and related sludge pelletization proprietary technologies to numerous municipalities for the treatment of WWTP sludges. Full-scale Bio Gro processing systems are currently in operation throughout the country and the world. System capacities range from 5 to 300 dry tons per day. RRS, as an affiliate company, can implement the full range of the Bio Gro sludge treatment technologies for applicable remedial operations.

\section{EXPERIENCE}

The Bio Gro-Seghers Pelletech $₫$ process has been successful in over seven years of continuous operation at a wastewater treatment plant in Bruges, Belgium. This fully automated system, owned and operated by the Seghers Engineering Company, is used to dry, pelletize, and combust over 60 tons (dry) of sludge daily without using supplemental fuel, while simultaneously meeting stringent air emissions standards.

A larger Pelletech® system, with a nominal capacity of $110 \mathrm{dry}$ tons of sludge per day, is currently in the design and construction phase. This system, to be located in Baltimore, MD, will be designed, constructed, owned, and operated by Bio Gro Systems, Inc. Bio Gro will also be responsible for the marketing, sales, and distribution of the pelletized product. Scheduled startup for this facility is mid-1994.

- Customer Contact:

- Bob Mohr 410/396-9828

Division Chief, Black River WWTP

- Company Contact:

- Ann Kennedy 410/224-0022

Bio Gro Systems, Inc. 


\section{PROCESS DESCRIPTION}

Soil pile bioremediation is a simple and cost-effective method for remediating soils. The technology effectively destroys organics through biodegradation, leaving behind harmless byproducts such as $\mathrm{CO}_{2}$ and $\mathrm{H}_{2} \mathrm{O}$. The net result is nonregulated soil. Soil pile bioremediation uses vacuum to provide continuous aeration to contaminated soil that has been excavated and innoculated with nutrients and bacteria.

As shown in the diagram below, contaminated soil is placed in layers on top of a bermed plastic liner. Each layer of the contaminated soil is sprayed with nutrients and bacteria.
Perforated piping is installed between soil layers in the pile an connected to a blower. Vacuum is pulled on the pile througl a separate network of perforated pipe. During operation, th blower supplies oxygen to the bacteria for degradation of th petroleum contamination. Some volatile contaminants ar removed from the soil and transferred to the off-gas, which $i$ treated in a biofilter and then polished in a series of carbol canisters. A plastic cover prevents odor, air emissions, moistur evaporation and loss of passive solar heat. Nutrients, water an! additional bacteria can be added as needed through a pipin system installed underneath the top cover.

Soil Pile Bioremediation Process Flow Diagram

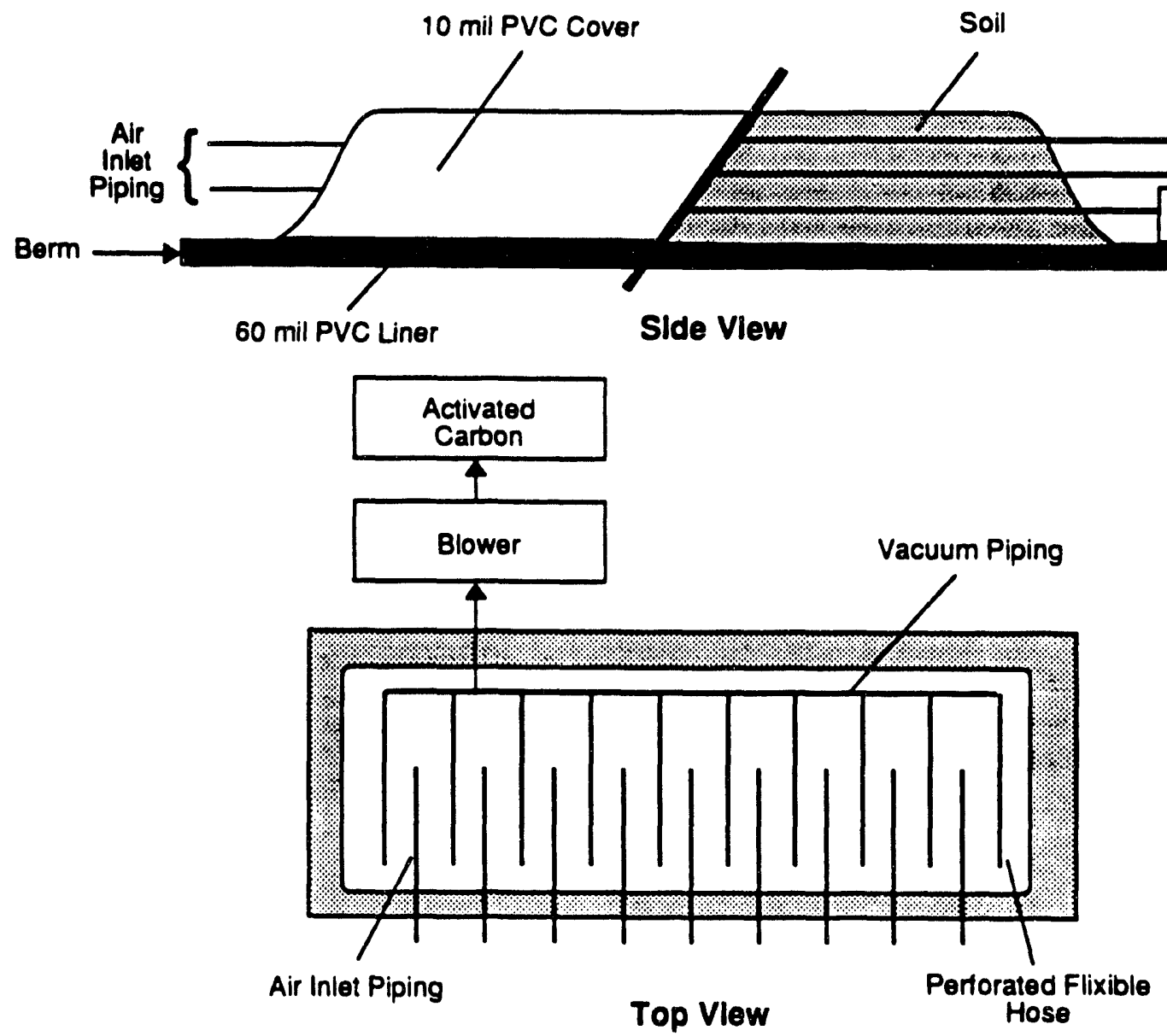




\section{APPLICABILITY}

\section{Contaminants Treatedi}

- Petroleum derivatives, including crude oil, no. 2 diesel fuel, gasoline, jet fuel (JP4), heating oil, waste oil, and motor oil.

- TPH (Total Petroleum Hydrocarbons).

- BTEX (benzene, toluene, ethyl benzene, xylene).

\section{Media Trentedi Soils.}

\section{Backoround Datai}

- Demonstrated on a variety of soils - from sand to very impermeable clays.

- TPH typically reduced to non-detectable leveis.

- Winter operation at air temperatures as low as -10_F has been demonstrated using a proprietary heating system.

\section{Limitations:}

- Maximum organic concentrations of 10,000 ppm (1\%).

- Maximum metals concentration of 10 ppm, to prevent bacterial inhibition.

- Clayey soils may need to be blended with wood chips or gypsum prior to treatment to improve soil aeration capabilities.

\section{STATUS / CAPABILTIES}

The Company has used soil pile bioremediation technology for full-scale remediations at client sites, as well as off-site in a commercial soil treatment center.

\section{On-site Bemediation:}

- Several successful full-scale field remediations have been completed.

- Sites with up to $2500 \mathrm{yd}^{3}$ of contaminated soil have been treated to meet remediation standards within nine weeks.

\section{Off-Site Commercial Soil Center:}

- Established for clients who do not want on-site remediation.

- As a permanent facility, allows clients to take advantage of low operating costs associated with a fixed site.
- Current facility is permitted to treat 296,000 tons/ year. New facilities could easily be designed and permitted with increased capacity.

\section{EXPERIENCE}

\section{Full-scale on-site remediation:}

- Oil pipelinespill at a California site required clean-up of $2,400 \mathrm{yds}^{3}$ of clay/silt soil contaminated with No. 2 diesel fuel and crude oil.

- Two soil piles constructed on-site.

- Samples taken at nine weeks confirmed that TPH as diesel fuel contamination had been reduced from 6700 ppm to 10 ppm while TPH as crude oil levels had been reduced from 3000 ppm to 1000 ppm, meeting the remediation standards.

- Treated soil was recycled for construction and landscaping purposes at another site.

\section{2) Full-scale on-site remediation:}

- Remediation of a site in Indiana - $2.500 \mathrm{yd}^{3}$ of soil contaminated with 400-2000 ppm TPH as diesel fuel.

- Two soil piles constructed on-site.

- After nineweeks of operation, soil sampling indicated that contamination was reduced to less than $10 \mathrm{ppm}$ TPH as diesel fuel.

- Upon approval from state officials, the treated soil was recycled by returning it to the original excavation area.

\section{3) Eull-scale off-site commercial Soil Center:}

- ELDA Soil Center, located at the ELDA solid waste landfill in Cincinnati, $\mathrm{OH}$.

- Consists of two soil pile treatment units, each with $15,000 \mathrm{yd}^{3}$ of capacity.

- Capable of treating and recycling 296,000 rons/year of petroleum contaminated soils (non-RCRA).

- Customer Contacts:

- Ken Roberds 513/932-3030

Ohio Department of Transportation

- Jerry Sheeley 419/422-2121

Marathon Oil Company

- Russ Dudeck 513/425-3414

Armco Steel Company 


\section{PROCESS DESCRIPTION}

The patented MecTool ${ }^{\mathrm{MM}}$ Remediation System, (see schematic below) provided by RUST Remedial Services through a partnering agreement with Millgard Corporation, utilizes deep soil drilling equipment to incorporate remediation agents (gases, liquids, or slurries) with contaminated soils and sludges. Primary system components include:

- A highly mobile, self-contained, crane- mounted assembly.

- A robust system of injection/mixing tools.

- A hollow stem Kelly bar with an integral gas/fluid delivery system.

- Very high torque earth drilling equipment.

- A shroud for containment/collection of dust and vapor emissions.

- A computerized monitoring system for control and documentation of treatment.

Uniform mixing during the treatment process is accomplished by the high torque applied to the mixing tool by the drill assembly. The varying diameters of the tool attachment and extension Kelly bars allows the equipment to achieve greater depths with a higher working efficiency. The full-scalesystem is able to treat soils and sludges to depths exceeding 100 feet, with a daily production rate of 400 to 1,200 cubic yards per 10-hour shift, depending on the material consistency and required treatment depth.

In the treatment process, the remediation agent is injected directly into the solid matrix, at pressures up to $150 \mathrm{psi}$, and mixed in-situ with the contaminated material. The agents are injected as a slurry, liquid, or gas. This feature, coupled with the rotary and verrical movements of the injection/mixing tool, provides for the effective penetration, distribution, and incorporation of the reagents with the in-place solids. The entire remediation process is performed below the impoundment surface. The immediate work area is covered with a fiberglass shroud to minimize the release of fugitive dust and/or vapors which may be generated.

\section{MecTool'TM Process Schematic}

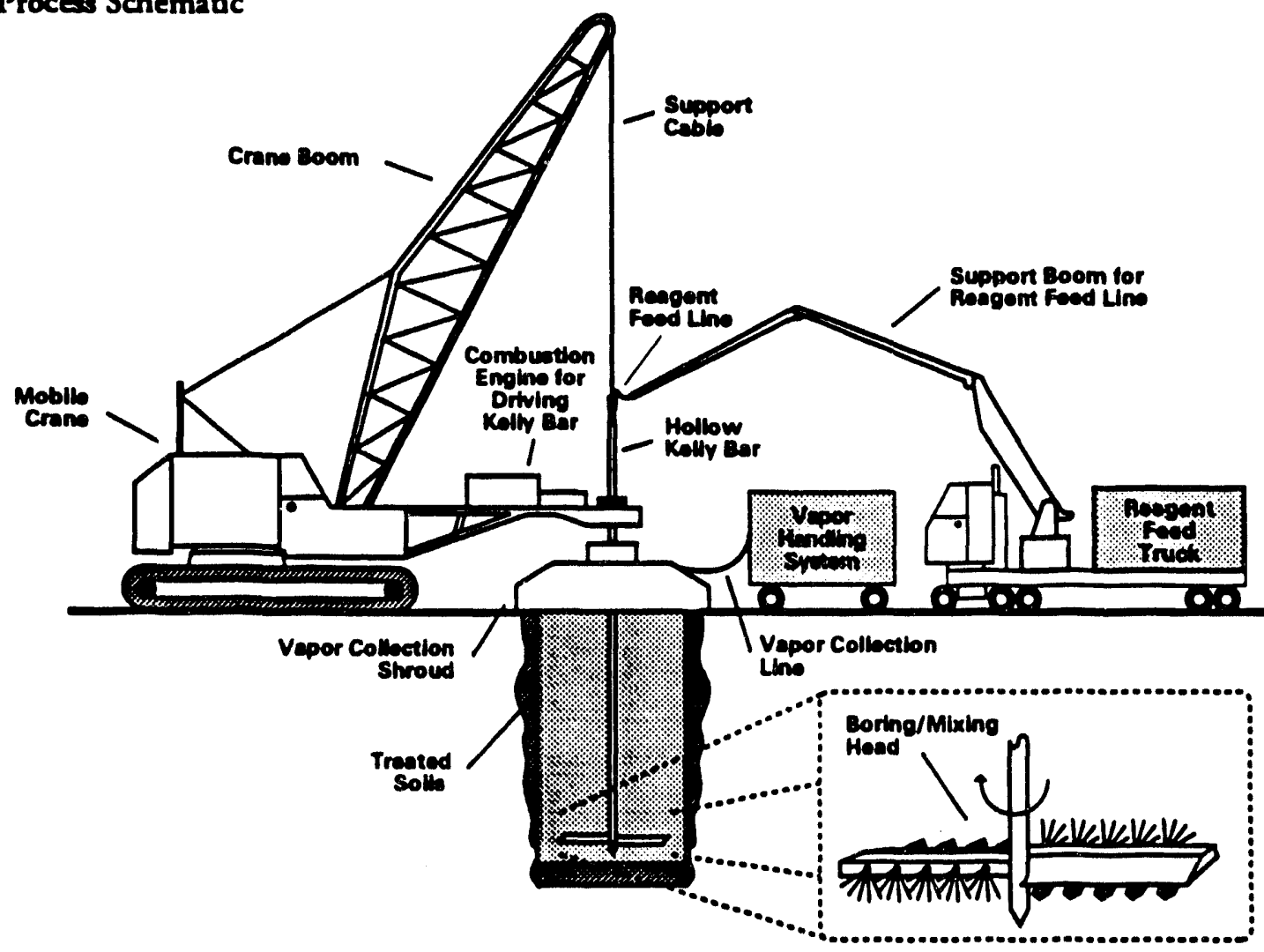




\section{APPLICABILITY}

The primary application of the MecToolm Remediation System is for the in-situ stabilization/solidification of metals contaminated soils, with pozzolanic and/or other type reagents being injected and mixed. The system can also be used for other applications, such 2s: 1) enhancement of VOC extraction by injection of hot gases into the soil column, with the vapors collected by the shroud assembly and treated; 2) in-situ bioremediation by the injection of nutrients and oxidizers; 3 ) neutralization of acidic or basic lagoon sludges; and 4) in-situ construction of bentonite barrier walls.

\section{Backaround Data:}

- In-situ treatment of soils and sludges to depths exceeding 100 feet.

- Production rates of 40 to $120 \mathrm{yd}^{3}$ per hour, depending on soil characteristics and depth of treatment.

- Proven monitoring and control system insures proper addition of reagents.

- In-situ process, containment shroud, and vapor handling system minimize emissions.

- Thorough mixing provided by high torque and robust action of the tool.

\section{Limitations:}

- Some swelling of the ground surface is likely, the extent of which is determined by the soil characteristics, the reagent proportions, and the depth of treatment.

\section{Stabilization Apolications}

- Primarily used for immobilization of heavy metals and other inorganics.

- With certain additives, can be used to immobilize low leveis of organics.

\section{Enhanced Soil Vapor Extraction}

- Hot air (or steam) injection combined with vigorous mixing produces faster and more efficient extraction of VOCs.

- Containment shroud and vapor handling system minimize emissions.

- Additional extraction wells, tied into primary vapor handling system, can be installed near the drill area to extract vapors below grade.

\section{In-SituBioremediation}

- Injection/mixing of nutrients and oxidizers to promote degradation of TPH and BTEX contamination by the native bacteria.

- Repeat applications at 2.3 month intervals insures complete biodegradation.

\section{In-Situ Neutralization}

- Neutralizing slurries injected into the waste as a final or pre-treatment step (e.g. - prior to solidification).

\section{Containment Barrier Construation}

- Overlapping cylinders of grouted soil to form a slurry wall, through injection and mixing of cement/ bentonite mixtures, varied to give the required strength and permeability.

- In-situ construction of impermeable lagoon bottoms or floors is possible by injection of the slurry at the appropriate depth. Can be accomplished during other operations (e.g. - stabilization) with two reagent feed systems.

\section{STATUS / CAPABILITIES}

The Millgard Environmental Company (MEC) is affiliated with the Millgard Corporation, the preeminent deep foundation contractor in the United States, with nearly 30 years experience in dealing with every kind of situation that can develop in subrerranean sertings. MEC has performed extensive stabilization/solidification research to develop and test the MecTool ${ }^{\text {TM }}$ Remediation System.

\section{Laboratory Sagle:}

- Extensive experience in performing treatability studies to determine the optimum formulation of reagents for the remediation of the wastes.

- Two bench-scale (12" diameter mixing tools) units are available for testing the reagent formulation developed in the treatability study.

\section{Bilot Sarle:}

- Two pilot systems available for on-site demonstrations of in-situ treatment.

- Pilor unit is a smaller version of the full-scale system, utilizing a $5^{\prime}$ diameter mixing tool.

- Mobile system, mounted on 2-3 trailers.

- On-site demonstrations, including mobilization and demobilization, can be completed in 2-3 weeks. 
Eull Sagale:

- Production systems consist of 8-12 trailers of equipment, utilizing a Manitowoc crane with a special high torque drilling unit to turn the $8^{\prime}-12^{\prime}$ diameter mixing rools.

- Three full-scale systems available.

\section{EXPERIENCE}

\section{Rortamouth Gaseous Diffusion Plant NPL Site.} Biketon. OH:

- Pilot project for the USDOE, through Martin Marietra Energy Systems.

- Full scale equipment used to demonstrate alternative remedial strategies for treatment of soil contaminated with TCE, TCA, heavy metals, and radionuclides.

- Selected strategies included:

- Dynamic air sparging with ambient $\left(100 \_F\right)$ and hot (280_F) air.

- Oxidation by injection and mixing of $5 \%$ hydrogen peroxide solution.

- Solidification with cement, flyash, and activated carbon admixture.

- Approximately $2000 \mathrm{yd}^{3}$ of tight clay soil treated, to depths of 22 feer.

- Air sparging reduced TCE and TCA levels by more than $98 \%$.

- TCLP analytes at non-derectable levels in solidification area.

- Project conducted in April-May, 1992.

- Customer Contact:

- Rober Siegrist 615/574-1441

Martin Marietta Energy Systems

\section{Iyson Dumo IINPL Site, Upoer Merion}

\section{Township PAi}

- Evaluation of MecToolm vapor extraction/ air sparging as alternative to currently operating pump and treat system.

- Ambient air injected into test area, 15'x15'x20' deep, adjacent to existing extraction wells.

- VOC removal over 3-day test period exceeded removal via well system during the previous 6 month period.
- VOC removal via well system enhanced during test due to soil mixing.

- Customer Contact:

- Joe Ferty 215/524-3500

CIBA-Geigy (PRP for Tyson Site)

\section{Wisaonsin Fuel and Liaht Manitowor. Wil:}

- Pilor project with full scale equipment to stabilize solidify coal tar contaminants in soils and underwater sediments with cement/flyash/carbon/day admixture.

- Barge mounted system utilized.

- Soils treated to depths of $\mathbf{4 0}$ feet.

- Sediments treated to 25' under 12' of water using patented Aqua-MecTool, without resuspending contaminants.

- Final permeability of $1.8 \times 10^{-7} \mathrm{~cm} / \mathrm{sec}$ and final UCS of 120 psi.

- Full seale soils remediation scheduled for startup in mid-1993.

- Customer Contact:

- Jim Venn 616/942-9600

W.W. Engineering (project consultant engineer for WF\&L)

\section{ConfidentialNPL Site. TX:}

- Estimated 140,000 yd ${ }^{3}$ of refinery sludges and wastes.

- VOC contamination to be stabilize in-situ using admixture of cement and flyash (formulation determined by previous on-site pilot rest).

- Multiple full scale systems to be deployed.

- Start up in mid-1993.

- Company Contact:

- Joe Anderson $713 / 875-1110$ RUST Remedial Services, Inc. 


\section{Dr. John North \\ RUST Remedial Services}

Technical Challenges Facing the Remediation Services Segment of the Commercial Environmental Industry

Dr. North will provide a real-world perspective on technical issues facing the remediation services industry through an informal presentation and discussions with PNL staff. All interested staff are encouraged to attend.

Monday, July 19

8:30 to $10: 30$ a.m.

ISB-1, White Bluffs Room

Contact Bruce Harrer at 375-6958 for additional information. 
Appendix D

E-MAIL Messages 
14] From: Dan W Barak at - PNL29 10/7/92 11:22PM (4975 bytes: 90 In)

o: Patrick S Lowery at $\sim$ PNL53

eceipt Requested

c: Bruce $J$ Harrer at $\sim$ PNL29, Donna E Pearson at $\sim$ PNL29

ubject: RAAS/REOPT Followup

Thanks for hosting me last week and giving me the overview of your current efforts in modeling. I am not sure how much time I may have available to work with you in general, but there may be several opportunities for interaction regarding our evaluation of many of the processes that you are modeling. Additionally some of the "smart plants" work may offer an opportunity for collaborative work in improving the operation of incinerators. This may be of interest to DOE since I believe that an incinerator is planned for the TREAT facility at Hanford.

I sent the following message to Mike White on Wednesday and I apologize that in my haste I neglected to copy you. (P.S. Sorry about the grammatical errors but that happens sometimes with stream of conciousness writing.)

Mike:

I appreciate your taking the time to present the status of your projects to me last week.

Just to refresh your memory I am here, from chemical waste Management, on a one-way staff exchange to survey the research being conducted here at PNL for possible commercialization or other collaborative opportunities.

The programs that you are developing have numerous potential applications in our business. I would like to get a "hands on" opportunity to evaluate the software and provide you with some feedback. To that end I would like to know the possibility of getting a Beta or Demo version that I can work with back at my Geneva office. This would allow me to review the technical data more easily with my colleagues. It would also afford me the opportunity to demonstrate the system to staff members in our remedial services areas.

I think that the framework that you have designed may be quite useful in carrying the remediation process beyond the RI/FS stage. By extending the application of the system into proposal preparation and submittal stages. It is too long of a subject to discuss fully here, but I here are some summary thoughts:

Remediations take to long to complete because there are numerous iterative review and evaluation phases (with long delays and time periods for each) that require EPA personnel to fully read and comment on each and every proposal to see that it meets the specifications and requirements of the ROD. This leads to every cleanup being treated as "custom" even though many are similar (i.e. PCB spills etc). I think that DOE, Industry, EPA and the country at large could

D.1 
benefit from reducing the administrative and overhead type delays and costs that result from the current manual process. If a computer program was used to prepare the ROD and RFP specifications then a related program could be used, by contractors, for bid preparation and another program could review the bid for conformity to the specification. Such standardization offers many benefits to all the involved parties and it allows for rapid consistent reviews, improved bids (requiring less notices of deficiencies), reduced resubmittal time and drastically reduced paper shuffling (which does nothing to clean up the problem), and finally reduced overall cost to: 1) the taxpayers (since EPA staff are more productive) 2) reduced cost to the responsible parties (DOE and Industry) and reduced overhead by the contractors.

These are some of my thoughts on this issue and I think that after I have had a chance to review the programs in more detail that it would be worthwhile to discuss this and other concepts for possible applications of your program in our industry.

I will be here at PNL through Wednesday (Oct 7) and after that back at our research center in Geneva, IL. My phone number here is 375-4590. At CWM my number is (708) 513-4568 and Fax is (708) 513-6401. You can send me PNL mail at K2-03 or to my home research center:

Dan Barak

Chemical Waste Management

1950 S. Batavia Ave.

Geneva, IL 60134

Thanks for your time. I look forward to hearing from you.

Dan Barak 
[23] From: Dan W Barak at PNL29 11/4/92 9:09AM (2410 bytes: 44 in) ro: Michael $\mathrm{K}$ White at $\sim$ PNL2

Receipt Requested

SC: Donna E Pearson at $\sim$ PNL29, Bruce $J$ Harrer at $\sim$ PNL29

Subject: RAAS/REOPT interest by Chemical Waste Management

In my previous messsage to you $I$ expressed in terest in evaluating and providing feedback on the software that you are developing.

As I mentioned in my last email:

The programs that you are developing have numerous potential applications in our business. I would like to get a "hands on" opportunity to evaluate the software and provide you with some feedback. To that end I would like to know the possibility of getting a Beta or Demo version that I can work with back at my Geneva office. This would allow me to review the technical data more easily with my colleagues. It would also afford me the opportunity to demonstrate the system to staff members in our remedial services areas.

Since that time I have talked to my colleagues in the remedial services area. They have expressed a great deal of interest in the programs and would like to get some more detailed write-ups. There is also the possiblility of a CRADA as the system is heading in the right direction for another need we have in documenting the decision flow for remediation activities.

I would like to discuss this further with you and arrange to get a Demo/Trial version for review at our end. It is also very possible that we could provide peer review of the technology descriptions, decision summaries and other key aspects of the system.

I will be at PNL Monday-Wednesday (Nov 9-11) with a colleague, if you want to meet during that time, let me know by contacting Donna Pearson at 375-2056. At CWM my number is (708) 513-4568 and Fax is (708) 513-6401. You can send me PNL mail at $\mathrm{K} 2-03$ or to my home research center:

Dan Barak Chemical Waste Management 1950 S. Batavia Ave.

Geneva, IL 60134

Thanks for your time. I look forward to hearing from you. Dan Barak 
[14] From: Dan W Barak at PNL29 11/23/92 8:13AM (706 bytes: 11 in)

To: Janet I Bryant at $\sim$ PNL2, Michael $\mathrm{K}$ White at $\sim$ PNL2

Receipt Requested

CC: Donna E Pearson at $\sim$ PNL29, Bruce $J$ Harrer at $\sim$ PNL29

Subject: RAAS/REOPT Seminar on December 8-9

When I was last at PNL we spoke on the phone about a seminar conducted with the EPA about the programs and their logic. I have a colleague who is very interested in attending that meeting. Could you please send me more info about it?

My Fax \# 708-513-6401 voice 708-513-4568.

Thanks.

Dan Barak

Chemical Waste Management 
0] From: Janet L Bryant at PNL2 11/23/92 9:58AM (1254 bytes: 22 In)

: Dan W Barak at - PNL29, Michael $K$ White

: Donna E Pearson at PNL29, Bruce J Harrer at -PNL29

bject: RAAS/REOPT Seminar on December 8-9

When I was last at PNL we spoke on the phone about a seminar conducted with the EPA about the programs and their logic. I have a colleague who is very interested in attending that meeting. Could you please send me more info about it?

My Fax \# 708-513-6401 voice 708-513-4568.

Thanks.

Dan Barak

Chemical Waste Management

Dan, I'm sorry, but we seem to be miscommunicating about timing and opportunities. RAAS is in a prototyping stage, only. We are having a client testing meeting in December to demo our latest prototype to the client. It would be inappropriate to have outsiders attend that meeting. I apologize for the confusion, and hope that this won't limit future opportunities when they are appropriate.

janet 
[14] From: Dan W Barak at PNL29 10/7/92 11:21PM (3540 bytes: 63 in) To: Evan 0 Jones at $\sim$ PNL26

Receipt Requested

cC: Bruce J Harrer at $\sim$ PNL29, Donna E Pearson at $\sim$ PNL29

Subject: Waste Oil Recovery Process

I appreciate your taking the time to present the status of your project to me last week.

Just to refresh your memory I am here, from Chemical waste Management, on a one-way staff exchange to survey the research being conducted here at PNL for possible commercialization or other collaborative opportunities.

I am interested in pursing the discussions of potential applications of waste acid recovery to our business. To that end I am planning to bring a colleague out here with me, either the last week of this month (Oct 26-29) or the first week of November (Nov 2-5). I am hoping to setup meetings on 3-5 technologies so if you could respond as to which dates, if any, are feasible I will respond when I hear from the others with a proposed agenda. We would like to spend about $1 / 2$ day with you reviewing technical questions, potential applications, project status, future plans and iicensing opportunities.

As I mentioned during your presentation, we have several competing technologies in use at this time. However, there may be situations that the process can be applied (i.e. waste minimization, zero discharge, etc.). Additionally upon closer review we may see applications in areas that we had not previously considered. The extreme corrosion resistance of the equipment is also of great interest.

It would be helpful if you could put together any preliminary economics information as to calculations of operating and capital costs for various loadings and scaleups. (you can get this to me either before or at the meeting)

Could you send through cc:mail, some ball park numbers on research \$ spent to date on this and planned future expenditures for use as reference. What are the potential licensing terms? How broad is the existing license of the technology? What is the business development plan for this process? Please send me a copy of any relevant papers or other documents that could aid us in understanding and evaluating the technology as well as helping us to prepare the CWM internal business plan for our potential use of this process.

I will probably have more questions for you later and I will send them through this medium. If I need to communicate with anyone else on this please send me their name and I will copy them on this and future communications.

I will be here at PNL through Wednesday (Oct 7) and after that back at our research center in Geneva, IL. My phone number here is 375-4590. At CWM my number is (708) 513-4568 
and Fax is (708) 513-6401. You can send me PNL mail at K2-03 or to my research center:

Chemical Waste Management

1950 S. Batavia Ave.

Geneva, II 60134

Thanks for your time. I look forward to hearing from you.

Dan Barak 
[11] From: Dan W Barak at PNL29 10/7/92 5:02PM (4031 bytes: 70 in) To: Michael $\mathrm{K}$ White at $\sim$ PNL2

Receipt Requested

CC: Bruce J Harrer at $\sim$ PNL29, Donna E Pearson at $\sim$ PNL29

Subject: RAAS/REOPT review

I appreciate your taking the time to present the status of your projects to me last week.

Just to refresh your memory I am here, from Chemical waste Management, on a one-way staff exchange to survey the research being conducted here at PNL for possible commercialization or other collaborative opportunities.

The programs that you are developing have numerous potential applications in our business. I would like to get a "hands on" opportunity to evaluate the software and provide you with some feedback. To that end I would like to know the possibility of getting a Beta or Demo version that I can work with back at my Geneva office. This would allow me to review the technical data more easily with my colleagues. It would also afford me the opportunity to demonstrate the system to staff members in our remedial services areas.

I think that the framework that you have designed may be quite useful in carrying the remediation process beyond the RI/FS stage. By extending the application of the system into proposal preparation and submittal stages. It is too long of a subject to discuss fully here, but I here are some summary thoughts:

Remediations take to long to complete because there are numerous iterative review and evaluation phases (with long delays and time periods for each) that require EPA personnel to fully read and comment on each and every proposal to see that it meets the specifications and requirements of the ROD. This leads to every cleanup being treated as "custom" even though many are similar (i.e. PCB spills etc). I think that DOE, Industry, EPA and the country at large could benefit from reducing the administrative and overhead type delays and costs that result from the current manual process. If a computer program was used to prepare the ROD and RFP specifications then a related program could be used, by contractors, for bid preparation and another program could review the bid for conformity to the specification. Such standardization offers many benefits to all the involved parties and it allows for rapid consistent reviews, improved bids (requiring less notices of deficiencies), reduced resubmittal time and drastically reduced paper shuffling (which does nothing to clean up the problem), and finally reduced overall cost to: 1) the taxpayers (since EPA staff are more productive) 2) reduced cost to the responsible parties (DOE and Industry) and reduced overhead by the contractors.

These are some of my thoughts on this issue and I think that after I have had a chance to review the programs in more detail that it would be worthwhile to discuss this and other 
concepts for possible applications of your program in our industry.

I will be here at PNL through Wednesday (Oct 7) and after that back at our research center in Geneva, IL. My phone number here is 375-4590. At CWM my number is (708) 513-4568 and Fax is (708) 513-6401. You can send me PNL mail at K2-03 or to my home research center:

Dan Barak

Chemical Waste Management

1950 S. Batavia Ave.

Geneva, IL 60134

Thanks for your time. I look forward to hearing from you.

Dan Barak 
[12] From: Dan W Barak at $\sim$ PNL29 10/7/92 5:44PM (3490 bytes: 63 In) To: Rodney $S$ skeen at $\sim$ PNL24

Receipt Requested

CC: Bruce J Harrer at $\sim$ PNL29, Donna E Pearson at $\sim$ PNL29

Subject: Active Landfill management for enhanced methane production

I appreciate your taking the time to discuss your research with me last week.

Just to refresh your memory I am here, from Chemical waste Management, on a one-way staff exchange to survey the research being conducted here at PNL for possible commercialization or other collaborative opportunities.

I am planning to bring a colleague out here with me, either the last week of this month (oct 26-29) or the first week of November (Nov 2-5). While we are not the most appropriate audience for biotreatment process I hope to gather enough additional information to make a case for collaboration to our Waste Mgmt sister company (Waste Mgmt. has an active program to recover methane from our landfills and use it to power turbines and generate electricity for area homes). I am hoping to setup meetings on 3-5 other technologies so if you could respond as to which dates, if any, are feasible I will respond when I hear from the others with a proposed agenda. We would like to spend about an hour or two with you reviewing technical questions, potential applications, any suggestions you have for joint cooperation (i.e. we may be able to provide full scale "test" landfills as "services in kind" in exchange for your assistance), future plans and licensing opportunities.

You can respond through cc:mail if convenient and later at the meeting.

Also if you could put together any preliminary economics information as to calculations of operating and capital costs for various scenarios. (i.e. estimates of improvement in methane production versus cost of treatments)

Could you send through cc:mail, some ball park numbers on research \$ spent to date on landfill/leachate management and planned future expenditures for use as reference. What are the potential licensing terms? Are there existing licenses of the technology? Is there a business development plan for this process?

Please send me a copy of that any papers that could aid us in understanding and evaluating the PNL research in this area.

I will probably have more questions for you later and I will send them through this medium. If I need to communicate with anyone else on this please send me their name and I will copy them on this and future communications.

I will be here at PNL through Wednesday (oct 7) and after that back at our research center in Geneva, IL. My phone number here is 375-4590. At CWM my number is (708) 513-4568 
and Fax is (708) 513-6401. You can send me PNL mail at K2-03 or to my research center:

Chemical Waste Management

1950 S. Batavia Ave.

Geneva, IL 60134

Thanks for your time. I look forward to hearing from you.

Dan Barak 
[12] From: Dan W Barak at -PNL29 10/7/92 5:31PM (3804 bytes: 70 in)

To: James I Buelt at PNL24

Receipt Requested

Cc: Bruce J Harrer at -PNL29, Donna E Pearson at $\sim$ PNL29

Subject: ISV/ESV Review meeting

Message Contents

I appreciate your taking the time to host me in the project presentations last week.

As you know I am here, from Chemical Waste Management, on a one-way staff exchange to survey the research being conducted here at PNL for possible commercialization or other collaborative opportunities.

I am interested in pursing further the discussions of potential applications of both ISV and ESV to our business. To that end I am planning to bring our vitrification specialist out here with me, either the last week of this month (Oct 26-29) or the first week of November (Nov 2-5). I am hoping to setup meetings on 3-5 other technologies so if you could respond as to which dates, if any, are feasible I will respond when I hear from the others with a proposed agenda. We would like to spend about $1 / 2$ day with you and perhaps Chris Chapman and/or others reviewing technical questions, potential applications, project status, future plans and licensing opportunities.

We will have read the papers that provided by chris and the information that you gave me. Any other suggested readings would be appreciated.

We will want to discuss the technical aspects in some detail as well as current shortcomings of each technology and the current research plans to address these problems. discussion of economics and licensing will take place as well so that we have a detailed understanding of the assumptions used in the estimates that we have seen the reported numbers are calculated.

You can respond through cc:mail if convenient and later at the meeting.

Also if you could put together any preliminary economics information as to calculations of operating and capital costs for various loadings and scaleups this would be helpful. (you can get this to me either before or at the meeting)

Could you send through cc:mail, some ball park numbers on research $\$$ spent to date on this and planned future expenditures for use as reference. What are the potential licensing terms? Are there existing licenses of the technology? What is the business development plan for this process? Could you send me a copy of other documents that could aid us in understanding and evaluating the technology as well as helping us to prepare the CWM internal business plan for our potential use of this process.

I will probably have more questions for you later and I will 
send them through this medium. If I need to communicate with anyone else on this please send me their name and I will copy them on this and future communications.

I will be here at PNL through Wednesday (Oct 7) and after that back at our research center in Geneva, IL. My phone number here is 375-4590. At CWM my number is (708) 513-4568 and Fax is (708) 513-6401. You can send me PNL mail at K2-03 or to my research center:

Chemical Waste Management 1950 S. Batavia Ave.

Geneva, IL 60134

Thanks for your time. I look forward to hearing from you.

Dan Barak 
[12] From: Dan W Barak at PNL29 10/6/92 1:14PM (4479 bytes: 80 in) To: Eddie G Baker at $\sim$ PNL26, Douglas C Elliott at $\sim$ PNL19

Receipt Requested

CC: Bruce J Harrer at $\sim$ PNL29, Donna E Pearson at $\sim$ PNL29

Subject: PST and TEES Followup

I appreciate your taking the time to present the status of your projects to me last week.

Just to refresh your memory I am here, from Chemical Waste Management, on a one-way staff exchange to survey the research being conducted here at PNL for possible commercialization or other collaborative opportunities.

I am interested in pursing the discussions of potential applications of PST, STORS and TEES to our business. To that end I am planning to bring a colleague out here with me, either the last week of this month (oct 26-29) or the first week of November (Nov 2-5). I am hoping to setup meetings on 3-5 technologies so if you could respond as to which dates, if any, are feasible I will respond when I hear from the others with a proposed agenda. We would like to spend about $1 / 2$ day with you reviewing technical questions, potential applications, project status, future plans and licensing opportunities.

We will have read the paper that you provided from your presentation dated December 12, 1991 on PST. Papers on TEES and any other suggested readings would be appreciated.

I have not received much information on TEES except that which was discussed in Doug's presentation. While CWM US may have limited application due to prior licensing of the technology, Waste Management International may have applications in Europe that can be explored.

With regard to $\mathrm{PST}$, I have read the papers/patents that Ed provided. The licensing of the technology appears to be somewhat encumbered by onsite*ofsite, and this may present an obstacle. I described our current situation with the competing technology evaluation. However, I think that it is worthwhile (for many reasons) that we discuss the technology in more detail and review of the economics and project timetable. We have thought of some additional markets/streams that may be candidates for the process and will discuss those with you further.

You can respond through cc:mail if convenient and later at the meeting.

Also if you could put together any preliminary economics information as to calculations of operating and capital costs for various loadings and scaleups this would be helpful. (you can get this to me either before or at the meeting)

Could you send through cc:mail, some ball park numbers on research $\$$ spent to date on this and planned future expenditures for use as reference. What are the potential 
licensing terms? Are there existing licenses of the technology? You have already provided me with a good start for preparation for discussions about PST. Could you send me a copy of any other documents that could aid us in understanding and evaluating the other technologies (STORS and TEES) as well as helping us to prepare the CWM internal business plan for our potential use of this process.

I will probably have more questions for you later and I will send them through this medium. If I need to communicate with anyone else on this please send me their name and I will copy them on this and future communications.

I will be here at PNL through Wednesday (Oct 7) and after that back at our research center in Geneva, IL. My phone number here is 375-4590. At CWM my number is (708) 513-4568 and Fax is (708) 513-6401. You can send me PNL mail at K2-03 or to my home research center:

Dan Barak

Chemical Waste Management

1950 S. Batavia Ave.

Geneva, IL 60134

Thanks for your time. I look forward to hearing from you.

Dan Barak 
[11] From: Dan W Barak at -PNL29 10/7/92 4:49PM (968 bytes: 16 in)

To: Douglas C Elliott at $\sim$ PNL19, Eddie G Baker at $\sim$ PNL26

Receipt Requested

cC: Bruce J Harrer at $\sim$ PNL29, Donna E Pearson at $\sim$ PNL29

Subject: PST/STORS/TEES/TEES II meeting

Gentlemen:

Message Contents

I received the information on TEES/TEES II that you sent after I had sent you my cc:Mail message. Based on what I have read I think that it may be worthwhile to spend a full day reviewing the technologies (PST, STORS, TEES, TEES II), rather than the $1 / 2$ day that I originally proposed.

Also some additional information on the licensing situation for TEES/TEES II would be useful.

Please let me know if this is feasible. We could split the review days, if necessary, to accomodate your schedules.

Dan Barak

Chemical Waste Management 
13) From: Dan W Barak at -PNL29 10/30/92 2:55PM (2014 bytes: 36 In)

0: Eddie G Baker at $\sim$ PNL26, Douglas C Elliott at $\sim$ PNL19, I John Sealock at $\sim$ PNL19

eceipt Requested

C: Donna E Pearson at $\sim$ PNL29, Bruce J Harrer at $\sim$ PNL29

ubject: Meeting to Discuss PST and TEES

My colleague and I would like to meet with you to discuss

PST and TEES on Monday November 9. We can take a $1 / 2$ day

for each process in either order.

I have discussed both technologies internally, and interest has been generated along with some additional questions.

One of the major questions concerns the high temp and pressures used by both processes from the standpoint of safety and cost (capital and operating). Please be ready to address this concern.

Concerns about cost (capital and operating) are many. Some have said that they "can't imagine that it can be cost effective" versus other options for K048-52 wastes. We will need to discuss this further when we get together.

one of our technical VP's is interested in the technology and may attend our dicussions if his schedule permits.

For my part I need to be able to complete a decision summary sheet after our meeting. This will include an analysis of the costs, status of development, efficacy of the process (BDAT), licensing terms available, $\$$ of research to date, etc. Please be prepared to discuss these and other related areas in detail.

Thanks for your assistance, and I look forward to seeing you on the 9th. Please let me know where and when to meet so that Donna Pearson can get the appropriate visitor badges prepared.

sincerely,

Dan Barak

Chemical Waste Management 
[17] From: Dan W Barak at PNL29 11/12/92 8:29AM (1610 bytes: 31 in)

To: Douglas C Elliott at $\sim$ PNL19, L John Sealock at $\sim$ PNL19, Eddie G Baker at $\sim$ PNL26

Receipt Requested

CC: Bruce J Harrer at $\sim$ PNL29, Donna E Pearson at $\sim$ PNL29

Subject: .PST and TEES followup

Gentleman:

Paul Farber and I appreciate the time that you spent with us discussing PST and TEES. We were very encouraged by the candor of the discussion. It makes our evaluation go much quicker when we can see the whole picure and we can present our conclusions/recommendations with a much greater degree of confidence.

A few questions came up after we were finished that I wanted to pass along for you to include in the short write up that you are providing:

What is the cost per million btus of gas produced in TEES when using biomass (a ballpark range is okay and figure 5 yr capital cost recovery)?

Please provide a cost estimate adjustment factor for PST if the heat transfer coefficient is that of oil rather than water, so that we can get some idea of worst case heat transfer/recovery.

Please prepare the bill of materials and other information necessary to get RUST to provide a cost estimate.

Thanks again and we look forward to working with you in the future!

Dan Barak 
19] From: Dan W Barak at -PNL29 11/18/92 6:38AM (3141 bytes: 53 in)

'riority: Urgent

'o: Eddie G Baker at PNL26, L John Sealock at $\sim$ PNL19, Douglas C Elliott at $\sim$ PNL19

leceipt. Requested

sc: Bruce J Harrer at $\sim$ PNL29, Donna E Pearson at $\sim$ PNL29, Robert $S$ Butner at $\sim$ PNL19

jubject: PST and TEES opportunity

Gentleman:

I spoke with my VP and briefly summarized our discussions. He agreed to present these technologies at the next strategic growth committee meeting set for Dec 11. Prior to that time, (with your help), I need to prepare sufficient: justification and documentation about the potential/risks/costs/licensing etc. for TEES and PST. To that end I will be making requests for information via cc:mail for the next two weeks; the sooner you can respond the better.

Since this is gaining momentum and I need to move quickly to preserve it I would like to get some idea of likely

licensing terms for PST and see a written summary of the PNL position regarding TEES and TEES II for licensing availability so that I can prepare a list of CWM/WMI options. I will be back at PNL the 2nd week of December and will likely try to visit onsite*ofsite during that same trip.

Cost estimate for TEES: I need a detailed ranged cost estimate for capital and operating for an organic waste water treatment stream (that results in the 2-3 cents/gal estimate). But I need a broader estimate with worst case assumptions (i.e. catalyst life is one month, etc) and other areas of possible uncertainty on the full scale system. I need estimate for a $5 \mathrm{gpm}$ and $50 \mathrm{gpm}$ system. (uncertainties on capital cost are OK just state them) I need to use this to quantify risks of assumptions and understand sensitivity variables for this process.

I need a similar estmate/analysis for biomass in TEES based on \$/MMBTU of gas produced. (if you can use the Anhaueser Busch scenario as a basis for size and feedstock that would be fine) I need to be able to quantify the needed revenue for the feed whether it is yard waste or brewery biomass to make the process viable. Use $10 \mathrm{MMBTU} / \mathrm{hr}$ net gas production as a base size and show feed rate of either yard waste (assume yard waste to be mostly grass clippings and some leaves) or the brewery that is required for that energy output. If convenient pick another size unit as well.

For PST: Have you ever evaluated (Coal) Tar Sands? I need a further breakdown of the category "Operating cost" on the cost estimate.

I will contact you with further questions as they develop. Thanks for your assistance. 
Dan Barak

Chemical Waste Management 
Date November 24, 1992

To Dan Barak, Paul Farber - Chem Waste Management

From Doug Elliott

Subject

\section{TEES Process}

EG Baker

RS Butner

GG Neuenschwander

LJ Sealock

File

This memo provides some supporting information on the cost analyses attached. The first page is a summary table of the four cases analyzed in our earlier report, Assessment of TEES Applications for Wet Industrial Wastes: Energy Benefit and Economic Analys is Report, PNL-7990. The analyses were done by Onsite*0fsite, Inc., based on PNL experimental results. The last three lines are my own calculations, based on numbers in the report. The second page provides a summary of the bases used in the calculations in the report. The third page provides some specific calculations you requested.

First, the spent grain case was adjusted to a five year 1 ife and the cost calculated on a $\$ / m i l l i o n$ Btu basis. The base cost increased to $3.7 \$ / g a l$ using a five year capital recovery. The cost per million Btu for the gas was $\$ 6.95$ or $\$ 8.50$ for the net gas from the process (product gas not used in the process). Note that the $0 * 0$ analyses were based on an $80 \%$ capacity utilization, so that if $100 \%$ capacity was achieved the net gas price would be $\$ 6.80 / \mathrm{milli}$ ion Btu. Also note that these costs do not include any credit for waste disposal cost avoided or disposal tipping fee.

The second field includes capital estimates from Onsite*0fsite, Inc. Note that these estimates are for installed units and already include engineering fees and a 35\% contingency/profit factor.

Third, I have shown that your requested $10 \mathrm{million} B t \mathrm{~h} / \mathrm{hr}$ plant is about a $1 / 5$ size plant based on the spent grain case in the PNL-7990 report.

Finally, the effect of shorter catalyst lifetime (one month versus 18) is calculated for the spent grain case from PNL-7990. Such a short lifetime (maximum demonstrated to date) would about double the costs.

I hope these calculations are what you need for your assessments and presentations. 


\section{INFO FROY PNL-7990}

Feed

gpd

\% Solids

57,400

6

$4.5 \mathrm{SCF} / \mathrm{gal}$

515

(electheat)

Total

$\mathrm{SCF} / \mathrm{d}$

Net SCF/d 151,116 (258300)

electrica 54

purchased

KWhr

(TEES+

Frontend)

Capital, $5,100,00$

$\$$

\$/unit $\quad 88.85 /$ tpd

Catalyst, 226

$\mathrm{ft}^{3}$

LHSV

1.41

Operating

Cost

$\$ / y r$

$407 \mathrm{~K} \quad 849 \mathrm{~K}$

$$
2.04 / g a l
$$

Annual

Cap cost a $10 \mathrm{yr}$, $12 \%$ DCF

Total cost

SCF/unit

$258,300(258,300)$

(728)

$5+0.1$

$4.64 / g a l$

$6.6 \% / g a l$
Pomace

Spent Grain

240,000

284,000

10 ?

9.2

\section{$1.15 \mathrm{~g} / \mathrm{ml}$ ? $1.15 \mathrm{~g} / \mathrm{ml}$ ?}

17,300

4

Chemical
$10.5+0.5$

$12+0.1$

+0.5 gas
SCF/drylb SCF/drylb
10.2
SCF/gal
9.9
SCF/gal

$454 \quad 550$

7.9

SCF/gal correct?

515

$2,442,000$

$1,939,797$

$2,218,909$

181

16

220

$12,700,000$

$11,000,00$

$2,520,00$

$99,099 / t p$

d

735

d

$105,833 / t p$

1030

$2.0+0.5$

0

145.66

/gpd

72

e $\$ 10 / 1 b$

1.82

1.54

1.34

$1,149 \mathrm{~K}$

$1,220 \mathrm{~K}$

233K

no labor

$1.4 \mathrm{c} / \mathrm{gal}$

1. $2 c / g a l$

$3.8 \% / g a l$

$2.4 \% / g a l$

$2.3 c / g a l$

$7.5 \% / g a l$

$3.8 \% / g a l$ 
operating cost includes labor, maintenance, supplies, power, catalyst, royalty, tax, \& insurance.

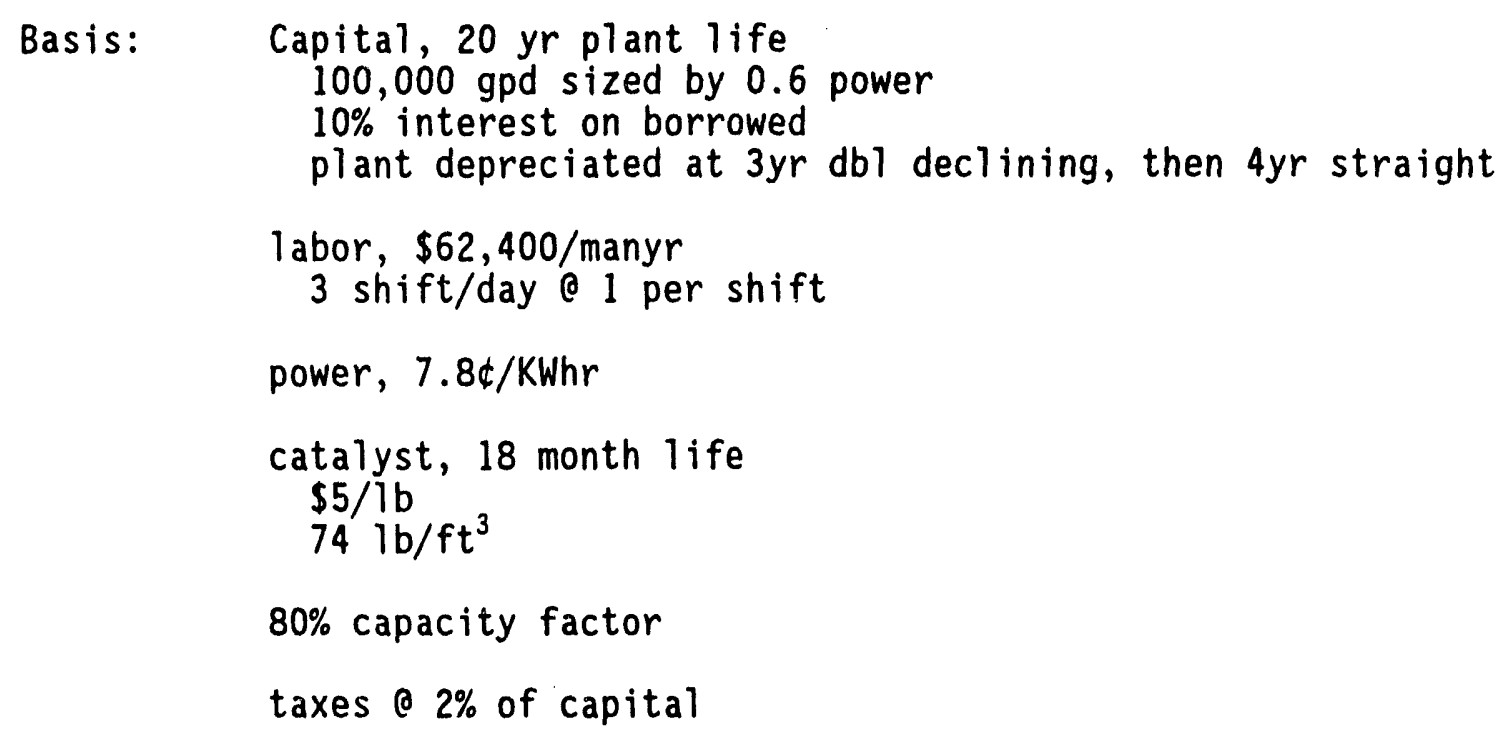


COST/MILLION BtU GAS FROM BIOMASS - 5 yr CAPITAL RECOVERY

based on spent grain case - straight line capital recovery, no interest $\$ 1,220,000$ operating [1300 t/d] [200gpm] $10 \%$ solids

$(\$ 12,100,000 / 5)$ capital ( $w / 0$ gas cleaning and separation) $\$ 3.64 M$ annual cost or $3.7 \% / g a l i o n$

$284,000 \mathrm{gpd} \times 7.8 \mathrm{net}$ SCF $/$ gal $\times 550 \mathrm{Btu} / \mathrm{SCF} \times 350 \mathrm{day} / \mathrm{yr}=5.410^{11} \mathrm{Btu}$

$=\$ 6.95 / \mathrm{MBtu}$ or $\$ 8.50 /$ Net million Btu

$=541,000 \mathrm{MBtu}$

(no waste disposal credit)

$(\$ 6.8$ e $100 \%$ capacity)

\section{5 gpm - 50 gpm CAPITAL ESTIMATE}

$\$ 1.1 M-\$ 5.4 M$ per Onsite*0fsite TEES II data (2.4 LHSV) installed. (Jan '90) (no front end feed processing)

engineering included $+35 \%$ contingency/cost rer overy

(includes overheads, taxes, insurance, initial catalyst load)

\section{PLANT SIZE TO GIVE 10 MILLION Btu/hr OF GAS YIELD}

$436,364 \mathrm{SCF} /$ day $0550 \mathrm{Btu} / \mathrm{SCF}$

$=20 \%$ of spent grain case

$=55,850 \mathrm{gpd}$ or 250 wet ton $/$ day $(10 \%$ solids)

(39gpm)

$(1.15 \mathrm{~g} / \mathrm{ml})$

\section{EFFECT OF CATALYST COST}

18 month case is given above (18 month lifetime for catalyst)

1 month case causes following changes:

catalyst cost per year increases from $\$ 254 \mathrm{~K}$ to $\$ 4573 \mathrm{~K}$

operating cost increases from $\$ 1.22 \mathrm{M}$ to $\$ 5.54 \mathrm{M}$

annual cost increases from $\$ 3.64 \mathrm{M}$ to $\$ 7.96 \mathrm{M}$

processing cost increases from $3.7 \$ / \mathrm{gal}$ to $8.1 \mathrm{l} / \mathrm{gal}$

gas cost increases from $\$ 8.5 / \mathrm{MBtu}$ to $\$ 18.6 / \mathrm{MBtu}$ 
9] From: Dan $W$ Barak at $\sim$ PNL29 11/25/92 12:55PM (890 bytes: 15 In)

io: Eddie G Baker at $\sim$ PNL26, Douglas C Elliott at $\sim$ PNL19, L John Sealock at $\sim$ PNL19

leceipt Requested

:c: Bruce J Harrer at $\sim$ PNL29, Donna E Pearson at $\sim$ PNL29 jubject: PST and TEES

I spoke with Norm Banns and have set up a meeting on Friday December 4 at his office near LA. I will be at PNL on the 7-9; are you available (on Tuesday $12 / 8$ or Wednesday 12/9) for some further discussions based on what Norm has to say and to further refine our approch to bringing these technologies forward within WMI/CWM?

Please let me know via reply.

Thanks

Dan Barak

Chemical Waste Management

P.S. The info from Doug has not yet come by mail... 
[81] From: Dan W Barak at -PNL29 11/25/92 3:33PM (758 bytes: 9 in)

To: Eddie $G$ Baker at PNL26, Douglas C Elliott at - PNL19, L John Sealock at -PNL19, James L Buelt at - PNL24, Christopher C Chapman at PNL24

cc: Bruce J Harrer at PNL29, Donna E Pearson at PNL29

Subject: December Meeting Problem

Due to a sudden corporate reorganization we will not be able

to come to PNL in December.... Please disregard my previous

message. We will need to reschedule in January.

I apologize for the sudden change in plans but it is beyond my control.

Dan Barak

Chemical Waste Management 
19] From: Eddie G Baker at PNL26 12/3/92 8:54AM (497 bytes: 3 in)

'o: Dan W Barak at $\sim$ PNL29, Douglas C Elliott at $\sim$ PNL19, I John Sealock at $\sim$ PNL19

C: Donna E Pearson at $\sim$ PNL29, Bruce $J$ Harrer at $\sim$ PNL29

iubject: Meeting on December 8 or 9

Re PST and coal tar. Any analytical information on the coal

tar you can bring would help us evaluate the application of

PST. Thanks for your hard work on behalf of PST and TEES. 
[10] From: Dan W Barak at PNL29 12/1/92 5:42PM (1471 bytes: 23 in) To: James L Buelt at $\sim$ PNL24, Christopher C Chapman at PNL24

Receipt Requested

CC: Donna E Pearson at $\sim$ PNL29, Bruce J Harrer at $\sim$ PNL29

Subject: Possible meeting on Dec 8 or 9 to discuss vitrification

We are currently undergoing a corporate reorganization and my last message was prompted by a decision to suspend all December travel. The decision was just rescinded and we have an opportunity for one last trip to PNL before the reorg takes effect.

our Chem-Nuclear group is starting up a haz waste and low level rad treatibility lab at clemson and we would like to begin to develop information that could be followed up by our clemson group after the reorganization is complete.

If your schedules permit Abid Bengali (our vitrification specialist) and I would like to meet with you and discuss you efforts in ISV, ESV and the ceramic melter. We would prefer to meet Tuesday morning (Dec 8) as we have a Tuesday afternoon meeting planned. Please let me know what time is preferred. (NOTE: If Tues AM is bad WED AM is possible)

I hope that we have the opportunity to meet with you and discuss these technologies.

Dan Barak

Chemical Waste Management 
[1] From: Dan W Barak at PNL29 12/8/92 11:50AM (4123 bytes: 70 In) To: Theresa M Bergsman at -PNL40, Willitam 0 Heath at $\sim$ PNL40, Jud W Virden at $\sim$ PNL40

cc: Bruce J Harrer at PNL29, Donna E Pearson at PNL29

\section{Subject: ISH and Electro Corona Message Contents}

Since I last met with you, my company has undertaken a rather substantial reorganization. I needed to wait until I had a better idea of the next step on these technologies before I proceeded. The situation is still very fluid, but I think that I now have sufficient information to pass on to you.

With regard to ISH: I have contacted the people in our remedial services group, (they have been moved to a new company (not CWM but RUST International Inc.) as a result of the reorg), and they are interested in keeping tabs on ISH but do not currently have a candidate project. This may change, but at the moment this where they stand. Until the reorg is complete (1-2 mos best estimate) and the groups have their marching orders, it will be next to impossible to get a committment on any emerging technology. Any progress that you make on the effect of pipes and buried drums/tanks will help keep this moving forward. I will forward the name(s) of the appropriate parties for followup as soon as I can get them.

Corona Discharge: This technology is at an early stage of development. Many of the questions that were discussed during our last meeting need to have answers before this technology can be seriously considered by our operating divisions who would use or market it. The discussions that we had pointed out several critical areas that need exploration.

1. What happens when an explosive mixture of gas is fed to the corona reactor?????? The answer is critical BEFORE we can think about corona dishcarge as a realistic replacement or augmentation of activated carbon. I realize that this is a chicken and egg type problem: you cannot be sure what will happen until you try BUT no one wants to take the risk of trying.

2. Very low detection level (part per billlion range or nanogram per cubic meter) determinations need to be made about possible dioxin and furan formation when chlorinated organics are present in the feed stream.

3 . Since the flowrates, of designs to date, are relatively low $(\sim 55 \mathrm{l} / \mathrm{min})$ and the fixed costs of many gas analyzers are high, the system has a fairly steep base cost which limits its potential application in low and intermittent flow environments; exactly the markets where it seems to 
have the greatest applicability.

4. Related to item 2. is a question about the effect of particulate in the gas stream, it is known that the presence of copper catalyzes dioxin formation. If particulate is a problem the filtration/cyclones must be introduced and the adsorbed organic on the particulate must be treated separately. (This impacts the potential application for treating the gas stream exiting a thermal desorption unit)

There are more questions than these but this forms a base list for further research efforts. I still have not received the technology summaries that we discussed in our meeting. Please forward these as soon as is convenient.

If you have any questions or need clarification of any points I will be at PNL Tuesday and Wednesday AM this week. You can reach me thru Donna Pearson 375-2056.

Thanks

Dan Barak

Chemical Waste Management 
36] From: Dan W Barak at PNL29 6/2/93 3:24PM (2304 bytes: 43 in)

'o: Bruce J Harrer at $\sim$ PNL29

leceipt Requested

:C: Donna E Pearson at $\sim$ PNL29

iubject: Upcoming visits

I just wanted to drop you a line to update you on our status. It looks like we may not be able to get out there until July.

My current project ends in June.

The Wheelabrator Engineered systems (WES) representative Steve Uban is still reviewing the TEES and PST information with the International group and regardiess of whether WES decides to proceed there is interest in establishing a relationship that may be utilized for projects of joint interest in the future. This wheelabrator group includes Johnson filtration and has one of the most advanced fluid screen systems that I am aware of and there are several fluid and particle flow issues that may benefit from the resources that PNL can bring to bear to assist in improving this. I will update with a further agenda and seek some possible dates toward the end of June.

The RUST remedial individual Dr. John North will plan to talk about current challenges facing the remediation industry and he is interested in possible collaboration to demonstrate innovative and improved remediation technologies at DOE facilities.

I am also trying to track down one of our PhD Chemists that is not at the clemson facility, to have him talk to Thom Dunning's group if possible. I will advise on my progress in this area. He would be flying from Georgia, I assume that this is oK travel wise?

Toward the end of June I will communicate with you again to firm up possible dates and agendas/attendees.

Thanks for all of your assistance in this project. I have experienced a great deal of frustration due to internal difficulties caused by the (still) ongoing restructuring and appreciate your patience as we muddle through this.

Thanks again.

Dan Barak

WMX Technologies $<=$ Note new name 
PNL-8950

UC-900

\section{Distribution}

No. of

Copies

OFFSITE

2 DOE Office of Scientific and Technical Information

M. Abbot

Laboratory Management Division U.S. Department of Energy Office of Energy Research Forrestal Building (ST-311) 1000 Independence Avenue, SW

Washington, D.C. 20585

T. Vojnovich

Technical Program Manager

ER Laboratory Technology Transfer Program

U.S. Department of Energy

Office of Energy Research

Forrestal Building (ST-311)

1000 Independence Avenue, SW

Washington, D.C. 20585

\section{A. Zerega}

Laboratory Management Divisiou

U.S. Department of Energy

Office of Energy Research

Forrestal Building (ST-311)

1000 Independence Avenue, SW

Washington, D.C. 20585
No. of

Copies

ONSITE

DOE/Richland Operations Office

G. M. McClure

?

14 Pacific Northwest Laboratory

E. G. Baker

P8-38

M. Clement

K1-17

B. J. Harrer (5)

K1-12

L. J. Sealock

K2-10 Technical Report Files (5)

Dist.1 

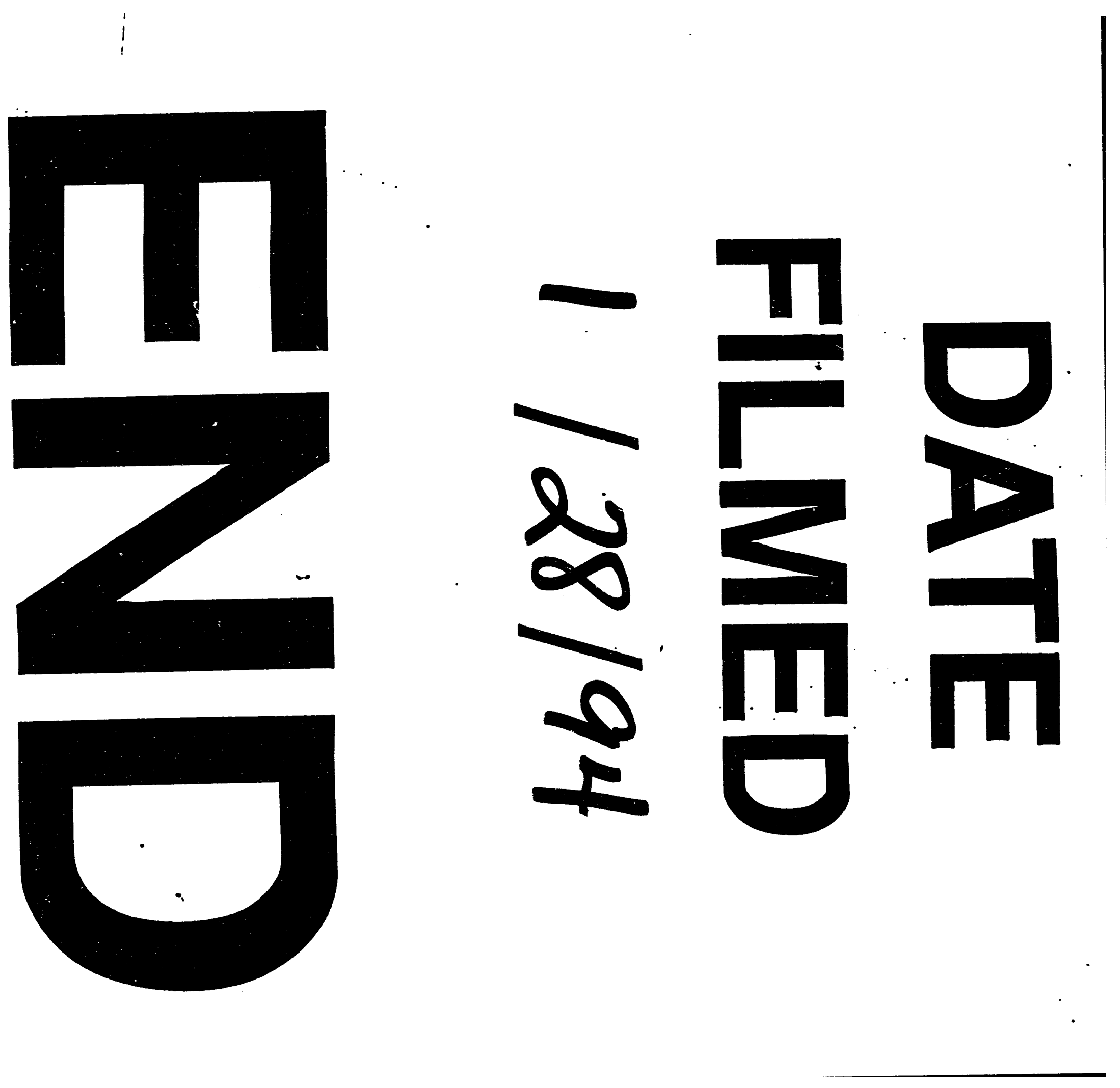


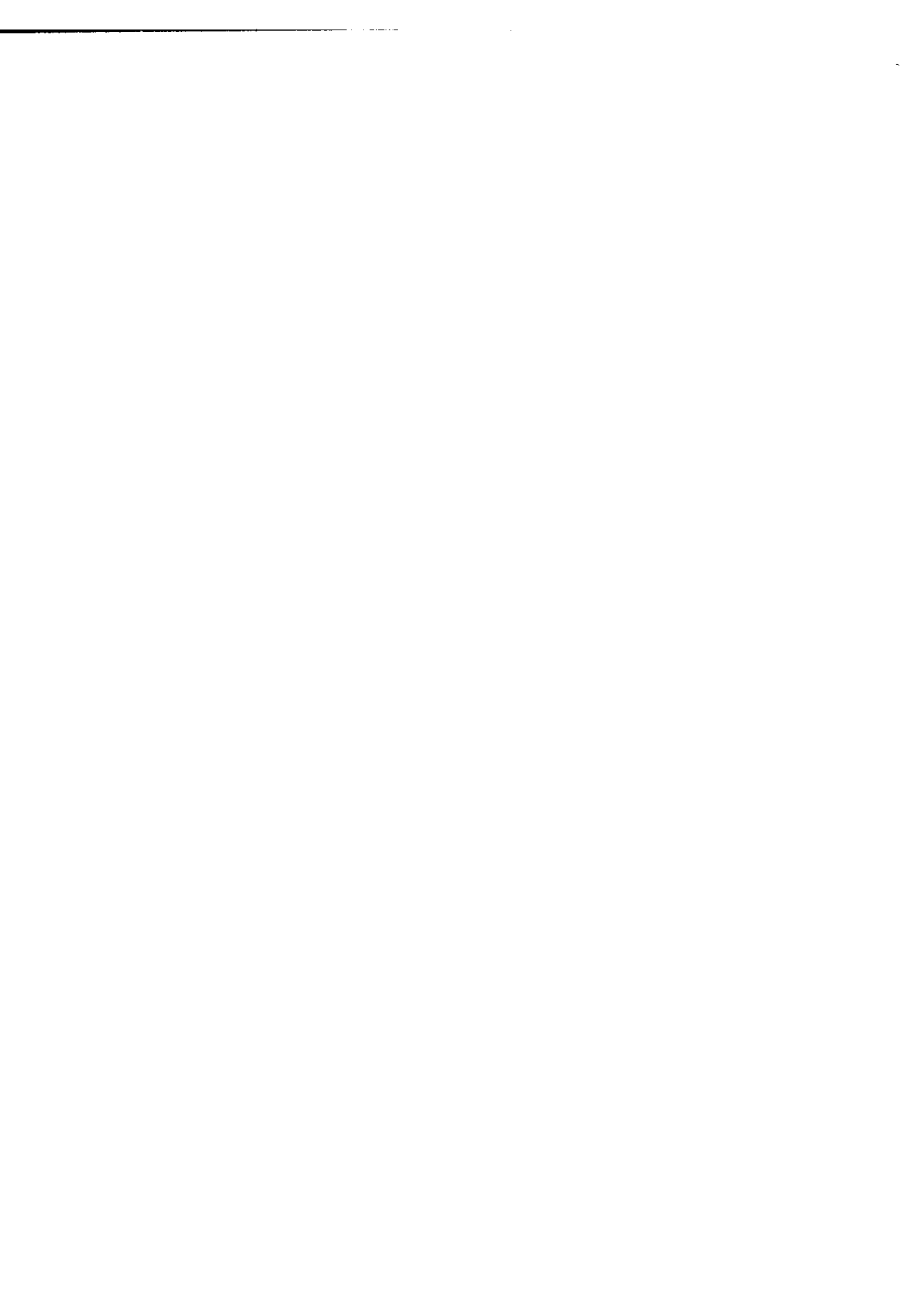

